\title{
US-CE-C
}

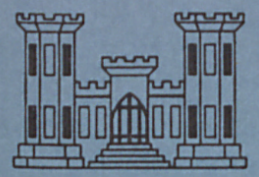

$$
\text { ADAOI2 } 140
$$

TECHNICAL REPORT S-75-7

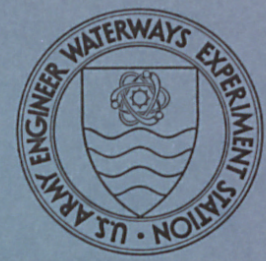

\section{AN ANALYTICAL STUDY OF PROJECTILE PENETRATION INTO ROCK}

\author{
by
}

\author{
Dwain K. Butler
}

Soils and Pavements Laboratory

U. S. Army Engineer Waterways Experiment Station

P. O. Box 631, Vicksburg, Miss. 39180

June 1975

Final Report

Approved For Public Release; Distribution Unlimited

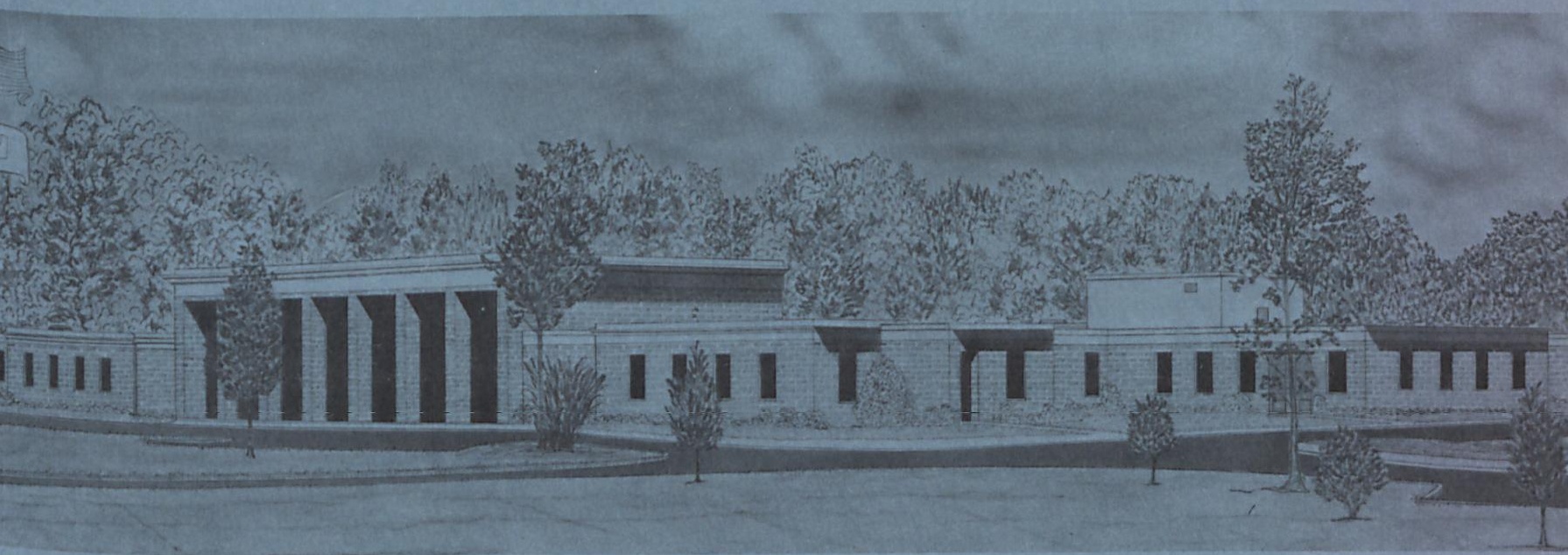

Prepared for Defense Nuclear Agency

Washington, D. C. 20305

Under Subtask SB21I, Work Unit 04,

"Earth Penetrator Calculation Studies

and Comparative Analyses with Field Measurements"

LUBRARY BRANCH

TECHNICAL INFORMATION CENTER 


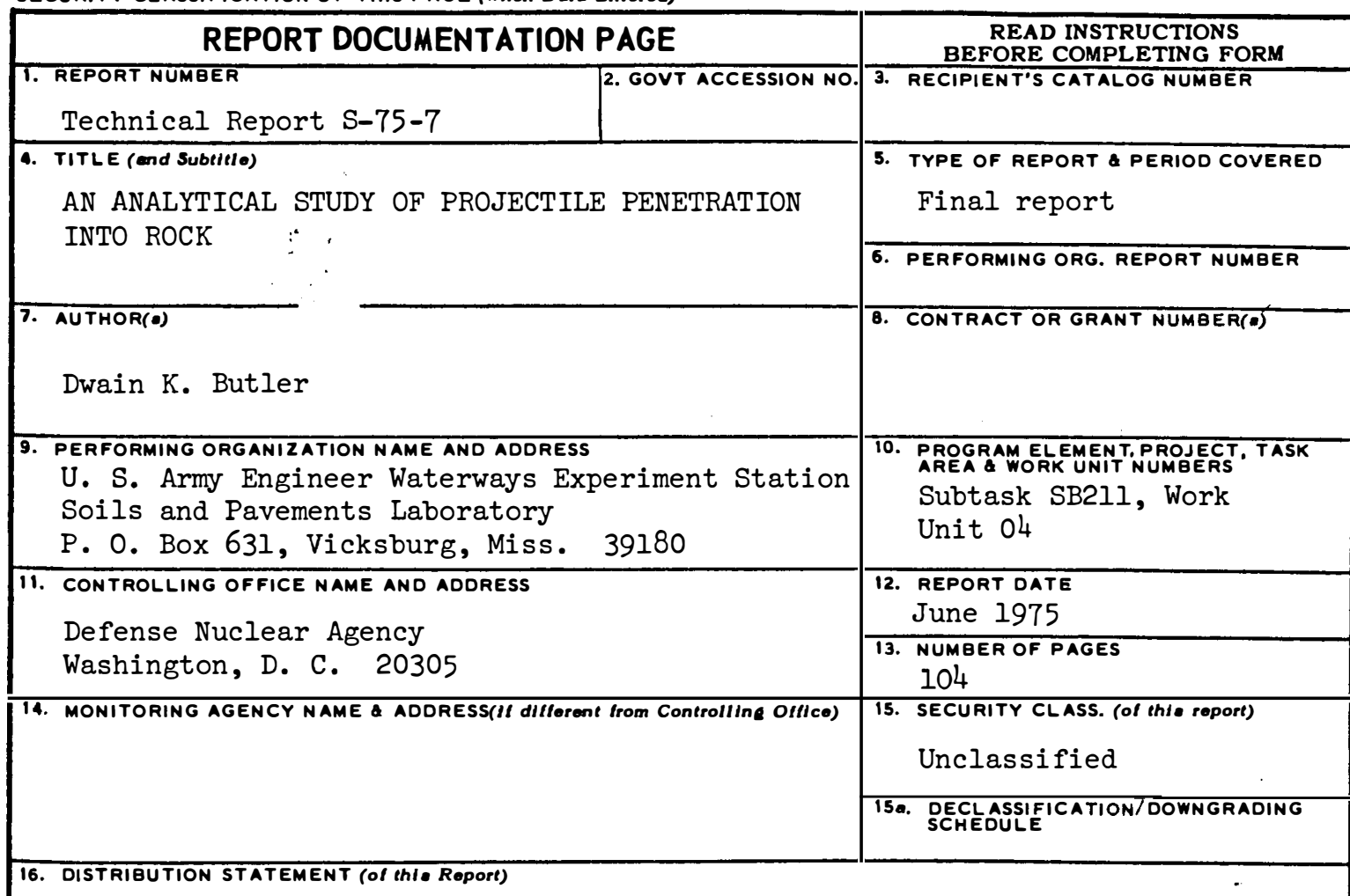

Approved for public release; distribution unlimited.

17. DISTRIBUTION STATEMENT (of the abotract ontered in Block 20, If difforont from Roport)

18. SUPPLEMENTARY NOTES

19. KEY WORDS (Continue on reverae elde if neceosary and identlly by block number)

Projectile penetration

Rock masses

Rock properties

20. ABSTRACT (Continue on reverae alde if neceaeary and identily by block number)

This report presents the results of a parameter study of projectile penetration into rock using a computer code based on U. S. Army Engineer Waterways Experiment Station modifications and extensions of the Ross-Hanagud penetration theory, which in turn is based on the dynamic cavity expansion theory of Goodier. The theory treats the projectile as a rigid body and the target as an elastic-plastic locking material. The objectives were to gain (1) a qualitative and quantitative understanding of the factors of importance in 


\section{ABSTRACT (Continued).}

rock penetration, (2) a feel for the depths of penetration which may be attainable, and (3) an appreciation for the complexities and uncertainties involved. Such an understanding is essential for the design of penetrating weapons for use against targets in rock or in situations in which, because of incomplete target intelligence, the possibility of encountering rock cannot be eliminated. Three rock targets were selected for the parameter study, with properties typical of the low-, medium-, and high-strength rock classifications in Deere and Miller's engineering rock classification scheme. The projectiles considered have ogive noses, a weight range of 250-1000 pounds, a diameter range of 5-10 inches, a caliber radius head range of 2-10, a sectional pressure range of 10-15 psi, and impact velocities of 1000-3000 fps. Using the penetration computer code, five actual field penetration tests into rock targets classified by Deere and Miller's method were simulated. The agreement between the predicted penetration depths and the actual measured depths is quite good. Based on this agreement, it is proposed that the penetration depth for a particular rock target can be bounded given only the engineering classification of the rock. The computer code was also used to calculate rigid body motion-time histories for two rock penetration events for comparison with the published finite difference code calculations of the same events. Good agreement between projectile time histories determined by the two procedures was obtained. 
$1 / 34$

N0.5.75-7

\section{PREFACE}

The investigation reported herein was conducted by personnel of the Soil Dynamics Division (SDD), Soils and Pavements Laboratory (S\&PL), U. S. Army Engineer Waterways Experiment Station (WES), during the period November 1973-June 1974. The research was sponsored by the Defense Nuclear Agency (DNA) under NWED Subtask SB211, Work Unit 04, "Earth Penetrator Calculation Studies and Comparative Analyses with Field Measurements." MAJ Todd D. Stong, CE, was the DNA Project Officer for Subtask SB2ll.

This study was conducted and the report prepared by $\mathrm{Mr}$. D. K. Butler, SDD. Technical consultation and direction were provided by Dr. B. Rohani, SDD Research Team Leader, and Dr. P. F. Hadala, Program Manager for DNA-sponsored work within SDD. SP4 D. C. Creighton assisted Mr. Butler with the computer calculations.

The work was performed under the general supervision of Messrs. J. P. Sale and R. G. Ahlvin, Chief and Assistant Chief, respectively, S\&PL, and Dr. J. G. Jackson, Jr., Chief, SDD. COL G. H. Hilt, CE, was Director of WES during the investigation and the publication of this report. Mr. F. R. Brown was Technical Director. 
PREFACE

CONVERSION FACTORS, U. S. CUSTOMARY TO METRIC (SI)

UNITS OF MEASUREMENT ................ 5

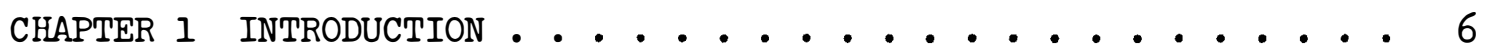

1.1 Setting the Stage ............... 6

1.2 Purpose.................... 8

1.3 Penetration Parameters ............ 8

1.3.1 Impact Geometry ............... 8

1.3.2 Projectile Shape and Material Properties .. . . . 8

1.4 Scope ................... 9

CHAPTER 2 PENETRATION MODEL . . . . . . . . . . 12

2.1 Force Laws and Empirical Relations . . . . . . . . . 12

2.2 Theoretical Penetration Model . . . . . . . . . 12

2.2.1 Original Formulation. . . . . . . . . . . 12

2.2.2 WES Extensions of the Penetration Model ....... 13

CHAPTER 3 SELECTION OF TARGET PARAMETERS . . . . . . . . . . 19

3.1 Intact and In Situ Rock Properties: An Overview . . . . . 19

3.2 Use of In Situ and Intact Rock Classification Schemes

To Estimate Ranges of Constitutive Properties . . . . . 20

3.3 Basic Criteria for the Selection of Rock Target

Constitutive Properties . . . . . . . . . . 24

3. 4 Selection of General Target Material Properties . . . . . 25

3.4.1 Selection of Strength and Modulus Values for

Representative Rock Groups . . . . . . . . . 25

3.4.2 Selection of Initial Densities and Methods for

Estimating the Compressibilities . . . . . . . 25

CHAPTER 4 COMPARISON OF PENETRATION MODEL PREDICTIONS WITH

EXPERIMENTAL RESULTS ................... 35

4.1 Comparison of Penetration Model Predictions Using General

Rock Properties with Experimental Results . . . . . . . 35

4.2 Target Parameter Study of Sandia Test No. 120-106 . . . . 36

4.3 Tentative Procedure for Bounding Penetration

Depth in Rock ................ 38

4.4 Extension of Penetration Model to Treat the Complete

Target Pressure-Density Curve. . . . . . . . . 39

4.5 Evaluation of Effect of Pressure-Density Curve

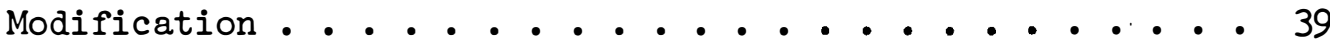

CHAPTER 5 GENERAL ROCK PENETRATION PARAMETER STUDY . . . • • 57

5.1 Systematics of Parameter Study . . . . . . . . . 57

5.2 Time Histories . . . . . . . . . . . . . 57

5.3 Penetration Versus Impact Velocity Plots ......... 58

5.4 Additional Parameter Study Plots .......... 58 
5.5 Discussion of Results .............. 58

5.5.1 Time Histories .............. 58

5.5.2 Penetration Versus Impact Velocity Plots ......6 60

5.5.3 Effects of W/A and $\mathrm{CRH}$.......... 61

CHAPTER 6 SUMMARY AND CONCLUSIONS . . . . . . . . . 79

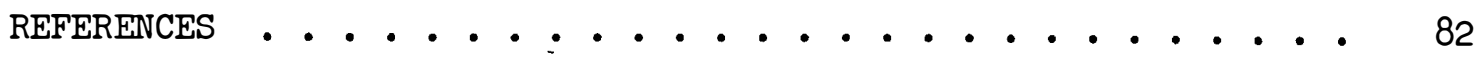

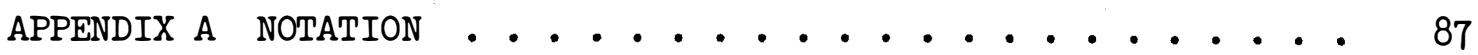

TABLES

3.1 Engineering Classification for Intact Rock . . . . . . 27

3.2 Engineering Classification for In Situ Rock ....... 27

3.3 Rock Properties ................ 28

4.1 Comparison of Penetration Model Predictions with

Field Penetration Test Results . . . . . . . . . . 44

4.2 Properties for Projectile Penetration into Tuff and Limestone ............... . . 45

5.1 Projectile Parameter Ranges ............ 63

5.2 W/A Combinations .............. 63

5.3 Parameter Study Systematics ............ 64

FIGURES

1.1 Projectile impact geometry . . . . . . . . . . . 10

1.2 Definition of $\mathrm{CRH}$................ 11

2.1 Idealized stress-strain curves for a locking elastic-plastic material . . . . . . . . . 18

2.2 Ogive nose factor . . . . . . . . . . . . . 18

3.1 Engineering classification for intact rock; summary plot for igneous rocks . . . . . . . . . . . 29

3.2 Rock modulus chart based on Schmidt hardness . . . . . . 30

3.3 Rock strength based on Schmidt hardness . . . . . . . 31

3.4 Variation of modulus ratio $E_{\text {insitu }} / E_{\text {intact }}$ with $R Q D$. . 32

3.5 Behavior of $E_{\text {insitu }} / E_{\text {intact versus } R Q D \text { for two }}$

3.6 Pressure-relative density relations for several rock types ...................

3.7 Impedance matching to obtain estimate of impact pressures for three rock targets at impact velocity $\mathrm{V}_{0}$ of $3000 \mathrm{fps}$

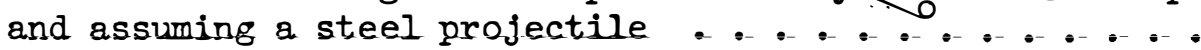

3.8 Estimation of compressibilities of the rock targets at the impact pressures indicated in Figure 3.7 . . . 34

4.1 Measured versus predicted depth of penetration into

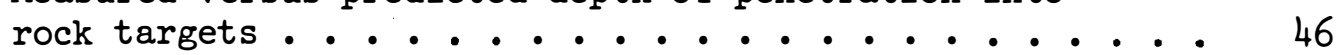

4.2 Effect of varying $Y$ on penetration versus impact velocity plot ............................ 47

4.3 Penetration versus modulus ratio for constant E . . . . 47

4.4 Effect of modulus on penetration .......... 48

4.5 Effect of $\rho_{\rho}$ and $\rho_{p}$ on penetration while maintaining

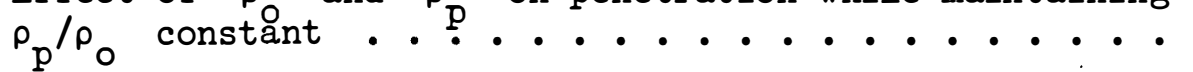


4.6 Effect of $\rho_{p} / \rho_{0}$ on penetration while maintaining

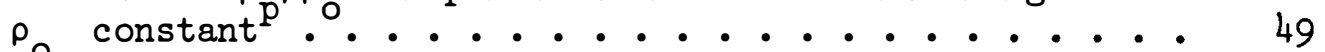

4.7. Effect of $\rho_{p} / \rho_{\rho}$ on penetration while keeping $\rho_{p} \ldots$

4.8 Establishment of upper and lower bounds for Test No. 120-106 . . . . . . . . . . . 50

4.9 Pressure-density relation for welded tuff based on Equation 6.1

4.10 Pressure-density relation for Madera limestone based

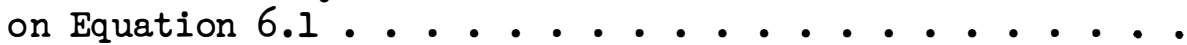

4.11 Plot of $p(n)$ for welded tuff ...........

4.12 WES rigid body acceleration versus time prediction super52 imposed on the Sandia finite difference results for particle located on nose tip of projectile . . . . . . .

4.13 WES rigid body model time histories superimposed on the finite difference time histories for particle on centerline located one nose length from nose tip ....

4.14 WES rigid body model time histories superimposed on the finite difference time histories for a particle on centerline located 2 feet from nose tip........

4.15 Constant locked plastic density model predictions for various compressibilities ..............

4.16 Comparison of complete target pressure-density model with two constant locked plastic density model predictions of deceleration versus time ........

4.17 Comparison of penetration model time histories for 1 percent compressibility and the complete target Hugoniot . . . . . . . . . . . . .

5.1 Time histories for Cases IBl and IB ......... 65

5.2 Time histories for Case IIIB3 ........... 66

5.3 Case IA ........................ 66

5.4 Case IB ....................... 67

5.5 Case IC ........................ 67

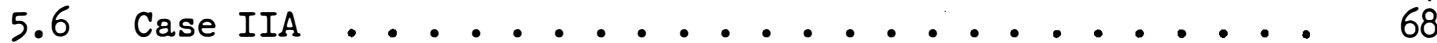

5.7 Case IIB ......................... 68

5.8 Case IIC . . . . . . . . . . . . . 69

5.9 Case IIIA ................. 69

5.10 Case IIIB ................. . . . 70

5.11 Case IIIC .................. . . . 70

5.12 Case IVA . . . . . . . . . . ... 71

5.13 Case IVB .................. . . 71

5.14 Case IVC ................... . . . 72

5.15 Effect of $\mathrm{W} / \mathrm{A}$ on penetration versus impact velocity plots for given rock type, $\mathrm{CRH}$, and weight . . . . 72

5.16 Effect of CRH on predicted penetration . . . . . . 73

5.17 Effect of W/A on predicted penetration ....... 75

5.18 Percent decrease in penetration versus impact velocity for all cases considered in this report between the low- and high-strength rock, between the low- and medium-strength rock, and between the medium- and high-strength rock .............. 
CONVERSION FACTORS, U. S. CUSTOMARY TO METRIC (SI)

UNITS OF MEASUREMENT

U. S. customary units of measurement used in this report can be converted to metric (SI) units as follows:

\begin{tabular}{|c|c|c|}
\hline Multiply & By & To Obtain \\
\hline inches & 2.54 & centimeters \\
\hline feet & 0.3048 & meters \\
\hline square inches & 6.4516 & square centimeters \\
\hline pounds (mass) & 0.45359237 & kilograms \\
\hline $\begin{array}{l}\text { pounds (mass) per } \\
\text { cubic foot }\end{array}$ & 16.0185 & kilograms per cubic meter \\
\hline slugs per cubic foot & 515.3788 & kilograms per cubic meter \\
\hline $\begin{array}{l}\text { pounds (force) per } \\
\text { square inch }\end{array}$ & 6894.757 & pascals \\
\hline $\begin{array}{l}\text { pounds (force) per } \\
\text { square foot }\end{array}$ & 47.88026 & pascals \\
\hline feet per second & 0.3048 & meters per second \\
\hline
\end{tabular}




\section{CHAPTER 1}

INTRODUCTION

\subsection{SETTING THE STAGE}

Penetration of projectiles into earth media is a subject of great interest due to the increasing number of potential applications. With respect to military applications, in which the projectiles may range from small-caliber munitions and shell fragments to bombs and missiles or specially designed earth penetrating weapons (EPW), ${ }^{1}$ interest arises from both offensive and defensive considerations. Typical applications include:

1. Destruction of underground targets by penetrating bombs or missiles which explode near or within the target.

2. Destruction or disablement of surface targets due to the cratering, ejecta, or direct-induced ground shock phenomena associated with a nuclear or high explosive detonation buried nearby at a shallowto-optimum depth.

3. Implantation of mines and sensors.

4. Design and construction of underground protective structures to resist penetrating weapons effects.

McNeill (Reference l) describes the potential use of instrumented penetrators for rapid mapping of soil and rock profiles. Typical situations might be the investigation of alternate construction sites and alternate routes for trenches, canals, and tunnels and the study of inaccessible and remote areas.

This report presents the results of a parametric study of projectile penetration into rock. Rock penetration has not been investigated in laboratory and in situ test programs as extensively as has

1 For convenience, symbols and unusual abbreviations are listed and defined in the Notation (Appendix A). 
penetration into soils. As military penetration interest extends to increasingly greater depths of penetration, the probability of encountering rock increases rapidly; also, there is a significant percentage of the earth's surface with exposed rock or rock covered by only a thin mantle of soil. Thus penetration into rocks must at least be considered in the "trade-off" studies involved in many penetrating weapon system designs.

In order to effect penetration into rock, design structurally sound penetrators for use in rock, and predict depth of penetration, it is important that rock penetration be more thoroughly investigated. Reference 2 describes a continuing program, initiated in 1966 by Sandia Laboratories, on the penetration of in situ rock; it is concluded in this reference that it is possible to design, construct, and instrument projectiles which can survive the environment of impact and penetration into low- and medium-strength rock. A brief history of rock penetration studies is given in Reference 2, and Reference 3 is a comprehensive state-of-the-art report on the subject. From the literature it is evident that the number of carefully documented, full-scale, in situ penetration tests is very small. Thus the empirical data base available is not yet sufficient to provide an adequate empirical basis for determining the effects of independent variables on the rock penetration process. If a theory could be found which would even approximately replicate the limited data on rock penetration, it could be used for parameter studies of the effects of its independent variables, and the results of this study would then be relevant to the performance of penetrating weapons impacting rock. By conducting a systematic parameter study using an analytical penetration model which does not rely on empirical "constants" and which has been successfully used in predicting depth of penetration for a number of shallow penetration events ${ }^{2}$ into a variety of materials, including rock and concrete, it is hoped that this report will allow the reader to gain a qualitative understanding of the factors of importance in rock penetration, a feel for the depths of penetration

See Chapter 4. 
which may be attainable, and an appreciation of the complexities and uncertainties involved.

\subsection{PURPOSE}

The purposes of this report are (1) to demonstrate that a rigid body penetration theory developed from the cavity expansion theory (References 4 through 6) can approximately predict the results of shallow penetration tests in hard media and (2) to parametrically investigate the effects of variations in rock properties, nose shape, sectional pressure, and impact velocity on penetration depth and deceleration-time histories over a range which is of potential interest in connection with the design of EPW's.

\subsection{PENETRATION PARAMETERS}

Penetration of a projectile into rock (or actually any material) is a function of parameters describing the impact geometry, projectile shape and material properties, and rock material properties. The following paragraphs describe the parameters involved in the general penetration problem and then discuss the assumptions and specializations used in this report.

1.3.1 Impact Geometry. The geometry for a general impact situation is shown in Figure $1.1 a$ and involves specification of an angle of obliquity and an angle of attack (also called angle of yaw); note that the projectile axis of symmetry does not necessarily lie in the plane of incidence, and the projectile may or may not be spinning about its axis at impact. Treatment of this general impact geometry is beyond the state of the art, and this report considers the case of normal impact of a nonspinning projectile (Figure l.1b) with the trajectory coincident with the projectile axis of symmetry. Figure 1.lc defines the depth of penetration as used in this report.

1.3.2 Projectile Shape and Material Properties. In general, projectiles of interest may be considered to be cylindrical, having a body length $\ell$, diameter $D$, and nose section which may be blunt (right-circular cylinder), hemispherical, conical, ogival, or some 
combination of these shapes. The projectiles considered in this report have ogival nose shapes, with the nose length and "sharpness" determined by the Caliber Radius Head (CRH) and the body diameter $D$ as illustrated in Figure 1.2. For the normal penetration case considered in this report, the projectile body length $\ell$ is not an explicit parameter. Also, the projectiles are considered to be rigid bodies; hence internal structure and material properties are not explicitly considered (body length, internal structure, and material density enter as implicit parameters in the determination of projectile mass $\mathrm{m}$ ).

\subsection{SCOPE}

The penetration model used for the work reported herein is presented in Chapter 2. A discussion of a general rock classification scheme, which will later be shown to be useful for predicting penetration into rock, is presented in Chapter 3, and the parameters necessary for use in the penetration model are selected. In Chapter 4, studies performed to demonstrate that the penetration model can qualitatively simulate many aspects of actual penetration tests into rock are presented. In Chapter 5, a systematic parameter study of the independent variables over the range of interest in rock penetration is presented. Depths of penetration are computed for a range of impact velocities for projectiles with various weights, diameters, and $\mathrm{CRH}$ values. 


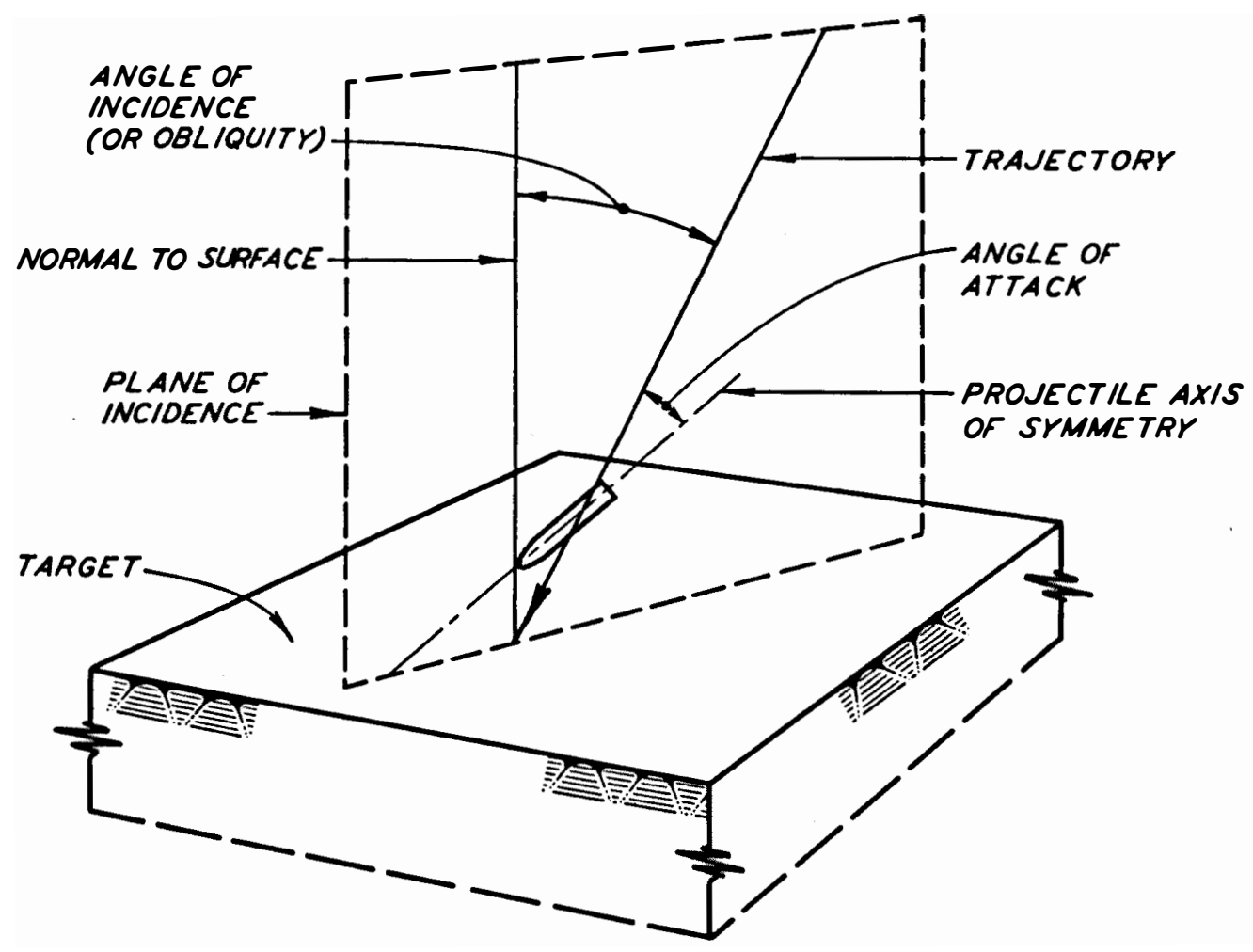

a. Geometry of generalized impact problem.

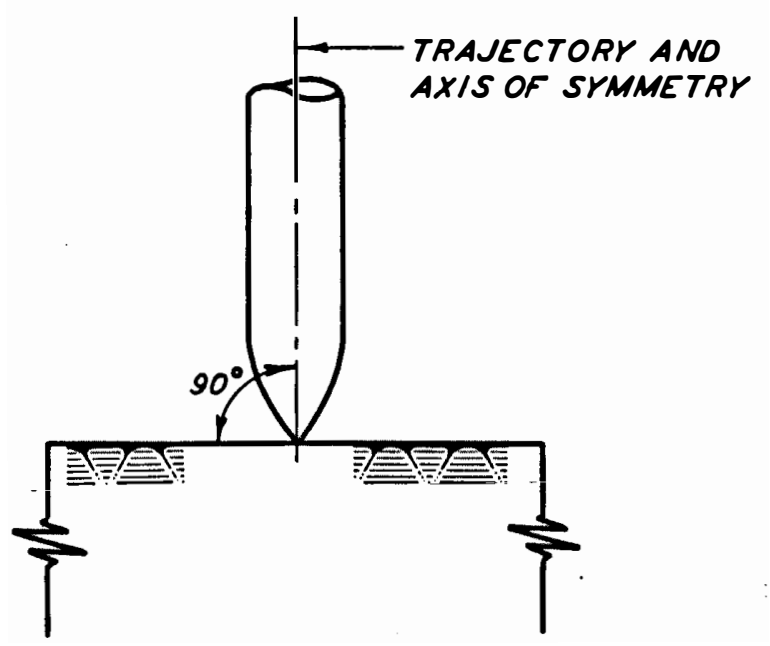

b. Normal impact.

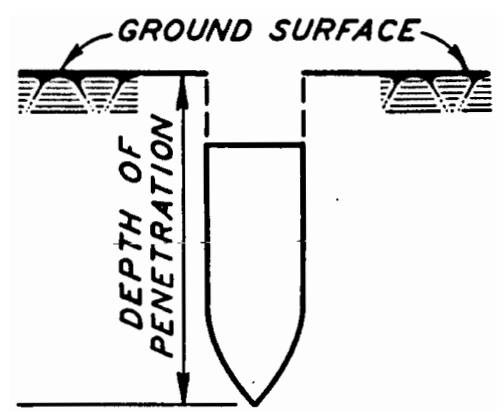

c. Definition of depth of penetration.

Figure 1.1 Projectile impact geometry. 


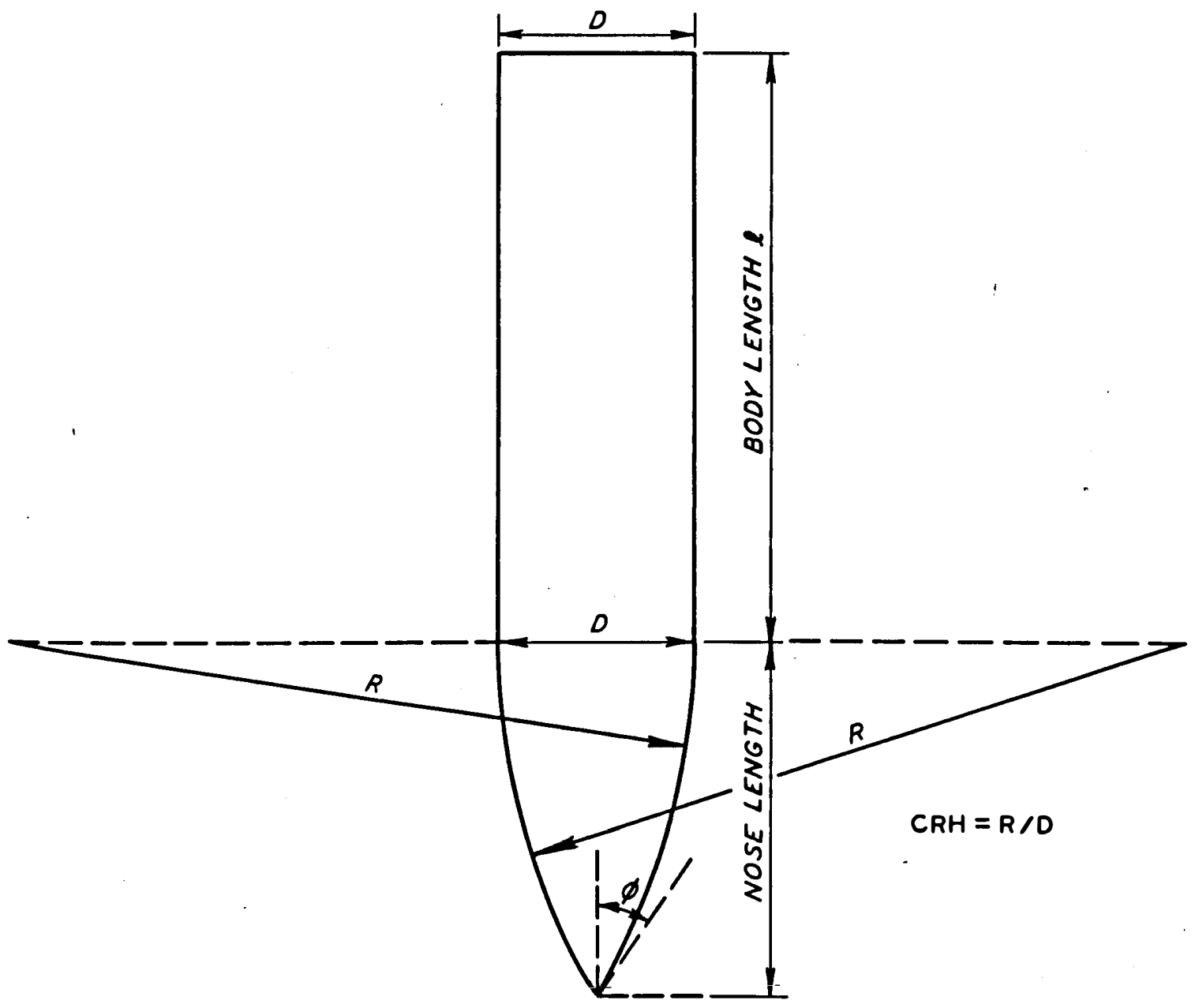

Figure 1.2 Definition of $\mathrm{CRH}$. 


\section{PENETRATION MODEL}

\subsection{FORCE LAWS AND EMPIRICAL RELATIONS}

References 1 and 4 present histories of the attempts to develop equations for predicting the depth of projectile penetration into earth materials. The prevalent procedures have been to develop purely empirical equations relating the measured depths of penetration for a set of experimental tests to various test parameters or to assume that the penetration event is governed by a particular form of force law. Using initial and end conditions, the equation of motion (based on the assumed force law) may be integrated to yield time histories and an equation relating final depth of penetration to initial velocity. The resulting equation will contain one or more constants which must be determined from actual penetration data by curve-fitting techniques.

The basic deficiency of both the purely empirical approach and the force law method is that they both contain coefficients not uniquely defined in terms of the physical properties of the target materials and the geometry of the projectile. Also, since the coefficients must be evaluated from penetration test results for a given velocity range, projectile geometry, and target type, the penetration equations cannot be used reliably outside the range of test conditions used in fitting the equations.

\subsection{THEORETICAL PENETRATION MODEL}

\subsubsection{Original Formulation. A theory of penetration of rigid} projectiles into incompressible elastic-plastic targets was developed by Goodier (Reference 5). The theory was extended by Ross and Hanagud (Reference 6) to include the compressibility of the target and has been used successfully in studies of penetration of ice, frozen soil, sand, and clay (References 4,.6, and 7). The theory has also been used to predict mine penetration into a variety of earth targets (Reference 8) and 
bomb penetration into concrete (Reference 9$).^{1}$ Treatment of penetration into a multilayered medium is presented in Reference 10.

The penetration theory is based on the theory of dynamic cavity expansion in locking elastic-plastic materials whose behavior can be idealized by the compressibility and shear behavior illustrated in Figure 2.1, in which $e_{i}$ is the volumetric strain related to the jump from zero to finite stress (elastic region), $e_{p}$ is the volumetric strain related to the jump from the elastic to the plastic region of the stress-strain curve, $E_{t}$ is the strain-hardening modulus corresponding to the locked plastic region, $G_{t}$ is the strain-hardening shear modulus, $E$ is Young's modulus of elasticity corresponding to the locked elastic region, and $\mathrm{G}$ is the elastic shear modulus. The resulting penetration equation is the solution of the equation of motion of a rigid body subjected to a distributed normal stress on its nose. The local normal stress is determined from the theory of dynamic cavity expansion for an assumed velocity field in the media adjacent to the projectile. The normal stress or cavity pressure is obtained from the solution of a boundary-value problem and is expressed in terms of parameters defined explicitly in terms of measurable material properties of the target and the mass and geometry of the projectile. 2.2.2 WES Extensions of the Penetration Model. ${ }^{2}$ In the original formulation, Ross and Hanagud assumed a hemispherical-nosed projectile and normal impact. WES is currently involved in theoretical efforts to extend the penetration model to apply to oblique impact conditions as well as to conical and ogival nose geometries and layered targets. Since this report considers ogival projectiles, the penetration equation as modified to apply to ogives is used. The relevant equations are listed without derivation, since the derivations and documentation of

I In this reference, results of application of this theory are shown to be in very good agreement with empirically based concrete penetration formulas within the range of the parameters for which the 2 formulas are considered accurate. The expression "penetration model" is used in the remainder of this report to refer to the Ross-Hanagud penetration theory and any WES modifications and extensions to the basic theory. 
the model will be the subject of a future WES technical report.

The equation of motion for a rigid projectile of mass $m$ and diameter $D$ penetrating in the z-direction (origin at ground surface, positive downward) is given by the following:

$$
m \frac{d^{2} z}{d t^{2}}+\frac{\pi D^{2}}{4}\left\{p_{s}+f(\varepsilon) \rho_{p}\left[B_{1} \frac{D}{2} \frac{d^{2} z}{d t^{2}}+B_{2}\left(\frac{d z}{d t}\right)^{2}\right]\right\}=0
$$

The parameters in Equation 2.1 are given in terms of the target material properties by the following:

$$
\begin{gathered}
B_{1}=1-\delta^{1 / 3} \\
B_{2}=\frac{3}{2}-\left(1+\alpha_{p}\right) \delta^{1 / 3}+\frac{1}{2} \delta^{4 / 3} \\
p_{s}=\frac{4}{9} E[1-\exp (-3 \beta)]-\frac{2}{3} Y \ln \delta+\frac{2}{27} \pi^{2} E_{t}-\frac{4}{9} E_{t} n \\
\delta=1-\frac{\rho_{0}}{\rho_{p}} \exp (-3 \beta) \\
\alpha_{p}=1-\frac{\rho_{0}}{\rho_{p}} \\
n=\sum_{n=1}^{\infty} \frac{\delta^{n}}{n^{2}} \\
\beta=\frac{Y}{2 E}-\frac{e_{i}}{3} \\
\rho_{p}=\rho_{0} \exp \left(e_{p}\right)
\end{gathered}
$$

where

$$
\begin{aligned}
\rho_{\mathrm{O}} & =\text { initial density of target material, slugs/cu } \mathrm{ft}^{3} \\
\mathrm{Y} & =\text { yield strength of target material (shown in Figure 2.1), psf } \\
\mathrm{E} & =\text { Young's modulus of elasticity, corresponding to locked elastic }
\end{aligned}
$$


region in Figure 2.1, psf $=3 G$ ( $G=$ elastic shear modulus)

$E_{t}=$ strain-hardening modulus, corresponding to locked plastic region in Figure 2.1, psf $=3 G_{t}\left(G_{t}=\right.$ strain-hardening shear modulus)

$e_{i}=$ volumetric strain related to the jump from zero to finite stress (elastic region) in the stress-strain curves in Figure 2.1

$e_{p}=$ volumetric strain related to the jump from the elastic to the plastic region of the uniaxial stress (i.e., unconfined compression) stress-strain curve in Figure $2.1 \mathrm{~b}$

The function $f(\varepsilon)$ is the ogive nose factor: ${ }^{4}$

$f(\varepsilon)=\frac{2}{\varepsilon^{2}} \int_{0}^{\phi(\varepsilon)}\left[\sin ^{2} \psi+\frac{\sin ^{3} \psi \cos ^{2} \psi}{1-(1-\varepsilon) \cos \psi}\right](\cos \psi-1+\varepsilon) d \psi$

where

$$
\begin{aligned}
\varepsilon & =\frac{1}{2 \mathrm{CRH}} \\
\cos \phi & =1-\varepsilon, \text { or } \\
\phi(\varepsilon) & =\tan ^{-1}\left(\frac{2 \varepsilon-\varepsilon^{2}}{1-\varepsilon}\right)
\end{aligned}
$$

$\mathrm{CRH}$ is defined in Figure 1.2 and $\phi$ is the limiting cone half-angle. A plot of $f(\varepsilon)$ versus CRH is given in Figure 2.2.

The target material is defined by six material parameters $\left(e_{i}, e_{p}\right.$ or $\rho_{p}, \rho_{o}, E, E_{t}$, and $Y$ ) and the projectile by three parameters $(m, C R H$, and $D)$. The parameters $e_{i}$ and $e_{p}$ can be obtained from a hydrostatic compression test on undisturbed specimens of target material conducted at strain rates and carried to peak stress levels generally anticipated during the penetration event. The parameters $\mathbf{E}$,

3 A table of factors for converting U. S. customary units of measure4 ment to metric (SI) units is presented on page 5.

R. S. Bernard, private communication, January 1974. Equation 2.10 represents a first attempt at incorporating nose shape effects into the model. 
$E_{t}$, and $Y$ can be determined from an undrained dynamic uniaxial stress test (unconfined compression) or from a dynamic triaxial test at a confining pressure simulating the in situ stress state.

The constitutive model assumed in the cavity expansion theory is a relatively simple one. Strength is independent of stress level, volume change can occur only at the initiation of stress or at the onset of plastic behavior, and dilatation in shear is not possible in the model. Such simplifications are at variance with the observed behavior of real soil and rock. Thus, it should be noted that the material properties used provide only a crude description of the stress-strain behavior of the material; and as with any analytical technique, it is within the realm of possibility to obtain "good results" from a fortuitous selection of parameters, even though individually the parameters might not be the correct choice for the particular event. ${ }^{5}$ Their use (as well as the use of the theory itself) can only be justified on the basis of agreement of the analytical results with available penetration data. Such agreement will be demonstrated later in this report for a number of cases within the range of variables of relevance to EPW rock penetration.

Equation 2.1 is easily amenable to an incremental solution in terms of velocity by using the initial and end conditions.

$$
\begin{aligned}
& \frac{d z}{d t}=v_{0}, \text { when } z=0 \\
& \frac{d z}{d t}=0, \text { when } z=P
\end{aligned}
$$

where $V_{0}$ is the impact velocity and $P$ is the final depth of penetration. After $\mathrm{n}$ time steps $\Delta t$, the velocity $\mathrm{V}$ is given by

The penetration event, for example, may produce a distinctive stress field in the target which in itself would establish the appropriate confining pressure for laboratory property determination (rather than the natural in situ stress field). 


$$
v(n \Delta t)=v_{0}-\sum_{k=1}^{n} \Delta v_{k}
$$

where $\Delta \mathrm{V}_{\mathrm{k}}$ is the incremental velocity change in the $\mathrm{k}^{\text {th }}$ time step as computed from Equation 2.1. The acceleration during the $k^{\text {th }}$ time step is $\Delta \mathrm{V}_{\mathrm{k}} / \Delta t$, and the distance penetrated during the $\mathrm{k}^{\text {th }}$ time step is computed as

$$
\Delta z_{k}=\frac{V(k \Delta t)+v[(k-1) \Delta t]}{2} \Delta t
$$

A number of small computer codes have been used to solve Equation 2.1 in the manner described. Although it can be solved in closed form to give a final depth of penetration in a homogeneous half space, solving the equation incrementally has a number of advantages. During the early phase of penetration, until the ogival nose is completely embedded, the effective cross-sectional area of the projectile varies; and by letting the diameter vary with penetration in Equation 2.1, as required to reflect the effective cross-sectional area, the embedding process is included in the model. Also the incremental solution allows the material properties of the target to be changed at any time step, which in turn allows layered targets to be considered. The computer codes may be accessed from time sharing terminals and are easy and inexpensive to operate. On-line plotters can be used to produce parameter plots.

One additional WES modification to the theory was to allow $\rho_{p}$ to be changed with time in the incremental method as the cavity pressure drops, i.e., the complete target pressure-volumetric strain curve may be used instead of the locking approximation. 

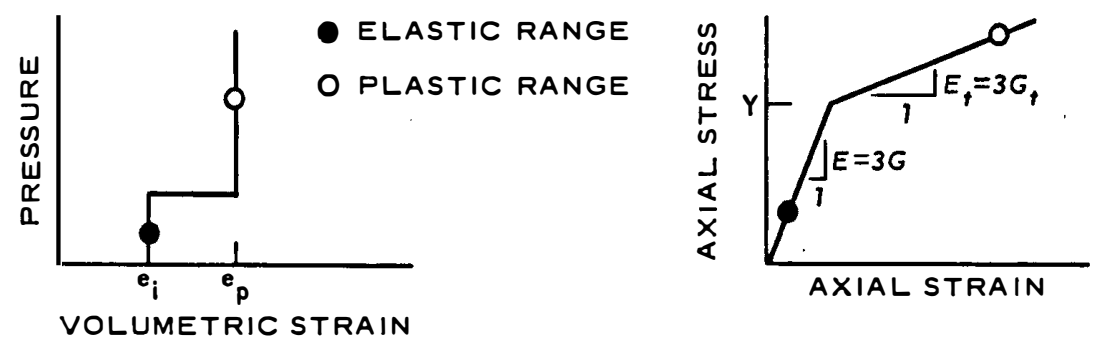

a. Behavior in hydrostatic compression.

b. Behavior in unconfined compression.

Figure 2.1 Idealized stress-strain curves for a locking elastic-plastic material.

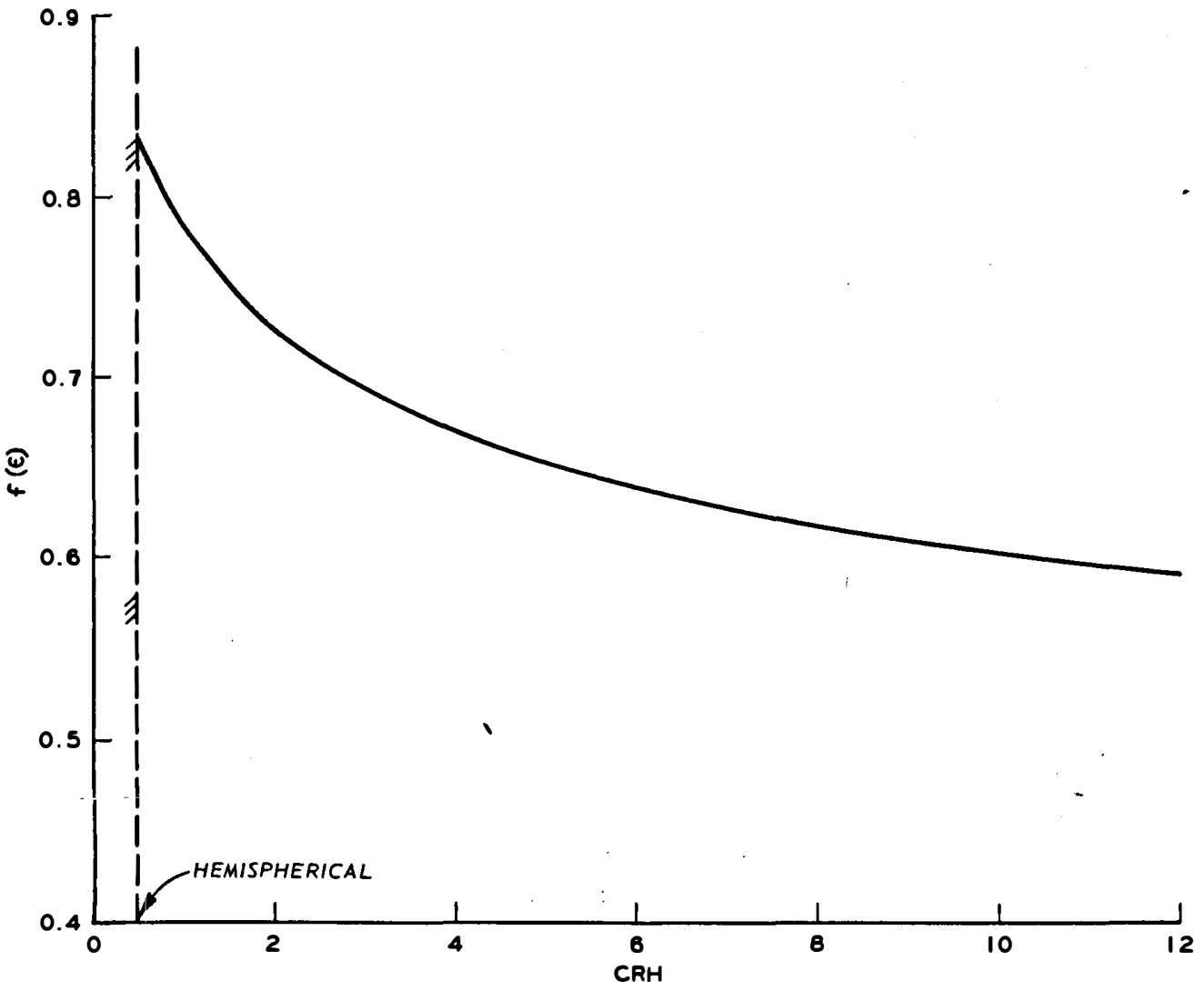

Figure 2.2 Ogive nose factor. 


\subsection{INTACT AND IN SITU ROCK PROPERTIES: AN OVERVIEW}

Rock is properly described as a nonlinear, hysteretic material and in its in situ state is nonhomogeneous, anisotropic, and discontinuous. Even the most sophisticated finite difference or finite element computer code cannot treat the intrinsic and discontinuum properties of the in situ rock mass in all their complexity. Rock mechanics, being a relatively new formal discipline, does not benefit from a large repertoire of carefully documented cases of engineering successes and failures. Also, unlike soil mechanics, rock mechanics has not enjoyed much success in using laboratory test results to design and predict the behavior of structures in and on rock. In a fundamental sense, the reasons for the problems encountered in rock mechanics might be reduced to a problem in probability and statistics (Reference 11$), 1$. although such an approach may prove to be of limited utility, since it is difficult to conceive how probability density functions, for example, could be constructed for general cases.

Rock contains not only small-scale defects such as cracks, flaws, inclusions, grain boundaries, etc., but also large-scale inhomogeneities, such as layers, joints, faults, fractures, folds, etc., with scales ranging from centimeters to hundreds of meters. Also the rock surfaces involved in these geologic structures may be weathered or may be characterized as being completely random with regard to asperities or as having undulating asperities with characteristic "wave lengths" and"amplitudes" ranging from centimeters to hundreds of meters. Thus the reasons for the existence of a "size effect" problem in the determination of constitutive properties become apparent. Not only are there variations in strength and deformability of intact rock specimens in.

\footnotetext{
1 This reference contains a discussion of reducing rock mechanics problems to a problem in probability and statistics and also a comprehensive bibliography.
} 
the laboratory as size increases (References 11 and 12), but also the mode of failure may change (brittle to ductile, for example). The "size effect" problem becomes even more significant when it is desired to extrapolate laboratory data for properties in situ. In situ tests have been a tremendous aid to engineers, but the obvious problem still arises, as emphasized by Heuze in Reference 13, that the size of the in situ test should be representative of the size of the in situ prototype. Since in situ rock mass strength and deformability depend on both the intact properties and the discontinuum properties, considerable effort has been expended in recent years to understand the mechanics of jointed rock (References 13 through 15, for example). Also, progress has been extensive in developing engineering oriented classifications and index properties for intact and in situ rock (References 16 through 18). The result of these efforts is the recognition of correlations between certain laboratory test results; between certain in situ test results, between laboratory and in situ test results, and importantly between discontinuum index descriptors and laboratory and in situ test results.

Obviously, the penetration model is intended to apply to a homogeneous isotropic continuum. Thuṣ, if it is to be used successfully in rock penetration, a methodology must be developed for selecting equivalent continuum properties for the rock target such that the theory gives answers which correlate with real tests on the discontinuum. A methodology for this purpose is described in this chapter.

\subsection{USE OF IN SITU AND INTACT ROCK CLASSIFICATION SCHEMES TO ESTIMATE RANGES OF CONSTITUTIVE PROPERTIES}

Reference 17 presents a classification scheme for intact rock based on two properties of engineering significance (strength and deformability). Table 3.1, which summarizes the classification scheme developed by Deere and Miller (Reference 17), evolved from numerous laboratory tests on many different rock types. Use of the modulus ratio concept results from an observed correlation between uniaxial compressive strength and tangent modulus of elasticity; Figure 3.1 (from Reference 17) illustrates the classification concept. Rocks can be classified under this scheme from a knowledge of the values of strength 
and modulus determined in laboratory tests. As illustrated in Figure 3.1 for the particular case of igneous rocks, rocks of a given type tend to cluster in a restricted region of the space. The limiting values for the average modulus ratio band were chosen to encompass the majority of the data for rocks with interlocking textures. Thus some of the power and utility of the classification scheme can be realized. In many cases, knowledge of rock type and texture may enable an "educated estimate" of engineering properties to be made; and if rock type and either strength or modulus are known, then the other property can be predicted with a much higher degree of confidence.

Other important correlations exist between the engineering properties and various quantitative rock index properties, such as Schmidt hardness, Shore hardness, and dry unit weight. The importance of these correlations is that the index tests can be performed easily, quickly, and economically on rock cores in the field. Nomograms based on the observed correlations, such as Figures 3.2 and 3.3 , can then be used to estimate strength and modulus. Thus rocks can be classified according to Table 3.1 based solely on simple index tests.

Reference 18 presents a systematic classification scheme for the quality of in situ rock (i.e., the degree to which the rock represents a continuum). The in situ classification scheme is based on a quantitative core logging procedure proposed by Deere in 1964. The in situ nature of the rock mass is described by its Rock Quality Designation (RQD), which is obtained by measuring the total length of all unweathered pieces of core greater than or equal to 4 inches and then dividing by the total length of core run. RQD has been shown to correlate with other qualitative descriptions of rock quality such as fracture frequency and velocity ratio $\left(v_{f} / V_{L}\right)^{2}$, where $v_{f}$ is the in situ and $V_{L}$ the laboratory (intact) compressional wave velocity. The RQD is expressed as a percentage, with an RQD of 100 percent corresponding to a fracture frequency of 0 and a velocity index of 1 . Table 3.2 summarizes the classification system.

On the basis of extensive in situ testing to determine apparent elastic moduli, such as plate jack tests, radial jack tests, borehole 
deformation tests, etc., various important correlations between RQD and the ratio of intact to in situ constitutive properties have been determined (References 18 and 19). Correlations have been established between the ratio of apparent Young's moduli ( $E_{\text {insitu }}$ ) and the intact specimen Young's modulus $\left(E_{\text {intact }}\right.$ ) and RQD. Figure 3.4 shows one of the correlations as given in Reference 20. The general trend of $E_{\text {insitu }} / E_{\text {intact }}$ versus $R Q D$ has been confirmed by other investigators in field tests, model studies, and finite element studies, although a straight line correlation should not be expected and it is probable that the ratio approaches a value of 0.1-0.15 at low values of RQD . This suggests that an estimate of in situ modulus of elasticity can be easily obtained from a knowledge of RQD, Schmidt hardness, and dry unit weight by using correlations such as those shown in Figures 3.3 and 3.4 . If the intact modulus is known, only an estimate of RQD is needed in order to estimate the in situ modulus.

In many instances rock masses may be described as being laminated or tri-orthogonally jointed. For these conditions, Duncan and Goodman (Reference 2l) derive an expression relating in situ modulus of deformation $E_{\text {insitu }}$ to the intact modulus $E_{\text {intact }}$, normal joint stiffness $\mathrm{K}_{\mathrm{n}}$, and fracture spacing $\mathrm{s}$ :

$$
E_{\text {insitu }}=\frac{1}{\frac{1}{E_{\text {intact }}}+\frac{1}{K_{n} s}}
$$

By using a correlation by Deere (Reference 20) between $R Q D$ and fracture frequency $f$, where

$$
f \equiv \frac{1}{s}=6\left(1-\frac{R Q D}{100}\right)
$$

it is possible to determine $K_{n}$ in terms of $E_{\text {intact }}$ if it is assumed that the ratio $E_{\text {insitu }} / E_{\text {intact }}$ approaches $0.1-0.15$ at $R Q D=0$ as suggested previously. Figure 3.5 shows the relation for the ratio values 0.1 and 0.15 at $R Q D=0$.

The discussion thus far has not referred to in situ strength, and 
indeed "handy" correlations such as those shown in Figure 3.5 for the relation of in situ and intact unconfined compressive strengths do not exist. Thus it is in general not possible to deduce in situ strength from a knowledge of $R Q D$ and intact strength, for example, as it was for the modulus values (Figure 3.5). Much of the problem arises from misconceptions regarding the nature of rock strength; as 'stated by Hudson (Reference 22), properties such as tensile and compressive strengths are experimental, not intrinsic, properties. Thus laboratory strength values depend on the method of testing and size of the test specimen. Despite these concepts, properties such as tensile and compressive strengths, yield strength, ultimate strength, crushing strength, etc., are still used and needed for many types of engineering analyses. Therefore, caution is required in specifying strength values and in describing the test method. Speaking in terms of a statistically significant number of tests for a given type of strength test, several "values of strength" may be observed as the size of the test specimen is increased, because in some cases failure occurs due to flaws or. discontinuities (References 11,12 , and 22) and the scale dimensions of the various types of discontinuities vary by several orders of magnitude (grain boundaries, cracks, layer boundaries, joint block boundaries, faults, etc.). Thus it is important that strength data or estimates apply to the size scale of interest.

In order to discuss in situ strength for projectile penetration calculations, it is necessary then to specify both the type of experimental strength value and the scale of the test. For the depths of interest in projectile penetration (<200 feet), confining pressures will probably not exceed $150 \mathrm{psi}$. Thus triaxial tests with very low confining pressures or unconfined tests will suffice. The maximum projectile body diameter considered in this report is 10 inches, which can be considered as a representative size scale for a large class of earth penetrators (Reference 23). Nearly all earth penetrators have a sharply pointed nose section (the projectiles considered in this report are all ogives). Compressive failure of the rock occurs in the region surrounding the tip of the nose, and failure is envisioned to progress radially 
outward from the initial region of failure as the nose penetrates; thus the size scale of interest for strength value considerations is of the order of or smaller than the body diameter. Based on these considerations, it is postulated that strength values determined from typical laboratory-size test specimens are adequate for penetration calculations and that corrections for the differences between the appropriate scale in situ test and the laboratory strength test are not necessary.

\subsection{BASIC CRITERIA FOR THE SELECTION OF ROCK TARGET CONSTITUTIVE PROPERTIES}

In Section 2.2.2, a penetration model requiring six constitutive parameters for the target is presented. The appropriate in situ Young's modulus $E$ can be estimated from a value for the intact (laboratory) modulus and the in situ rock quality RQD by the methodology presented in Section 3.2. It is fortunate, for calculational purposes, that most rocks at low confining pressures (<1000 psi) exhibit brittle failure or at least little or no strain hardening (References 24 and 25). For these rocks, the yield strength, ultimate strength, compressive strength, and crushing strength can all be considered the same in unconfined or triaxial compression tests at low confining pressure. Thus the strainhardening Young's modulus $E_{t}$ can be set equal to zero, and the value for the strength $Y$ can be determined from unconfined compression tests on laboratory-size specimens. For finely jointed and weathered rock (low RQD), it may be necessary to apply reduction factors to the intact (laboratory) value for $Y$, using results such as those presented in References 14, 15, 26, and 27 as guides.

The concept of locking material behavior is discussed in Reference 6. While the plastic locking strain or density concept might be a valid one for rocks, it is felt that the actual locked plastic density is not the appropriate value to use for $\rho_{p}$ in Equation 2.1. The locked plastic density may be approached in the material surrounding the point of impact, but the density increase will be much less during the remainder of the penetration event. The pressure-relative density behavior of several rock types is shown in Figure 3.6. For soils, the "lock-up" density or volumetric strain can be estimated as being equal 
to the porosity. However, due to the strength of the rock matrix itself, the porosity of rocks is not such a controlling factor, although it obviously affects the total compressibility. The porosity of rocks ranges from essentially zero to as much as 30 percent. If the impact pressure, average pressure in the media during penetration, existing cavity pressure, etc., can be estimated or approximated and the initial density $\rho_{0}$ is known, then a value for $\rho_{p}$ can be obtained from a pressure-relative density relation (such as Figure 3.6).

The parameter $e_{i}$ has been shown not to be a sensitive parameter in maximum penetration predictions (Reference 4 ). It is postulated that setting $e_{i}$ equal to zero for rocks is an appropriate assumption.

\subsection{SELECTION OF GENERAL TARGET MATERIAL PROPERTIES}

3.4.1 Selection of Strength and Modulus Values for Representative Rock Groups. It was desired to keep the parameter study in this report very general with respect to the rock target parameters. Using the intack rock classification scheme presented in Section 3.2 as a guide, low-strength (6000 psi), medium-strength ( $12,000 \mathrm{psi})$, and high-strength (24,000 psi) rock targets were selected, with the strength values representing the median values for Classes $D, C$, and $B$, respectively (Table 3.1). The targets were characterized as being in the average modulus ratio Class $M$ with modulus ratio of 350 . Thus the three targets would be classified as $\mathrm{BM}, \mathrm{CM}$, and $\mathrm{DM}$. The strain-hardening modulus $E_{t}$ is set equal to zero based on the arguments presented in Section 3.2.

\subsubsection{Selection of Initial Densities and Methods for Estimating} the Compressibilities. The remaining three parameters needed for the three rock targets as input to the penetration model are the initial densities $\rho_{0}$, locked elastic volumetric strains $e_{i}$, and locked plastic volumetric strains $e_{p}$ or plastic densities $\rho_{p}$. While it is not true in general that rocks with higher densities have higher strengths, it is true in many cases and correlations exist to this effect (Reference 16). Thus initial densities were selected which were thought to be representative of the three strength classes in an increasing 
fashion: $2.1,2.6$, and $2.9 \mathrm{~g} / \mathrm{cm}^{3}$ for low-, medium-, and high-strength targets, respectively. The locked elastic volumetric strain $e_{i}$ was set equal to zero for all three rock targets.

The procedure used to estimate $\rho_{p}$ for the three rock targets was to estimate first the peak stress at impact by graphical impedance matching $^{2}$ (for the maximum impact velocity of 3000 fps considered in this report) in pressure versus particle velocity space (Figure 3.7) and then the compressibilities at the peak stresses from the relations in pressure versus $\rho_{o} / \rho$ space (Figure 3.8). The value of $\rho_{p}$ for use in Equation 2.1 is then estimated from the compressibility at a stress level approximately one-half the peak stress for each rock type. Neither the method used here nor the actual curves in Figures 3.7 and 3.8 are intended to be rigorous or strictly representative of particular rocks. The curves are intended to be representative of rocks in the three strength categories and are composites of data, such as those presented in Figure 3.6 and References 28, 30, 33, and 34. Discussion of the graphical impedance matching techniques and the equations connecting the various parameters of interest can be found in many sources (see References 34 through 37 for examples). Table 3.3 summarizes the assumed rock properties for $\mathrm{DM}, \mathrm{CM}$, and $\mathrm{BM}$ rocks.

Plane wave assumption. 
I. On basis of strength

Uniaxial Compressive Strength

\begin{tabular}{cc}
\hline psi & kbar $=\left(10^{9} \frac{\text { dynes }}{\mathrm{cm}^{2}}\right)$ \\
\cline { 3 - 3 } Over 32,000 & 2.2 \\
$16,000-32,000$ & $1.1-2.2$ \\
$8,000-16,000$ & $0.55-1.1$ \\
4,000-8,000 & $0.28-0.55$ \\
Less than 4,000 & 0.28
\end{tabular}

II. On basis of modulus ratio

\begin{tabular}{clc} 
Class & \multicolumn{1}{c}{ Description } & Modulus Ratio \\
$\mathrm{H}$ & High modulus ratio & Over 500 \\
$\mathrm{M}$ & Average modulus ratio & $200-500$ \\
$\mathrm{~L}$ & Low modulus ratio & Less than 200
\end{tabular}

Classify rock as $\mathrm{BM}, \mathrm{BH}, \mathrm{BL}$, etc.

a Modulus ratio $=E_{t 50} / \sigma_{a}$.

where

$$
\begin{aligned}
\mathrm{E}_{\mathrm{t} 50} & =\text { tangent modulus at } 50 \% \text { ultimate strength; } \\
\sigma_{\mathrm{a}} & =\text { uniaxial compressive strength. }
\end{aligned}
$$

TABLE 3.2 ENGINEERING CLASSIFICATION FOR IN SITU ROCK

\begin{tabular}{lccl}
\hline RQD, \% & Velocity Index & $\begin{array}{c}\text { Fracture } \\
\text { Frequency } \\
\text { No./ft }\end{array}$ & \\
\cline { 2 - 3 } $0-25$ & $0-0.2$ & $6-4.5$ & Description \\
$25-50$ & $0.2-0.4$ & $4.5-3$ & Very poor \\
$50-75$ & $0.4-0.6$ & $3-1.5$ & Poor \\
$75-90$ & $0.6-0.8$ & $1.5-0.75$ & Fair \\
$90-100$ & $0.8-1.0$ & $0.75-0$ & Good \\
\hline
\end{tabular}


TABLE 3.3 ROCK PROPERTIES

\begin{tabular}{|c|c|c|c|c|c|c|}
\hline Rock Type & $\mathrm{E}^{\mathrm{a}}, \mathrm{psi}$ & $\underline{E_{t}}$ & $Y, p s i$ & $\rho_{0}$, slugs $/ \mathrm{ft}^{3}$ & $\rho_{p}$, slugs $/ \mathrm{ft}^{3}$ & $\mathrm{e}_{i}$ \\
\hline Low strength & $2.1 \times 10^{6}$ & 0 & 6,000 & 4.07 & 4.95 & 0 \\
\hline "DM" & (0.14 Mbar) & & (0.414 kbar) & $(\mathrm{sp} g r=2.1)$ & $(\mathrm{sp} g r=2.55)$ & \\
\hline Medium strength & $4.2 \times 10^{6}$ & 0 & 12,000 & 5.04 & 5.72 & 0 \\
\hline "CM" & (0.29 Mbar) & & $(0.828 \mathrm{kbar})$ & $(\mathrm{sp} \mathrm{gr}=2.6)$ & $(\mathrm{sp} \mathrm{gr}=2.95)$ & \\
\hline High strength & $8.4 \times 10^{6}$ & 0 & 24,000 & 5.63 & 6.3 & 0 \\
\hline "BM" & (0.58 Mbar) & & (1.65 kbar) & $(\operatorname{sp} g r=2.9)$ & $(\mathrm{sp} \mathrm{gr}=3.25)$ & \\
\hline
\end{tabular}

a Average modulus ratio, i.e., E/Y, $=350$ for all three rock types. 
UNIAXIAL COMPRESSIVE STRENGTH $\sigma_{a}(U L T)$, PSI $\times 10^{3}$

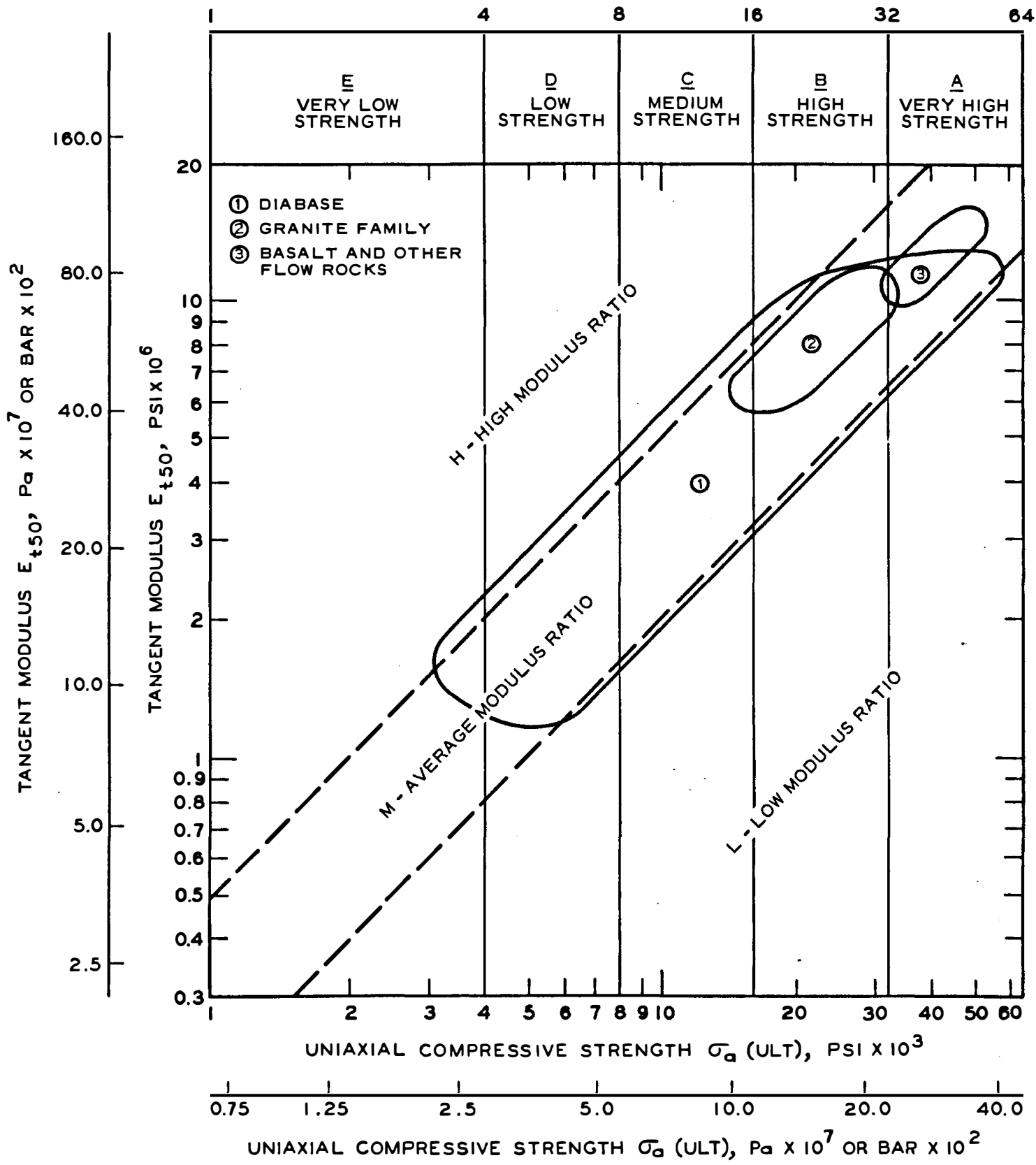

Figure 3.1 Engineering classification for intact rock; summary plot for igneous rocks (176 specimens, 75 percent of points) (Reference 17). 


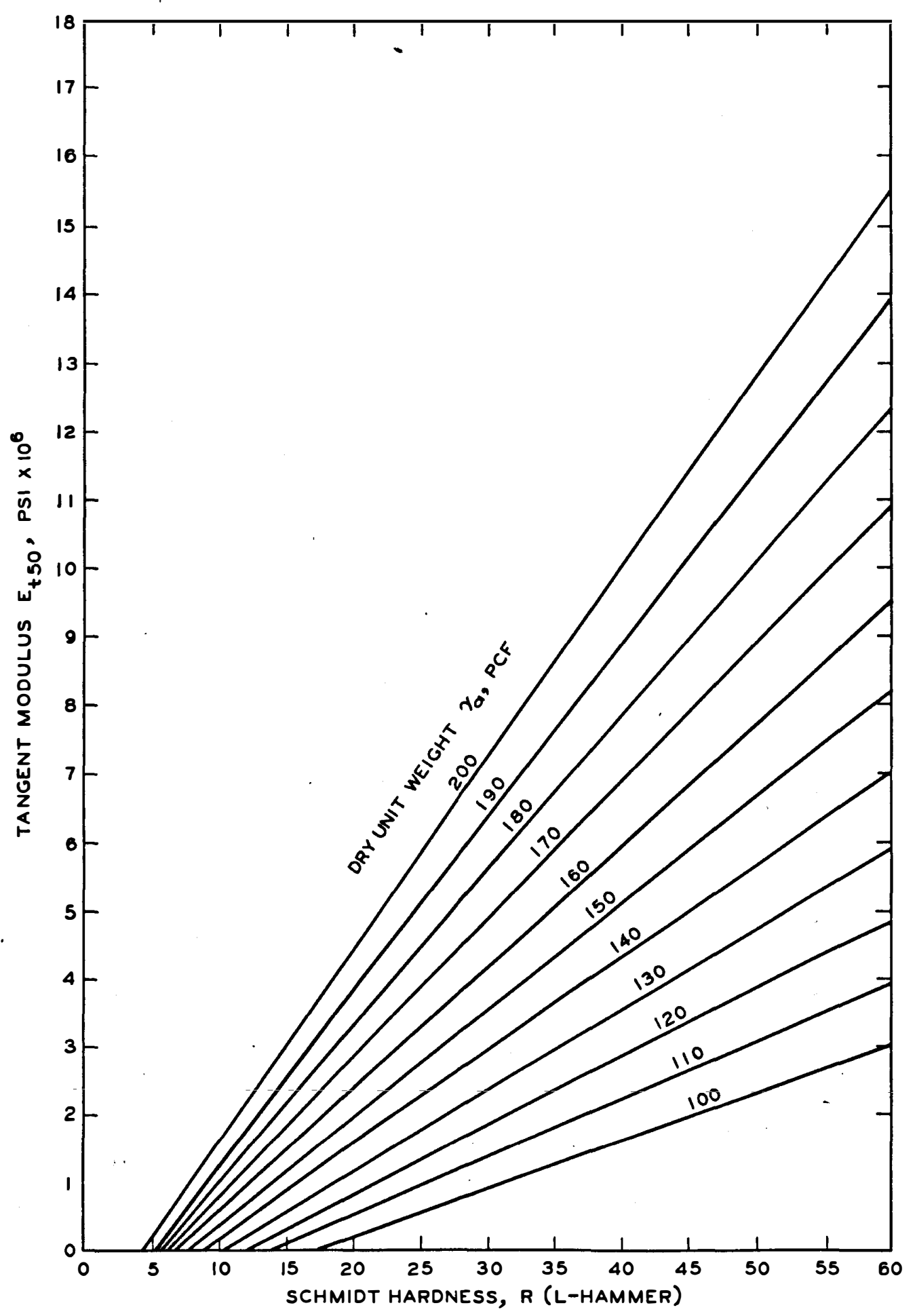

Figure 3.2 Rock modulus chart based on Schmidt hardness (Reference 16). 


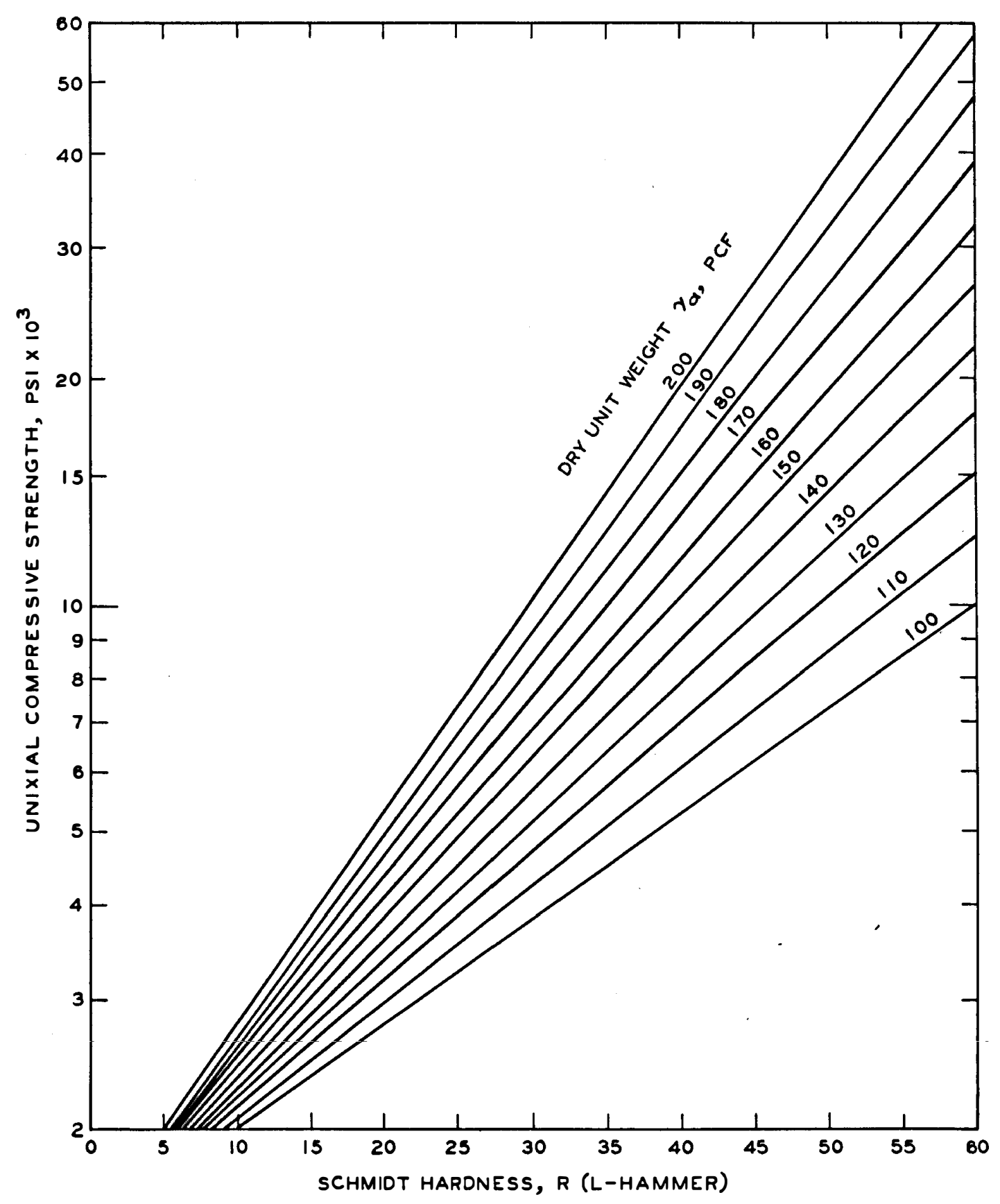

Figure 3.3 Rock strength based on Schmidt hardness (Reference 16). 


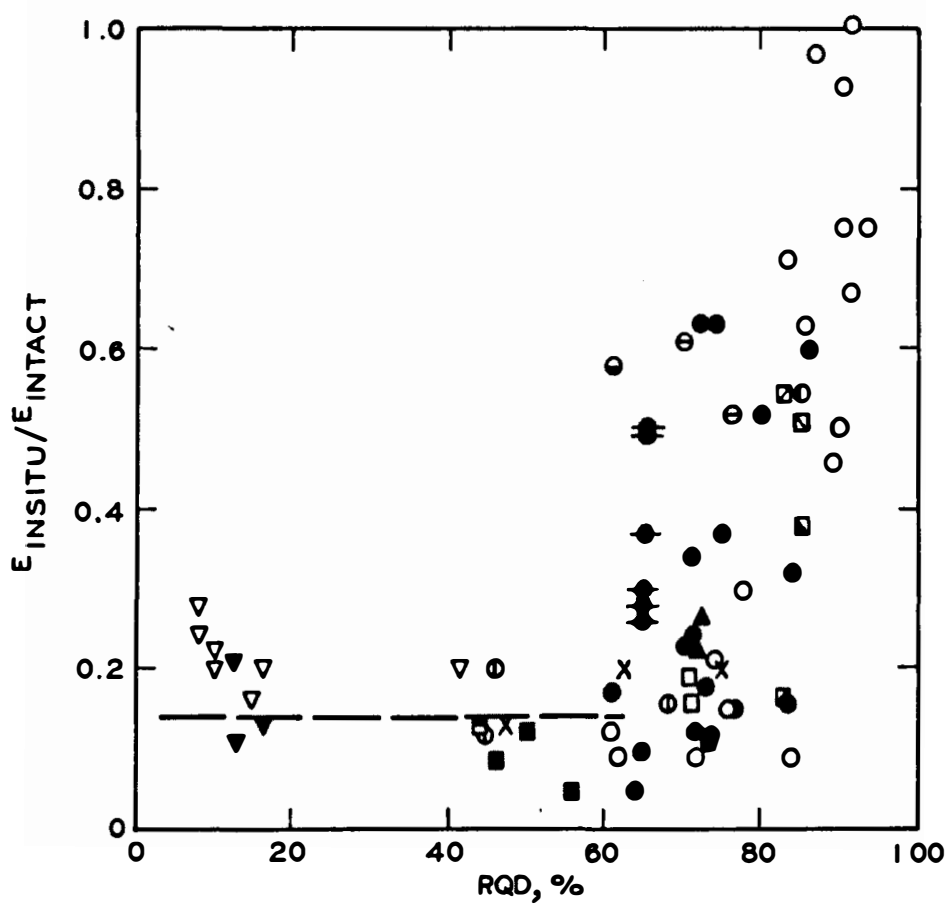

Figure 3.4 Variation of modulus ratio 'E insitu' $^{\prime}$ $E_{\text {intact with } R Q D}$ (Reference 20).

Figure 3.5 Behavior of $\mathrm{E}_{\text {insitu }} / \mathrm{E}_{\text {intact }}$ versus $R Q D$ for two limiting values.

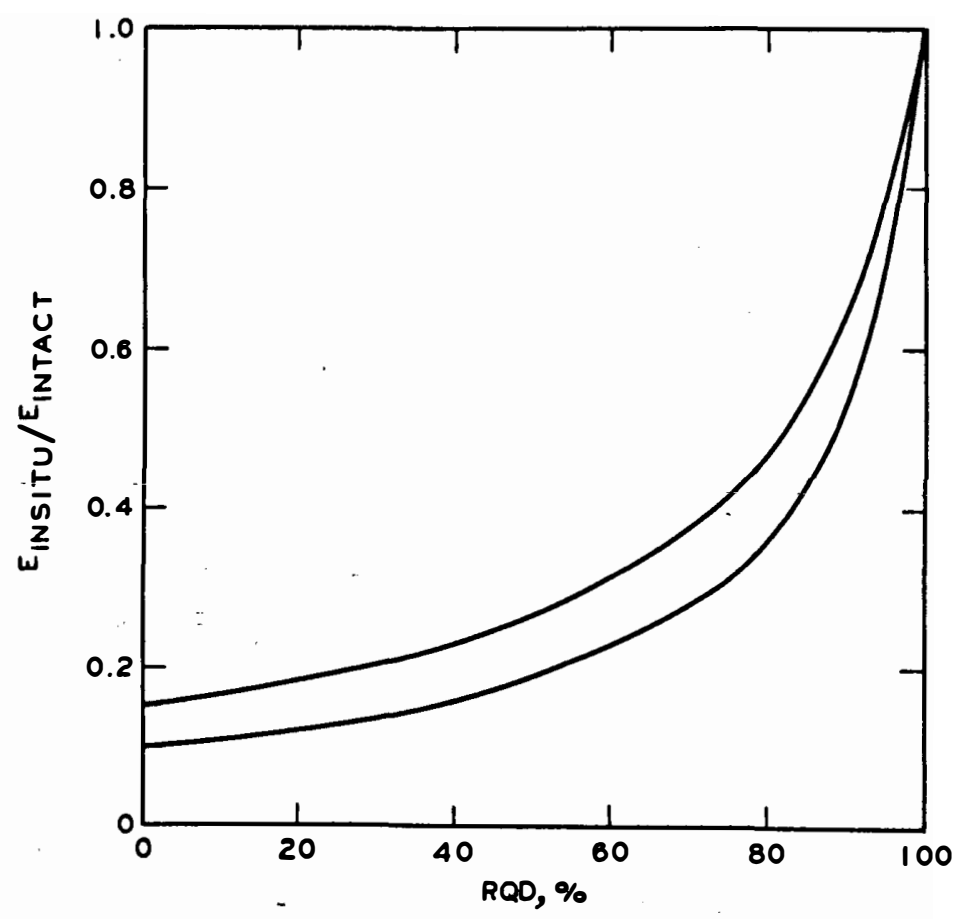




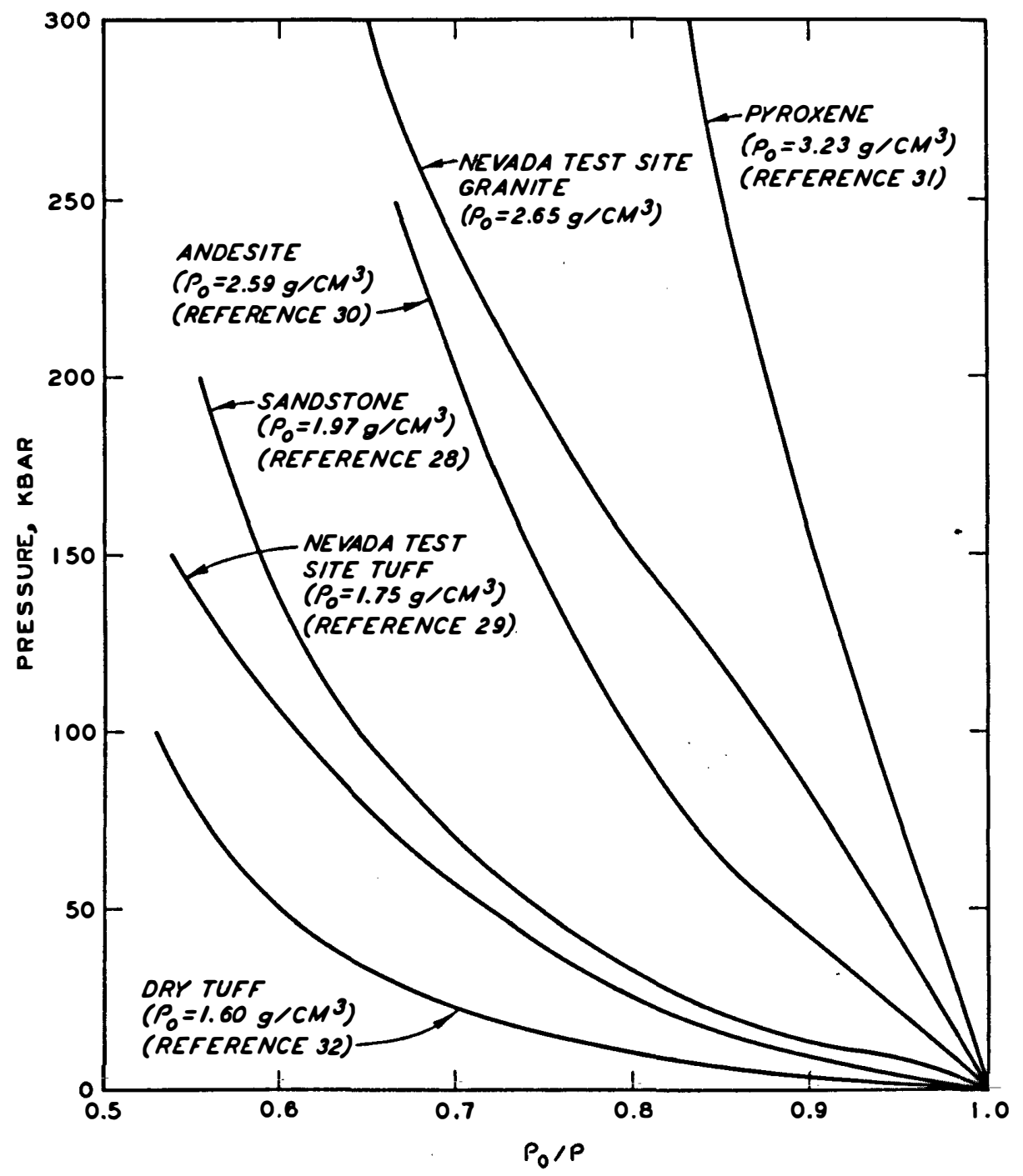

Figure 3.6 Presure-relative density relations for several rock types. 


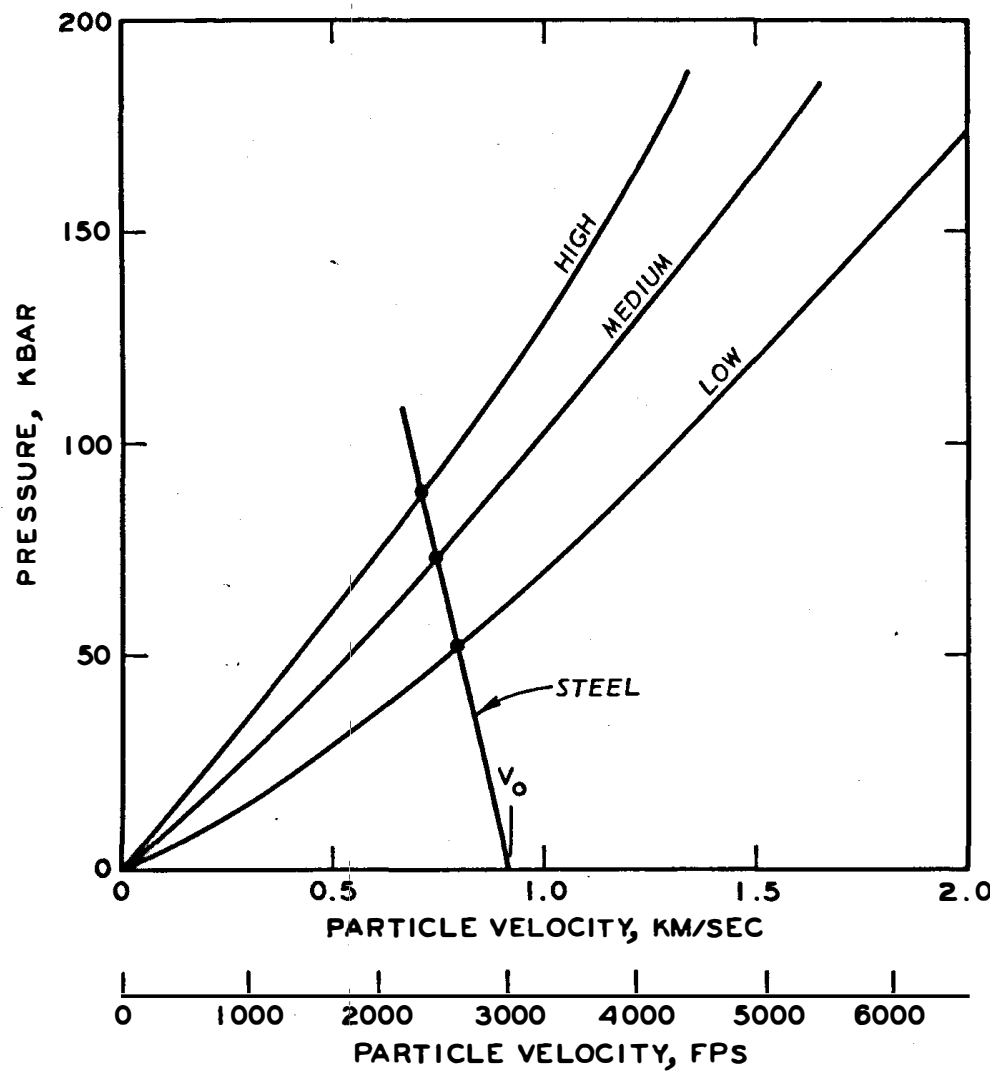

Figure 3.7 Impedance matching to obtain estimate of impact pressures for three rock targets at impact velocity $V_{0}$ of 3000 fps and assuming a steel projectile.

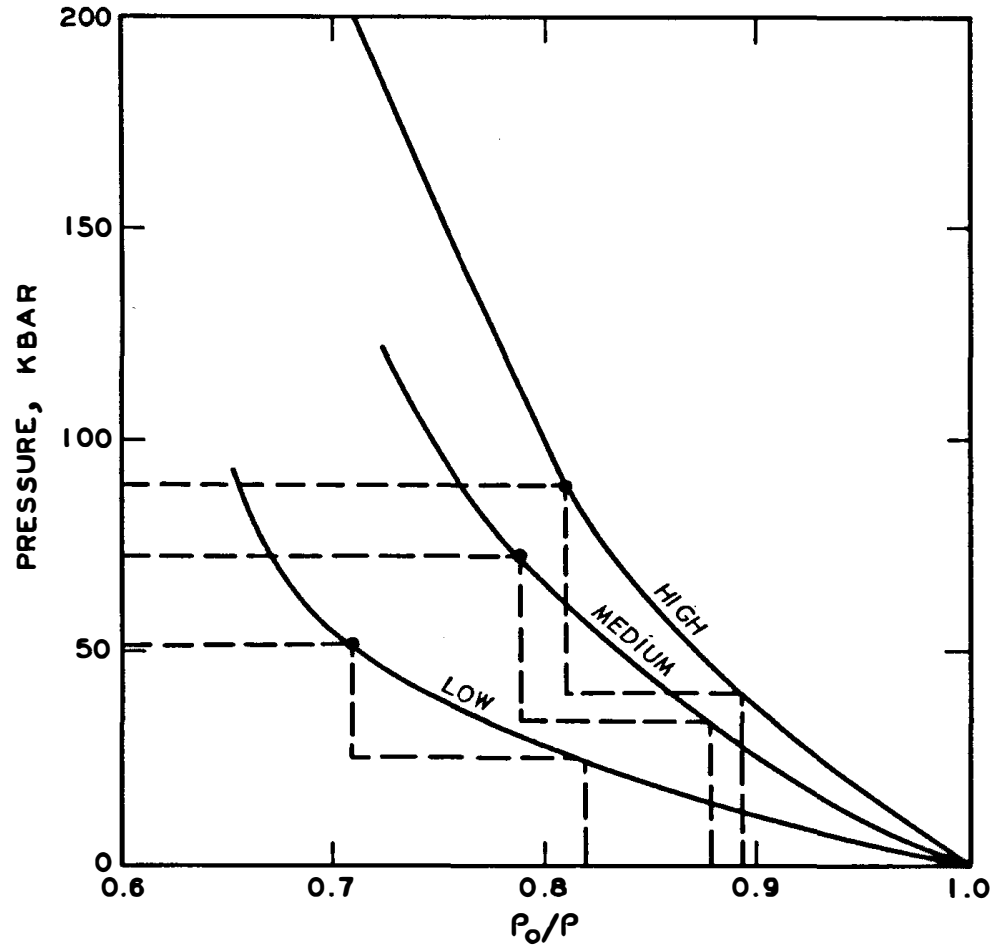

Figure 3.8 Estimation of compressibilities of the rock targets at the impact pressures indicated in Figure 3.7. 


\section{COMPARISON OF PENETRATION MODEL PREDICTIONS}

WITH EXPERIMENTAL RESULTS

\subsection{COMPARISON OF PENETRATION MODEL PREDICTIONS USING GENERAL ROCK PROPERTIES WITH EXPERIMENTAL RESULTS}

In an effort to gain insight concerning the reliability of the penetration model for predicting actual dynamic penetration into rock, five field tests were modeled and penetration predictions obtained. The tests were selected from those reported in Reference 2. The author of the reference reported $R Q D$ values for the targets and classified the rock according to the scheme presented in Table 3.1. Based on the classification of the targets, the general rock properties listed in Table 3.3 were used as presented, except that if the target was listed as having a high modulus ratio, the value 500 was used in conjunction with the $Y$ value to obtain $E$; likewise, for low modulus ratio classifications, a value of 200 was used. Table 4.1 presents the projectile characteristics and target properties used in the penetration model and compares the predicted and measured depths of penetration. The projectile type and test numbers refer to identification numbers used in Reference 2. The agreement between the predicted and measured penetration depths is very good in most cases. It is emphasized again that the rock properties used were those of Table 3.3 for low-, medium-, and highstrength rock and that actual stress-strain and strength data were not available. The fact that adequate simulation.could be obtained from such limited rock property information is fortunate, since the military targeteer rarely has detailed material property data for specific targets available to him.

The worst agreement was obtained for Test No. 120-127, for which the prediction is 36 percent lower than the measured value for penetration into Madera limestone. For this case the RQD at the site was not reported. For Test No. 120-106, the initial prediction was about 25 percent too low. Based on judgment, it was felt that the low value of RQD (32 percent) for the weathered granite at the test site was due 
to vertical as well as to horizontal fractures (contrasted to a sedimentary rock, for which a low value of RQD might be due entirely to horizontal fractures). Since vertical fractures would obviously enhance penetration and reduce strength, a second calculation was attempted with the value of $Y$ lowered to $4000 \mathrm{psi}$, which is the lower limit for lowstrength rocks in Table 3.1. This attempt yielded results which agreed much better with those obtained in the experiment (second entry for Test No. 120-106 in Table 4.1). In similar fashion, a second calculation for Test No. 120-127 with Y lowered to $8000 \mathrm{psi}$ (the lower limit of $\mathrm{CH}$ rocks) yielded much better agreement with the experimental result (second entry for Test No. 120-127).

For the limited number of comparison cases, the good agreement shown in Table 4.1 could be due to fortuitous combinations of material parameters. Thus it is profitable to obtain upper and lower limit penetration predictions for each case and then compare these with the measured penetration depths. This comparison is shown in Figure 4.1, in which predicted upper and lower limit depths of penetration are plotted versus measured depth of penetration (the perfect correlation line is shown for reference). The upper and lower limits of penetration for each case were calculated using the lower and upper limits, respectively, of the compressive strength for a given intact rock classification (i.e., a factor of two variation in strength). Furthermore, since the compressibility characteristics of the target materials were not known, it was assumed that the upper limits of compressive strengths correspond to 1 percent and the lower limits to 20 percent compressibility. Any other reasonable combinations of material properties will result in penetration depths which fall within these limits. As shown in Figure 4.1, the use of the rather extreme range of properties still produces ranges of predicted penetration depths which are acceptable for many practical applications.

4.2 TARGET PARAMETER STUDY OF SANDIA TEST NO. 120-106

In order to determine if the success achieved by changing the yield strength of the target ( $E$ adjusted to keep modulus ratio at:500) and 
keeping other target properties constant was accidental, a parameter study of Sandia Test No. 120-106 was conducted to illustrate the sensitivity of penetration predictions to all the target properties. The projectile parameters were not varied: weight $\mathrm{W}=613$ pounds, diameter. $D=8$ inches, sectional pressure $W / A=12.2 \mathrm{psi}$, and $\mathrm{CRH}=9.25$. Figure 4.2 illustrates the effect of varying $Y$ within the range 40008000 psi, using $E, \rho_{o}$, and $\rho_{p}$ from Table 3.3 for a low-strength rock. The penetration data in Figure 4.2 are replotted in Figure 4.3 for selected velocities as a function of modulus ratio, where in this case the modulus ratio varies due only to $Y$ since $E$ is held constant. In Figure 4.4, $\mathrm{E}$ is varied by a factor of 20 , and the effect on penetration is seen to be very small (less than 5 percent over the entire velocity range). Thus, for a factor of two change in $Y$, the effect on predicted penetration depth for a given velocity will be of the order of 40 percent, while $E$ has a minimal effect (at least for a factor of 10 change in $E$ ).

The effect of rock target density and compressibility on penetration is investigated in Figures 4.5 through 4.7 for constant values of $E$ and $Y$. A constant value of the quantity $\rho_{p} / \rho_{0}$ is maintained in Figure 4.5 while varying both $\rho_{o}$ and $\rho_{p}$; the effect on penetration is seen to be minimal at low velocities and approaches a spread of only 7 percent about the median penetration depth at $1900 \mathrm{fps}$. The effect of varying the compressibility while keeping $\rho_{0}$ constant is shown in Figure 4.6, and Figure 4.7 shows the effect of varying compressibility while keeping $\rho_{p}$ constant. While it is obviously important to choose realistic values for $\rho_{\circ}$ and $\rho_{p}$, it is the ratio $\rho_{p} / \rho_{\circ}$ which appears to have a more significant effect on predicted depth of penetration (for a given $Y$ ). As shown in Figure 4.6, in the upper range of compressibility (for example, $1.11 \leqslant \rho_{p} / \rho_{0} \leqslant 1.35$ ), a variation of 10 percent in $\rho_{p} / \rho_{0}$ affects the predicted depth of penetration by the order of 10 percent. For the relatively incompressible range (for example, $\left.1.00 \leqslant \rho_{p} / \rho_{0} \leqslant 1.01\right)$, a variation of only 1 percent affects the predicted depth of penetration by the order of 15 percent. For the range of velocity of 1000-3000 fps, the value of $\rho_{p} / \rho_{o}$ should be 
in the range $1.01 \leqslant \rho_{p} / \rho_{0} \leqslant 1.20$ for most rocks. Considering Figure 3.8 , a reasonable maximum variation of the estimate of $\rho_{p} / \rho_{\circ}$ should be \pm 5 percent. For the above range of $\rho_{p} / \rho_{o}$, this variation in $\rho_{p} / \rho_{o}$ would produce maximum variations in the predicted depth of penetration of the order of \pm 10 percent.

For Test No. 120-106, the RQD in situ is given as 32 percent; using the general parameter value (Table 3.2) for low-strength rock of $2.1 \times 10^{6} \mathrm{psi}$ as the intact modulus, the in situ modulus can be estimated using Figure 3.6 (upper curve) to be $0.4 \times 10^{6} \mathrm{psi}$. Reference to Figure 4.4 indicates that this reduction in $E$ will probably have negligible effect on penetration at the impact velocity of $860 \mathrm{fps}$. Thus, it is seen that, for this case, a reasonable range of variation in $Y$ has a much more significant influence than does a reasonable range of variation of any other parameter in the theory. It is expected that this same statement will hold true for each of the other four rock penetration tests simulated.

4.3 TENTATIVE PROCEDURE FOR BOUNDING PENETRATION DEPTH IN ROCK

It is proposed that reasonable upper and lower bounds for penetration predictions into rock within the range of interest for EPW's can be obtained if a strength classification such as "DH" for the intact target material is known or can be inferred (e.g., from comparison with similar rocks, from aerial photos, geologic maps, or literature, etc.) by using the $\rho_{o}, \rho_{p}$, and $E$ values from Table 3.3 and varying $Y$ between the limits indicated for the particular strength classification in Figure 3.1. If in addition the RQD is known or can be estimated, the $E$ value can be lowered by use of Figure 3.5 as previously shown. This concept is illustrated in Figure 4.8 for Test No. 120-106. For badly weathered or fractured rock, this procedure may not be valid, and more work is needed on correlations between RQD, for example, and in situ strength. The measured penetration depth for Test No. 120-106 lies at the upper bound of Figure 4.8 ( $R Q D=32$ percent). The cutoff for the validity of this method may be in the range of $R Q D=30-40$ percent, although as discussed in Chapter 3 , the type of rock may influence the 
limit of validity of the method. While the procedure proposed here needs further verification, it is in general agreement with all known relevant data and is based on a rational theory whose assumptions and limitations are defined.

4.4 EXTENSION OF PENETRATION MODEL TO TREAT THE COMPLETE TARGET PRESSURE-DENSITY CURVE

In Chapter 3, for simplicity and generality, a single value of locked plastic density was estimated for each hypothetical rock target and used in the penetration model for the entire velocity range considered. The effect of target compressibility on depth of penetration predictions has been discussed previously in this report. The effect of compressibility on deceleration-time histories will be discussed in this section. A better way of treating the compressibility, which is still within the framework of the constant locked plastic density concept, would be to input a value for $\rho_{p}$, estimated as in Section 3.3.2, for example, for each impact velocity. The idea of using a value for compressibility at a stress equal to one-half the impact stress at the maximum velocity of interest was arbitrary and a representation of the fact that the stress in the target media drops very rapidly following impact and in fact is probably much below one-half the peak stress value for most of the penetration event. To improve the treatment of compressibility in the penetration model, a logical and desirable extension is to input the correct $\rho_{p}$ for the existing cavity pressure at each integration cycle, i.e., the complete target pressure versus density curve should be an input to the model. Since the cavity pressure is available from the calculations in the computer codes, the extension to treat the complete target pressure-density relation was not difficult and was carried out as part of this study.

\subsection{EVALUATION OF EFFECT OF PRESSURE-DENSITY CURVE MODIFICATION}

The improvements, made are expected to have their greatest influence on the deceleration-time history. Regrettably, no deceleration records were available for the five events simulated earlier in this chapter. However, Reference 38 presents calculated deceleration-time histories 
for particular points in deformable projectiles as part of the results of numerical solutions to projectile penetration into two rock types. These numerical solutions were obtained by using a large, multipurpose, two-dimensional, Lagrangian finite difference computer code. The two rock types were welded tuff (low-strength rock) and Madera limestone (medium-strength rock). The results of these two calculations are used to test the penetration model as presented in this report and as modified to treat the complete target pressure-density relation using projectile and target properties presented in Reference 38. The target hydrostats are modeled in Reference 38 using the Mie-Grlineisen equation of state:

$$
p=\frac{\rho_{0} c_{0}^{2} \eta}{(1-q \eta)^{2}}\left[1+\frac{\gamma_{0}}{2} n(1-\eta)\right]+\gamma_{0} \rho_{0} E_{i}
$$

where

$$
\begin{aligned}
\rho_{0}= & \text { initial density } \\
c_{0}= & \text { initial velocity of sound } \\
\eta= & 1-\rho_{0} / \rho \\
q= & \text { material constant relating shock velocity to sound and } \\
& \text { particle velocities } \\
\gamma_{0}= & \text { Gruneisen constant } \\
\mathrm{E}_{i}= & \text { internal energy } \\
\rho= & \text { density }
\end{aligned}
$$

Table 4.2 (data taken from Reference 38 ) surmarizes the target and projectile properties for the two penetration events. In the finite difference code calculation, very large yield strengths were input to assure that no plastic deformations took place in the projectile. Body forces, heat conduction, and energy sources were also neglected. In the present penetration model, a rigid projectile is assumed and the other factors are not considered. Figures 4.9 and 4.10 are pressure versus density relations obtained from Equation 4.1, using the data in Table 4.2; Figure 4.11 is a higher pressure extension of Figure 4.9. Figure 4.12 is a reproduction of a plot from Reference 38 showing the finite difference code computed deceleration versus time response for the welded tuff penetration calculation of a particle located at 
the tip of the projectile nose. Superimposed on this is the rigid body prediction from the penetration model calculation (dashed line). In Figure 4.13 the penetration model deceleration-, velocity-, and displacement-time histories (dashed lines) are superimposed on the time histories calculated by the finite difference code for a particle located on the centerline of the projectile at a distance equal to the nose length from the tip. As can be seen in these figures, the penetration model deceleration-time histories are quite similar to the lower frequency portion obtained from the deformable body finite difference calculations. These high-frequency oscillations represent particle accelerations and decelerations due to stress wave propagation in the projectile, which of course cannot be simulated with a rigid body penetration model. As shown in Figure 4.13, the effect of differences in the acceleration curves has a negligible effect on velocity- and displacement-time histories from the two calculational methods. It is interesting to note that the observed final penetration depth for the test simulated in Figure 4.13 was 4.95 feet. This value is in close agreement with the calculated results.

As discussed in Reference 38, although the peak decelerations in Figures 4.12 and 4.13 for the finite difference calculation are drastically different, the decelerations for both curves should oscillate about the common "rigid body deceleration" of the projectile; and it is evident that the agreement of the penetration model prediction of the rigid body motion with that predicted from the finite difference code results is excellent in terms of general shapes of the time histories, magnitudes, and duration of the event.

Figure 4.14 presents the time histories for the limestone penetration calculated with the penetration model superimposed on the finite difference code generated time histories (base figure reproduced from Reference 38). For this case, the time histories are for a particle on the projectile centerline at a distance of 2 feet from the nose tip. Again the penetration model predictions are in excellent agreement with the finite difference results. The maximum depth of penetration observed in the event simulated here was 3.6 feet. Again 
both calculations are in reasonably good agreement with this value. Also, both the penetration theory and the finite difference decelerationtime results are in qualitative agreement with the experimental deceleration-time history shown in Figure 4.14 (this represents the only available complete deceleration-time record for projectile penetration into a nonlayered rock target).

To illustrate the importance of the details of target compressibility on the prediction of deceleration-time histories, a parameter study was conducted. The results are shown in Figures 4.15 and 4.16. Figure 4.15 shows the effect on penetration versus time plots of using the constant locked plastic density model with various compressibility estimates for the welded tuff case. The plot for 0.5 percent compressibility agrees approximately in final penetration depth and event duration with the prediction based on the complete pressure-density curve as shown in Figure 4.13. Figure 4.16 shows deceleration versus time plots for the 5.3 and the 0.5 percent compressibilities along with the deceleration-time curve from Figure 4.13. The concept begins to emerge that if the "right" constant locked plastic density value could be selected, then the simple constant locked plastic density model could be used to obtain results in good agreement with those obtained when the complete pressure-density relation is known and used.

If the details of the deceleration-time history of rock penetration events are of interest, it is clearly important to choose the "right" $\rho_{p}$. How should one go about estimating a "right" constant locked plạstic density for a particular penetration problem? Another estimate of target compressibility can be obtained by considering the contribution to the dynamic cavity pressure expressed by the term $f(\varepsilon) \rho_{p} B_{2} v_{-}^{2}$, where $V$ is the velocity (see Equation 2.1). By using the impact velocity $V_{0}$ in this term, an estimate is obtained of the peak dynamic cavity pressure contribution from this term. For impact and penetration into the medium-strength rock of Chapter 3 at a velocity of $1000 \mathrm{fps}$, with $\mathrm{CRH}=6, \mathrm{~W}=750$ pounds, and $\mathrm{D}=8$ inches, the calculated peak dynamic cavity pressure is about 2 kbar. Following the procedure of estimating the compressibility at half of this peak stress, which was 
proposed in connection with Figure 3.8, yields approximately 1 percent compressibility compared to ( 1 ) the 5 percent compressibility estimated from the same procedure but using peak stresses at impact estimated from impedance matching for $\mathrm{V}_{0}=1000 \mathrm{fps}$ and (2) the 13 percent compressibility used in Table 3.2 (based on impedance matching for the upper limit of $\left.v_{0}=3000 \mathrm{fps}\right)$. Figure 4.17 shows the time histories for this case for a 1 percent compressibility and for the case in which the entire hydrostat of Figure 3.8 was used. The event duration, depth of penetration, and peak deceleration agree very closely. The general effect of using the model with constant locked plastic density with a compressibility which is too large is to overestimate the depth of penetration and the event duration and to underestimate the peak deceleration. A compressibility of 0.5 percent (shown in Figure 4.16 ) is too small, at least for the early part of the event, and the peak deceleration is slightly overpredicted compared with the plot for the complete pressure-density relation calculation.

It is emphasized that if only the final depth of penetration is of interest, then the need to select the "right" $\rho_{p}$ is not of overriding importance, and a simple method such as the impedance matching procedure will be adequate. Based on these considerations, the original rock property values given in Table 3.3 were used in the parameter study in Chapter 5, since penetration depth was the primary dependent variable of interest. However, the penetration predictions to be presented in Chapter 5 should be viewed as upper bound estimates, particularly at the lower impact velocities, since the compressibilities are somewhat high. 


\section{TABLE 4.1 COMPARISON OF PENETRATION MODEL PREDICTIONS WITH FIELD PENETRATION TEST RESULTS}

\begin{tabular}{|c|c|c|c|c|c|}
\hline \multirow{2}{*}{$\begin{array}{c}\text { Sandia } \\
\text { Test No. } \\
\text { (Reference 2) } \\
\end{array}$} & \multirow{2}{*}{$\begin{array}{c}\text { Projectile } \\
\text { Velocity Type }\end{array}$} & \multirow[b]{2}{*}{ Rock Type } & \multirow[b]{2}{*}{ Code Input } & \multicolumn{2}{|c|}{ Penetration } \\
\hline & & & & Predicted & Measured \\
\hline \multirow[t]{2}{*}{$120-112$} & Type III & Sandstone & $p_{0}=4.07$ & 126 in & 122 in \\
\hline & $\begin{aligned} \mathrm{CRH} & =9.25 ; \mathrm{D}=10.188 \mathrm{in} \\
\mathrm{W} / \mathrm{A} & =14.3 \mathrm{psi} \\
\mathrm{v}_{\mathrm{O}} & =825 \mathrm{fps}\end{aligned}$ & $\begin{array}{c}\stackrel{\mathrm{DH}}{\mathrm{RQD}}=37 \% \\
=3\end{array}$ & $\begin{aligned} P_{p} & =4.95 \\
E & =3 \times 10^{6} \mathrm{psi} \\
Y & =6000 \mathrm{psi}\end{aligned}$ & & \\
\hline \multirow[t]{4}{*}{$339-16$} & Type IV & $\begin{array}{l}T_{T R}^{a} \text { welded } \\
\text { tuff }\end{array}$ & $p_{0}=4.07$ & 99 in & 110 in \\
\hline & $C R H=6.0 ; D=9$ in & & $p_{p}=4.95$ & & \\
\hline & $\mathrm{W} / \mathrm{A}=16.0 \mathrm{ps} 1$ & $\begin{aligned} & \stackrel{D L}{R} \\
R Q D & =80 \%\end{aligned}$ & $E=1.2 \times 10^{6} \mathrm{ps} 1$ & & \\
\hline & $v_{0}=650 \mathrm{fps}$ & & $Y=6000 \mathrm{psi}$ & & \\
\hline \multirow[t]{5}{*}{$120-77$} & Type I & TTR welded & $p_{0}=4.07$ & 161 in & 156 in \\
\hline & $\mathrm{CRH}=9.25 ; \mathrm{D}=9 \mathrm{in}$ & agglomerate & $P_{p}=4.95$ & & \\
\hline & $\mathrm{W} / \mathrm{A}=13.5 \mathrm{ps} 1$ & $\underline{\mathrm{DM}}$ & & & . \\
\hline & & $R Q D=60 \%$ & $\mathrm{E}=2.1 \times 10^{6} \mathrm{ps}$ & & \\
\hline & $v_{0}=1065 \mathrm{fps}$ & & $Y=6000 \mathrm{ps} 1$ & & \\
\hline \multirow[t]{5}{*}{$120-106$} & Type II & $\begin{array}{l}\text { Weathered } \\
\text { granite }\end{array}$ & $p_{0}=4.07$ & 113 in & 150 in \\
\hline & $\mathrm{CRH}=9.25 ; \mathrm{D}=8 \mathrm{in}$ & & $p_{p}=4.95$ & & \\
\hline & $\mathrm{W} / \mathrm{A}=12.2 \mathrm{ps} 1$ & DH & & & \\
\hline & & $R Q D=32 \%$ & $E=3 \times 10^{6} \mathrm{psi}$ & & \\
\hline & $v_{0}=860 \mathrm{fps}$ & & $Y=6000 \mathrm{ps} 1$ & & \\
\hline \multirow[t]{3}{*}{$120-106$} & & & $p_{0}=4.07$ & 144 in & 150 in \\
\hline & & & $\begin{aligned} P_{p} & =4.95 \\
E & =2 \times 10^{6} \text { psi }\end{aligned}$ & & \\
\hline & & & $Y=4000 \mathrm{ps} 1$ & & \\
\hline \multirow[t]{4}{*}{$120-127$} & Type V & $\begin{array}{l}\text { Madera } \\
\quad \text { limestone }\end{array}$ & $p_{0}=5.04$ & 79 in & 124 in \\
\hline & $\mathrm{CRH}=9.25 ; \mathrm{D}=8 \mathrm{in}$ & $\underline{\mathrm{CH}}$ & $\rho_{p}=5.72$ & & \\
\hline & $\mathrm{W} / \mathrm{A}=13.4 \mathrm{psi}$ & & $E=6 \times 10^{6} \mathrm{psi}$ & & \\
\hline & $\mathrm{v}_{\mathrm{o}}=950 \mathrm{fps}$ & & $Y=12,000 \mathrm{ps} 1$ & & \\
\hline \multirow[t]{4}{*}{$120-127$} & & & $p_{0}=5.04$ & 101 in & 124 in \\
\hline & & & $P_{p}=5.72$ & & \\
\hline & & & $E=4 \times 10^{\circ} \mathrm{ps}$ & & \\
\hline & & & $Y=8000 \mathrm{ps} 1$ & & \\
\hline
\end{tabular}

a Tonopah Test Range. 
TABLE 4.2 PROPERTIES FOR PROJECTILE PENETRATION

\section{Welded Tuff Penetration}

Tuff Properties

$$
\rho_{0}=1.85 \mathrm{~g} / \mathrm{cm}^{3}=115 \mathrm{pcf}
$$

Poisson's ratio $=0.1$

$$
\begin{aligned}
Y & =3.8 \times 10^{8} \text { dynes } / \mathrm{cm}^{2} \\
& =5510 \mathrm{psi} \\
\mathrm{c}_{0} & =2.05 \times 10^{5} \mathrm{~cm} / \mathrm{sec} \\
& =6725 \mathrm{fps} \\
\gamma_{0} & =2.00 \\
q & =1.49
\end{aligned}
$$

Projectile Properties

$$
D=22.86 \mathrm{~cm}=9 \text { in }
$$

\begin{tabular}{|c|c|}
\hline Limestone Properties & Projectile Properties \\
\hline $\begin{aligned} \rho_{\circ} & =2.69 \mathrm{~g} / \mathrm{cm}^{3}=168 \mathrm{pcf} \\
\text { Poisson's ratio } & =0.32\end{aligned}$ & $\begin{aligned} D & =20.32 \mathrm{~cm}=8 \mathrm{in} \\
\mathrm{W} & =3.055 \times 10^{5} \mathrm{~g} \\
& =673.6 \mathrm{Ib}\end{aligned}$ \\
\hline $\begin{aligned} \mathrm{Y} & =9.44 \times 10^{8} \text { dynes } / \mathrm{cm}^{2} \\
& =13,690 \mathrm{psi}\end{aligned}$ & $\mathrm{W} / \mathrm{A}=13.4 \mathrm{psi}$ \\
\hline $\begin{aligned} c_{0} & =3.4 \times 10^{5} \mathrm{~cm} / \mathrm{sec} \\
& =11,150 \mathrm{fps}\end{aligned}$ & $\underset{\mathrm{CRHI}}{\text { Nose }}=9.25$ \\
\hline$\gamma_{0}=2.00$ & $\mathrm{v}_{\mathrm{O}}=17,374 \mathrm{~cm} / \mathrm{sec}=570 \mathrm{fps}$ \\
\hline$q=1.27$ & \\
\hline
\end{tabular}$$
\mathrm{W}=4.55 \times 10^{5} \mathrm{~g}=1000 \mathrm{lb}
$$$$
\mathrm{W} / \mathrm{A}=15.76 \mathrm{psi}
$$$$
\underset{\mathrm{CRH}}{\text { Nose }}=6
$$$$
V_{0}=21,184 \mathrm{~cm} / \mathrm{sec}=695 \mathrm{fps}
$$

Madera Limestone Penetration 


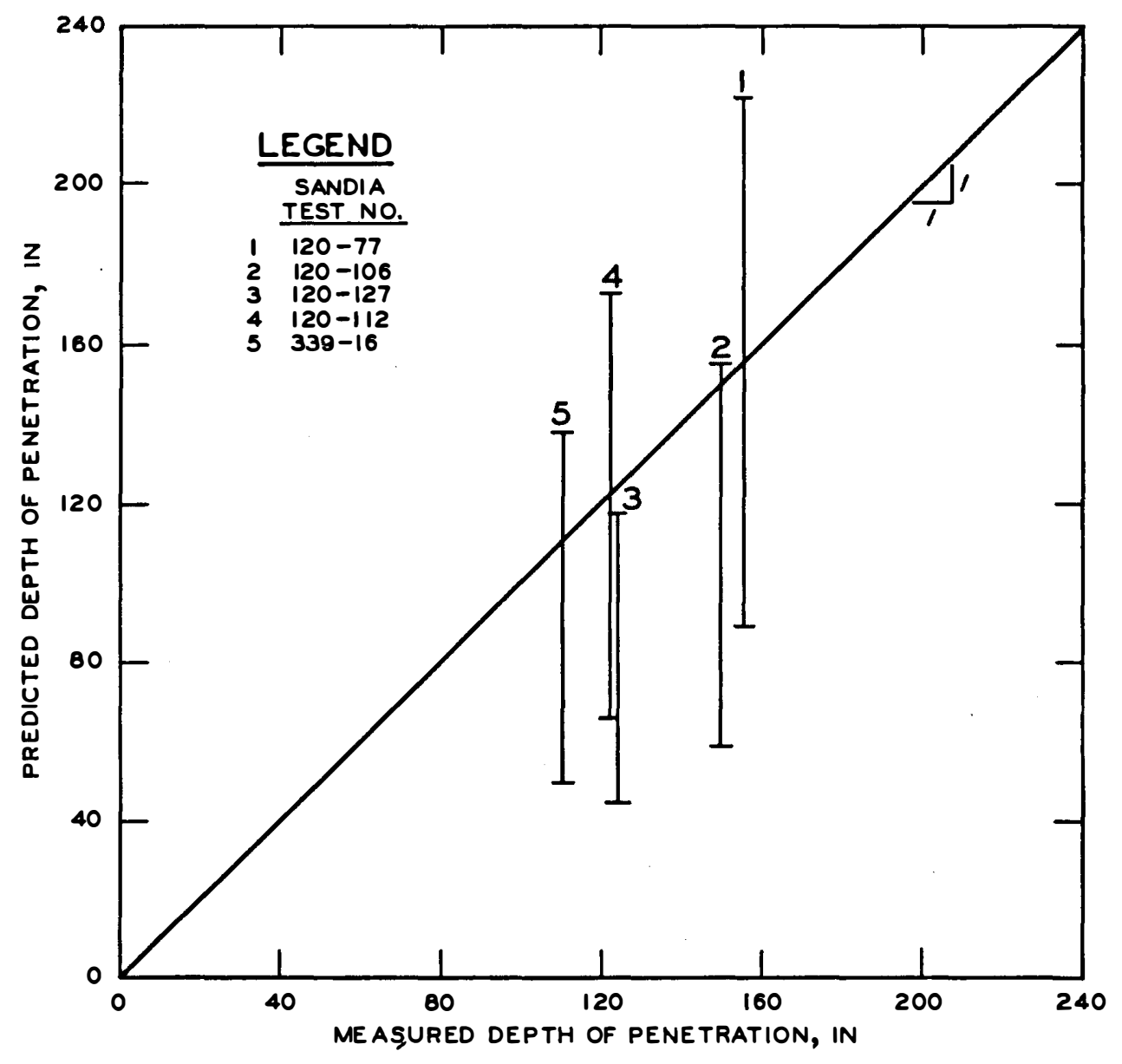

Figure 4.1 Measured versus predicted depth of penetration into rock targets. 


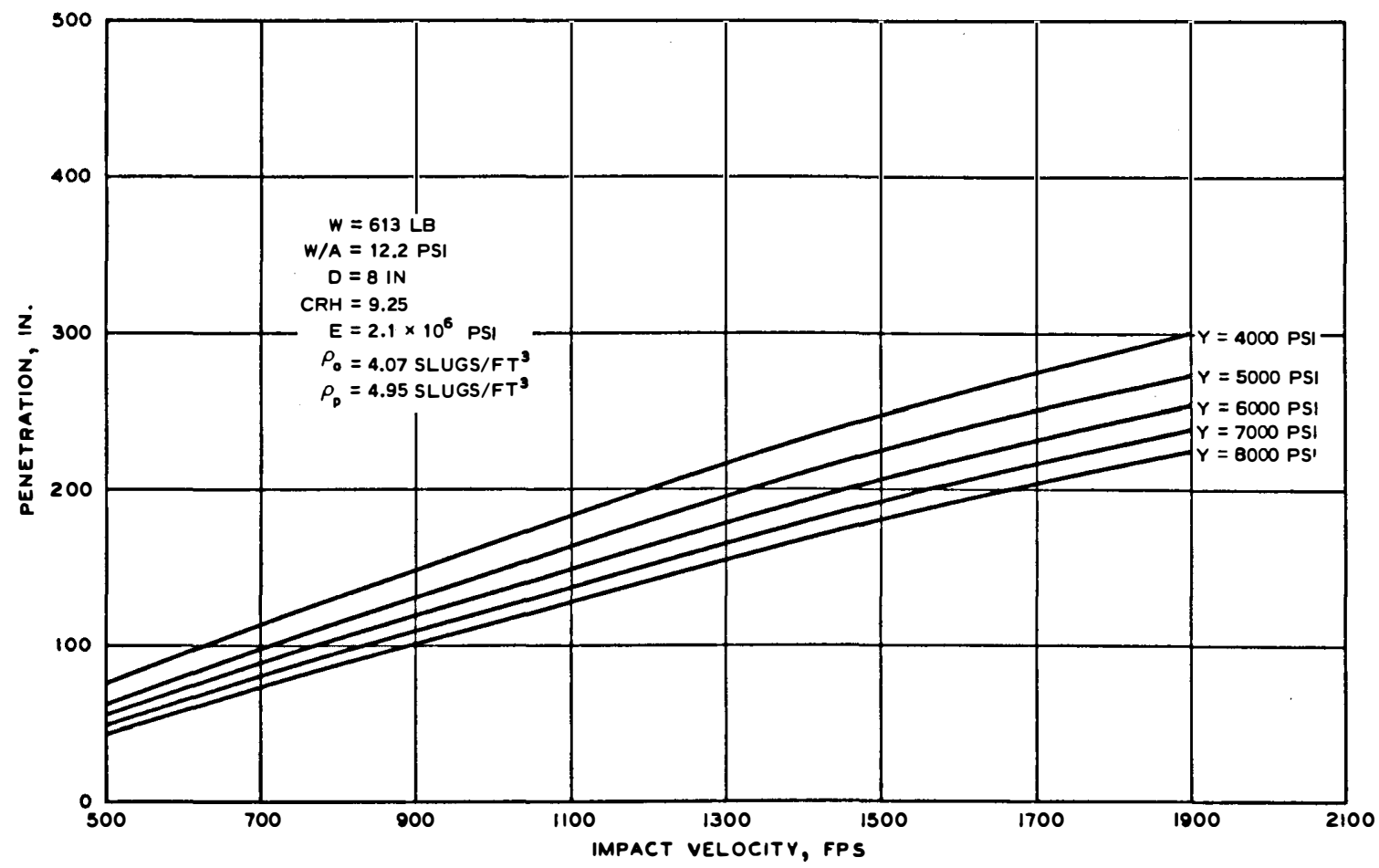

Figure 4.2 Effect of varying $Y$ on penetration versus impact velocity plot (Test No. 120-106).

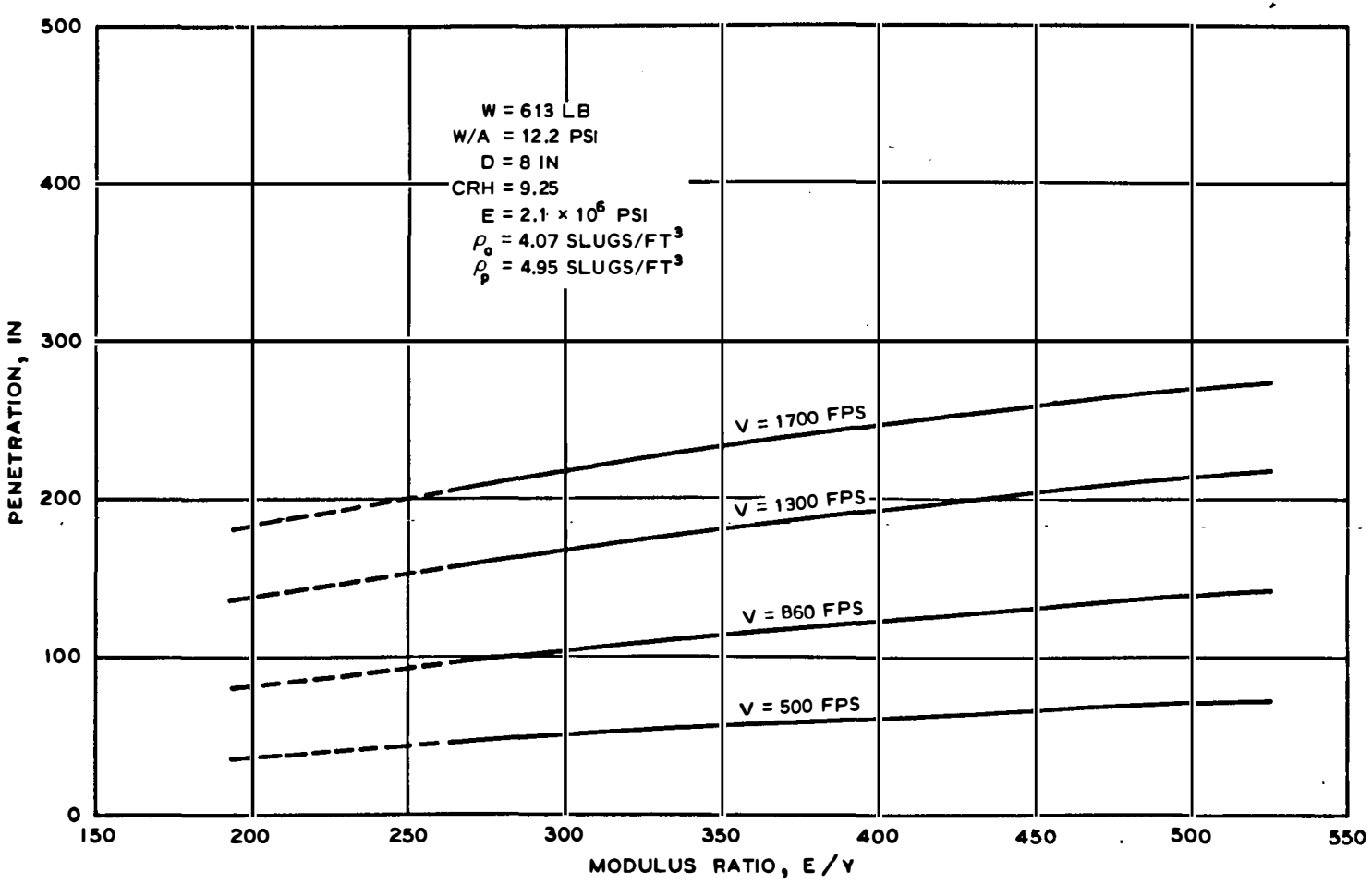

Figure 4.3 Penetration versus modulus ratio for constant E. 


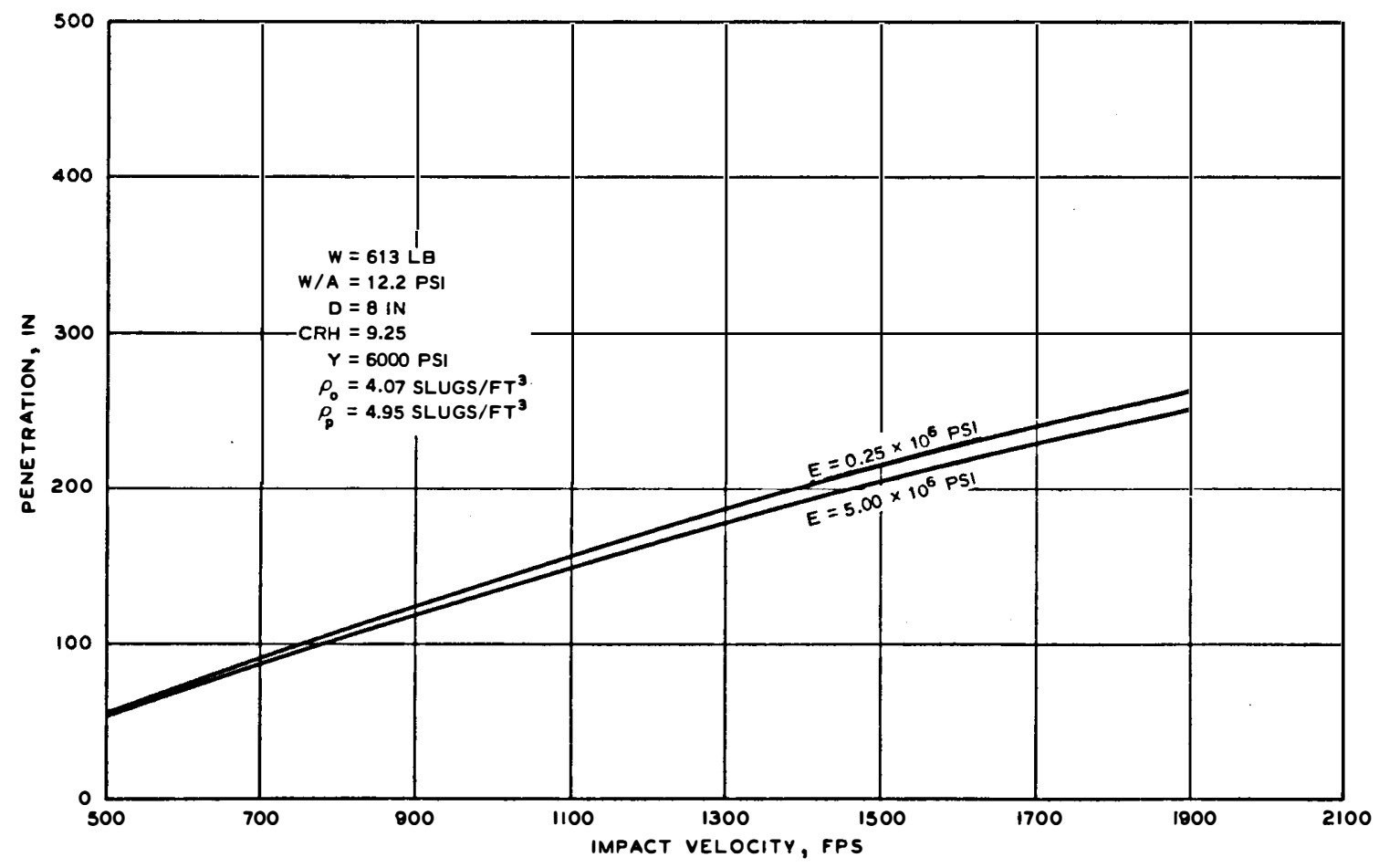

Figure 4.4 Effect of modulus on penetration.

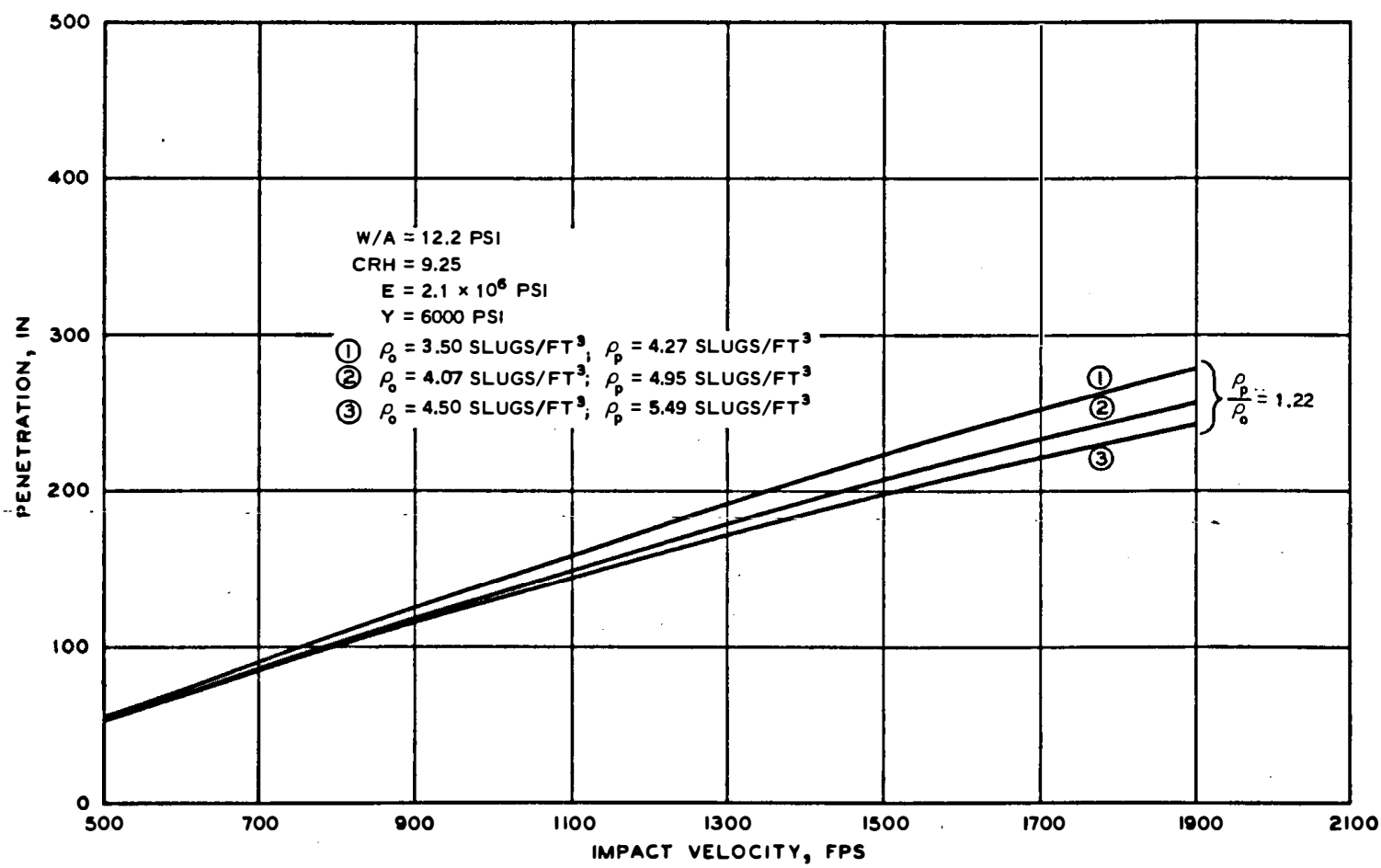

Figure 4.5 Effect of $\rho_{o}$ and $\rho_{p}$ on penetration while maintaining $\rho_{p} / \rho_{0}$ constant. 


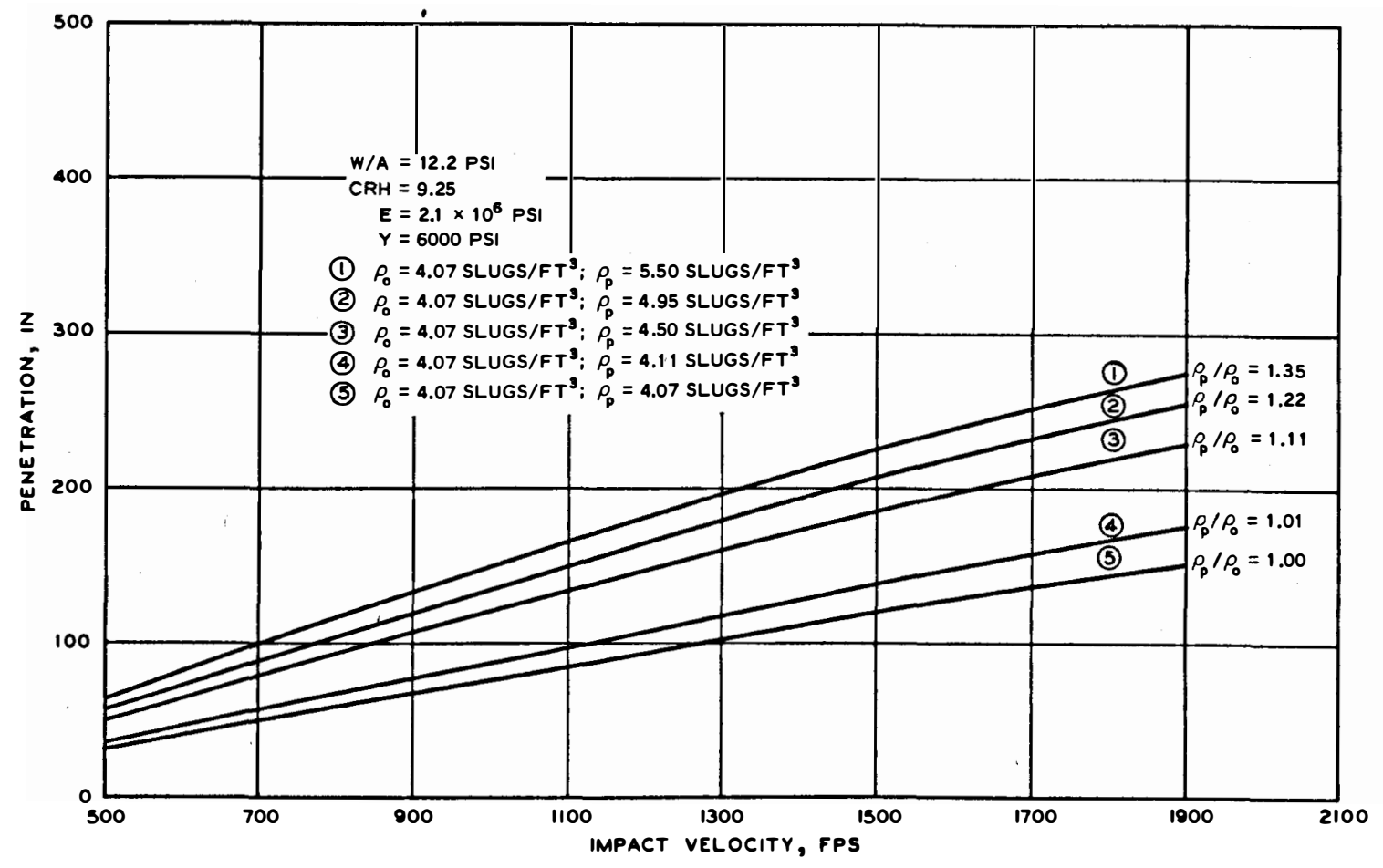

Figure 4.6 Effect of $\rho_{p} / \rho_{0}$ on penetration while maintaining $\rho_{0}$ constant.

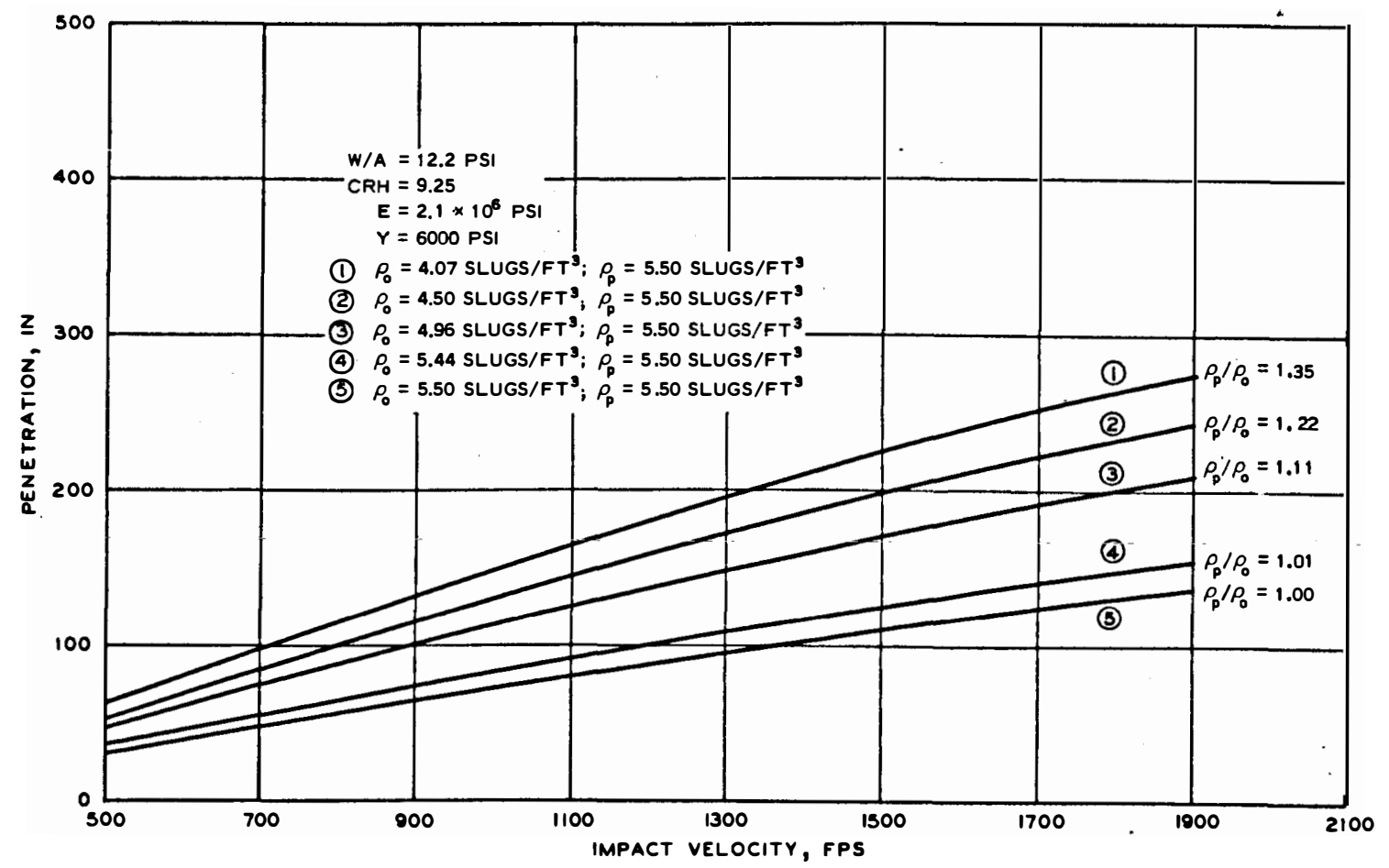

Figure 4.7 Effect of $\rho_{p} / \rho_{0}$ on penetration while keeping
$\rho_{\text {constant. }}$ 


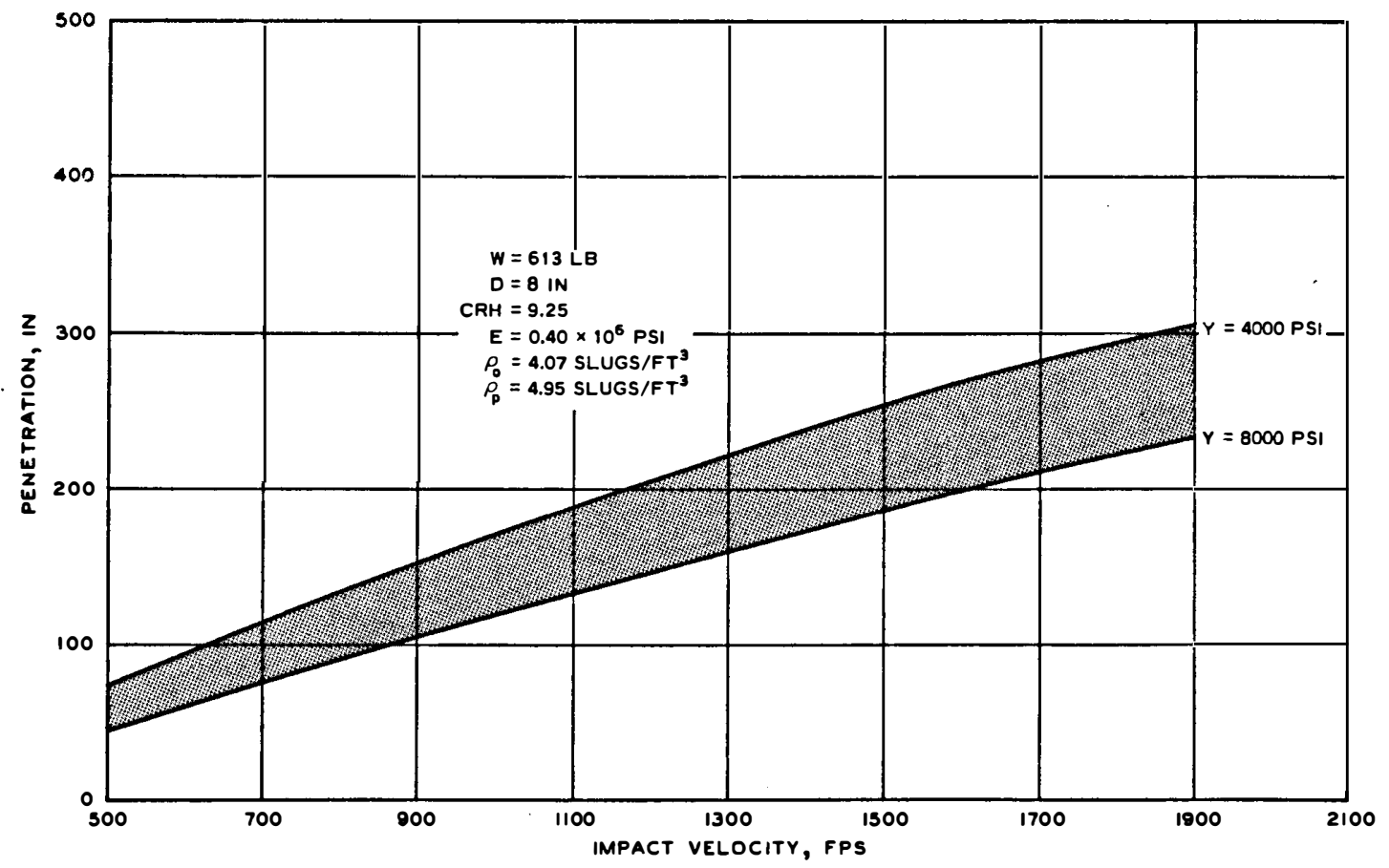

Figure 4.8 Establishment of upper and lower bounds for Test No. 120-106.

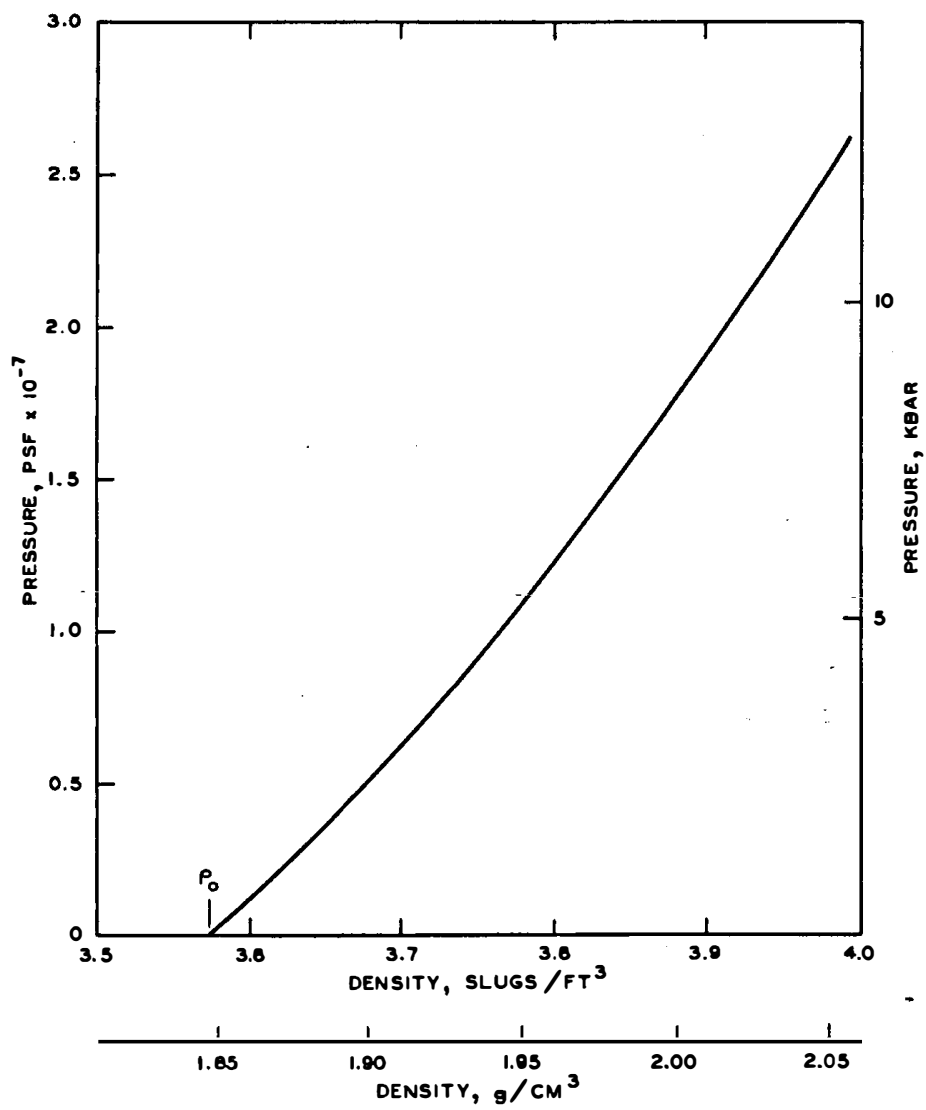

Figure 4.9 Pressuredensity relation for welded tuff based on Equation 4.1. 


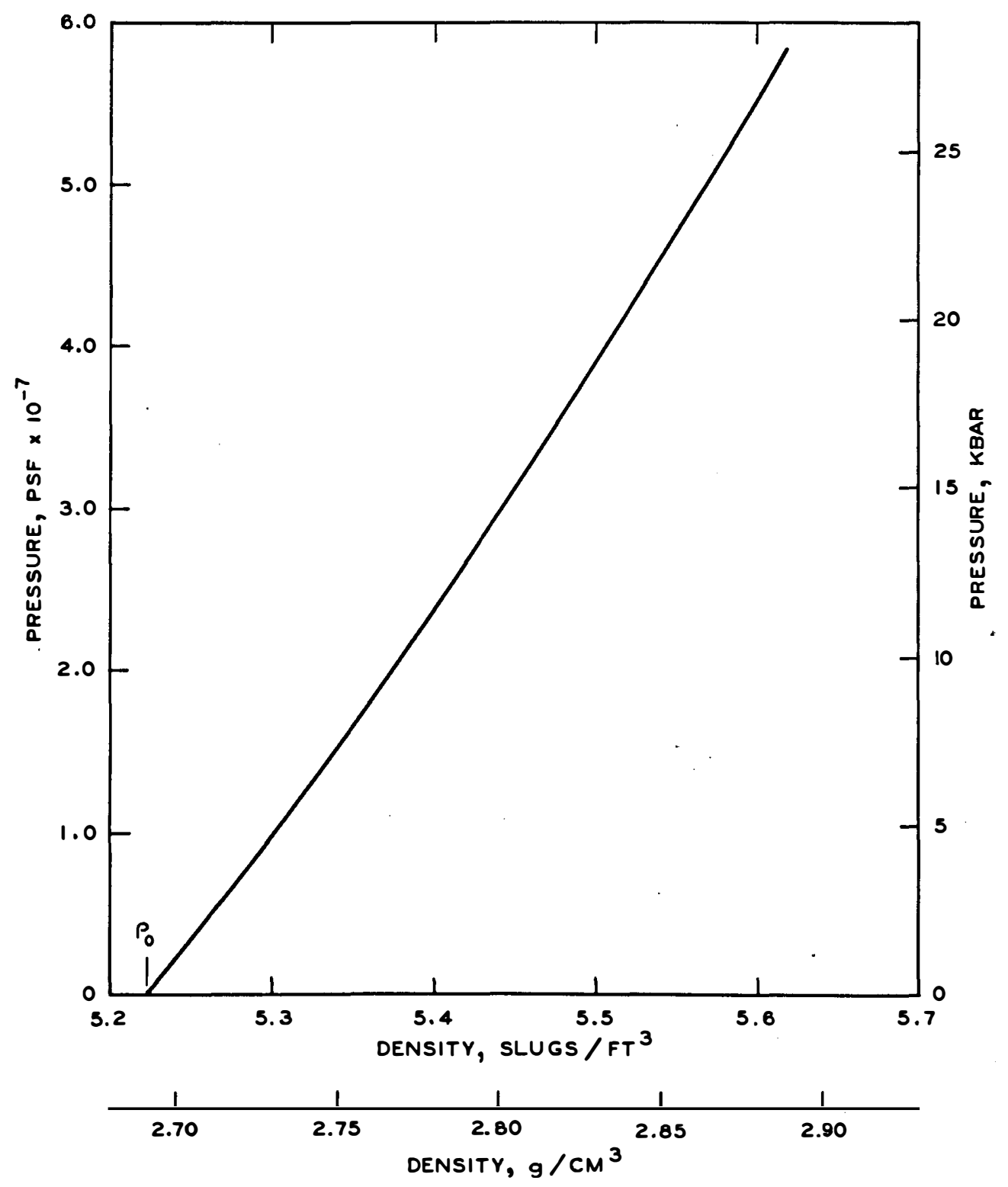

Figure 4.10 Pressure-density relation for Madera limestone based on Equation 4.1. 


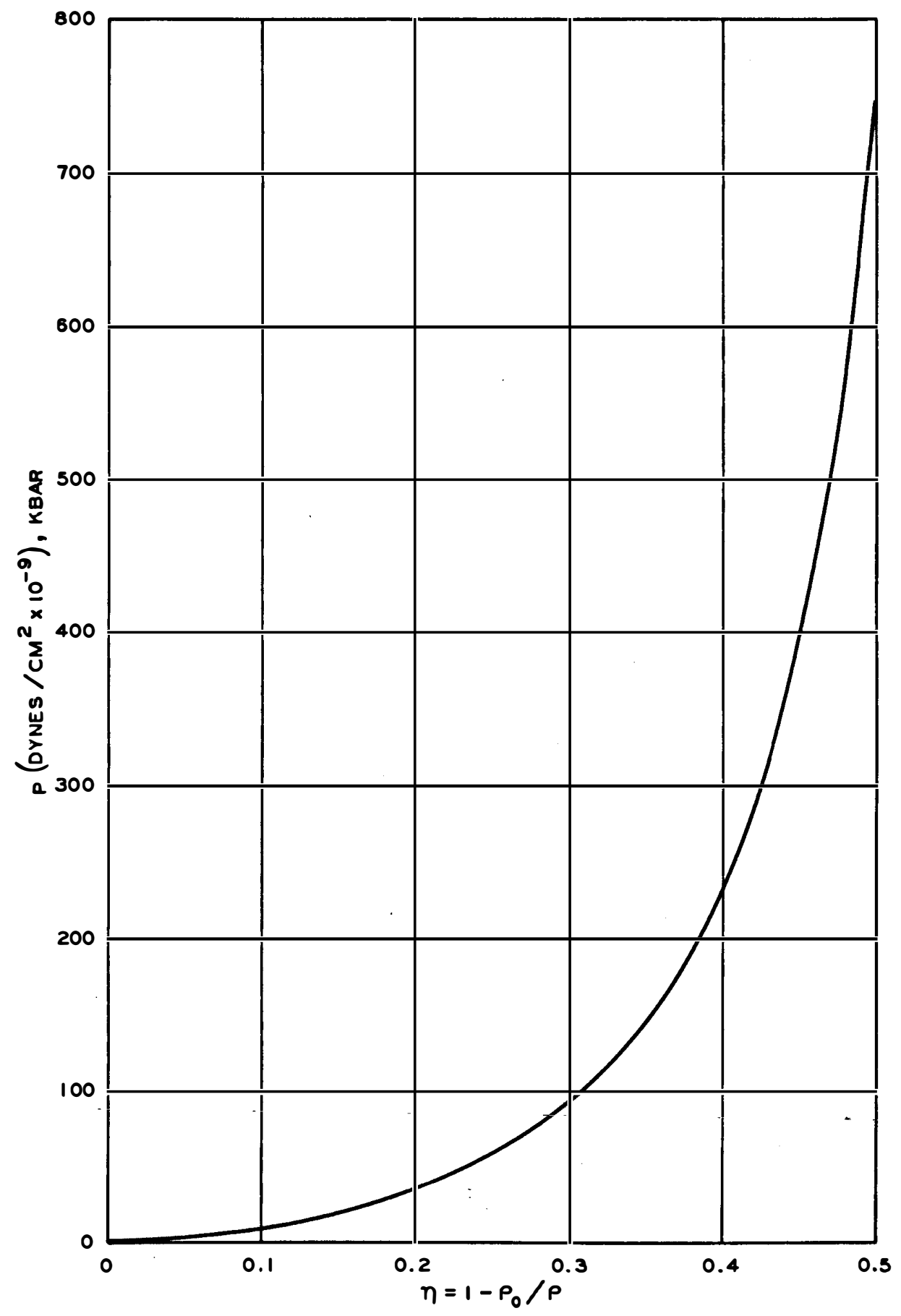

Figure 4.11 Plot of $p$ versus $n$ for welded tuff. 


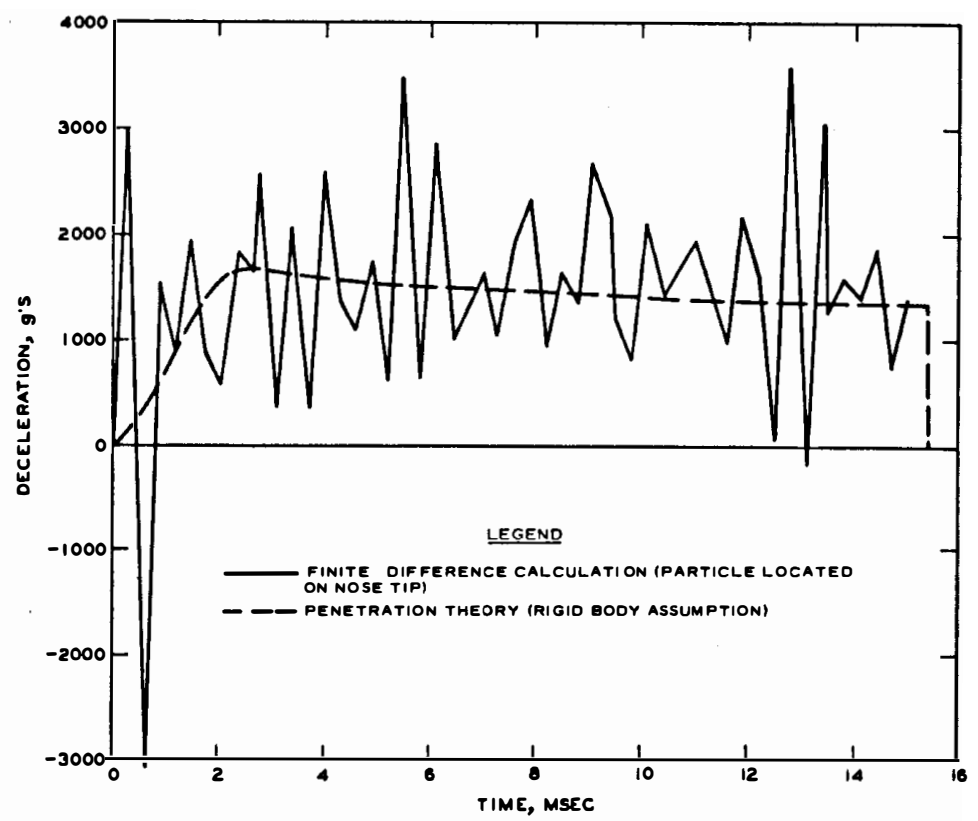

Figure 4.12 WES rigid body acceleration versus time prediction superimposed on the Sandia finite difference results for particle located on nose tip of projectile; tuff penetration.

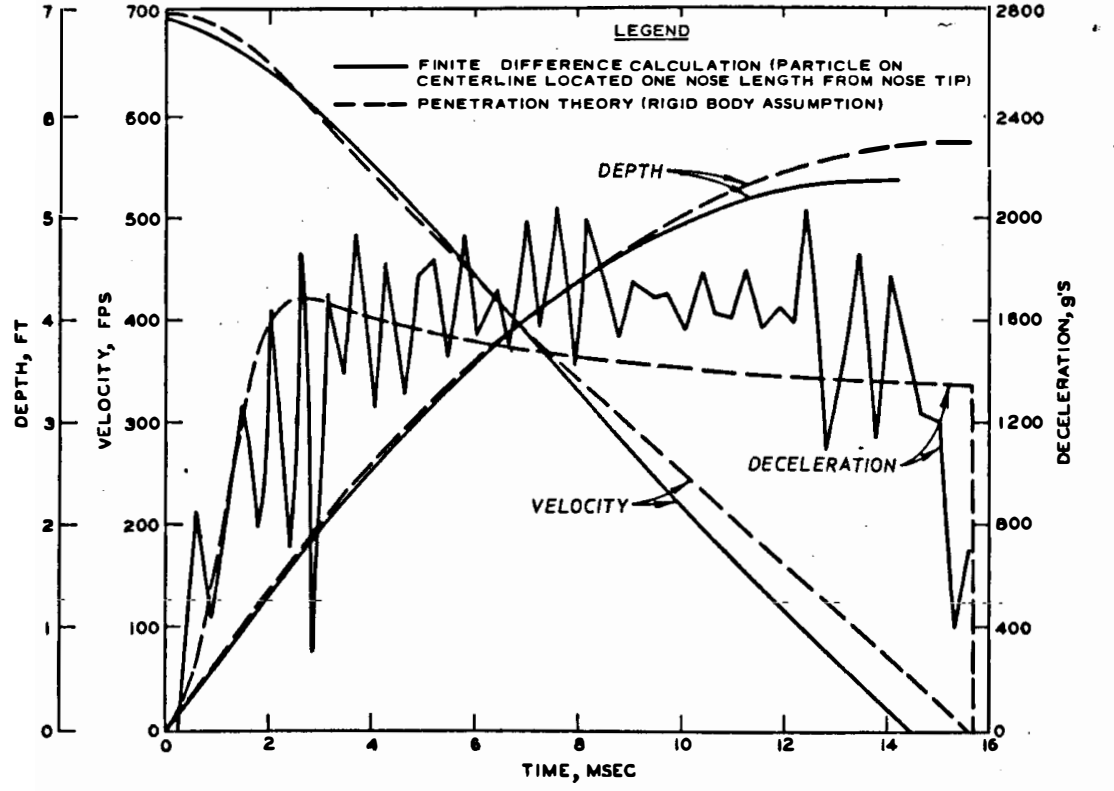

Figure 4.13 WES rigid body model time histories superimposed on the finite difference time histories for particle on centerline located one nose length from nose tip; tuff penetration. 


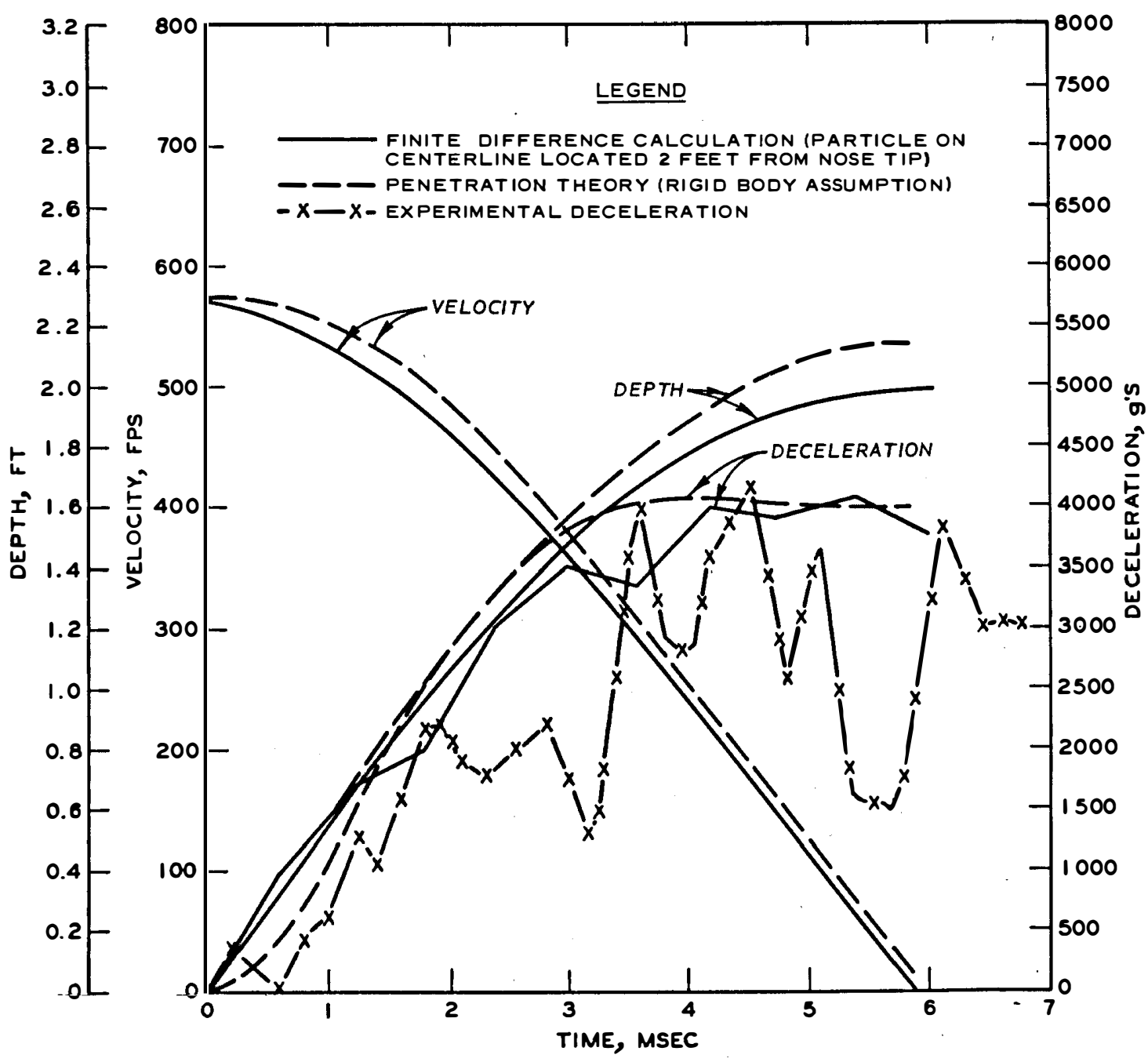

Figure 4.14 WES rigid body model time histories superimposed on the finite difference time histories for a particle on centerline located 2 feet from nose tip; limestone penetration. 


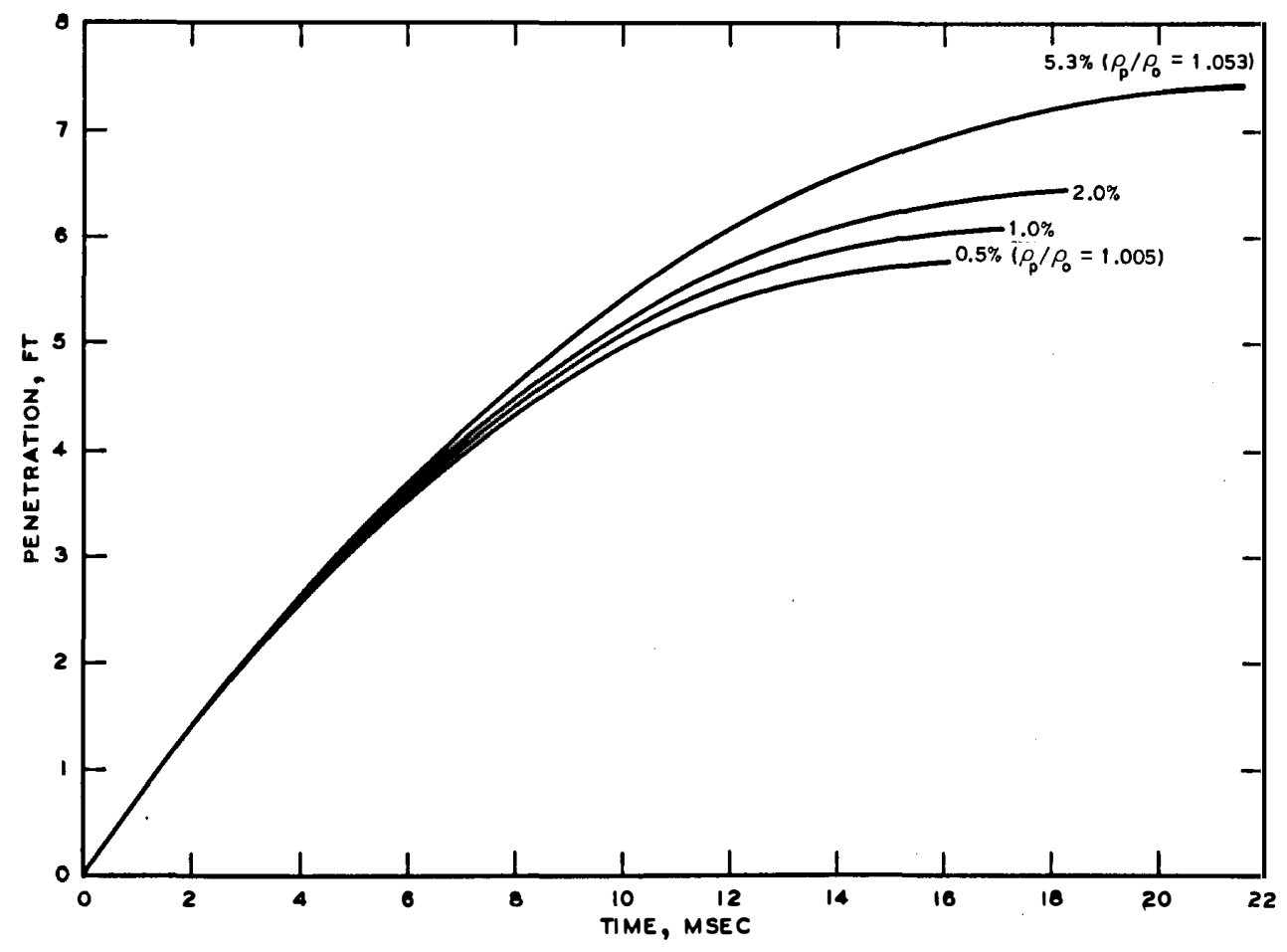

Figure 4.15 Constant locked plastic density model predictions for various compressibilities; tuff penetration.

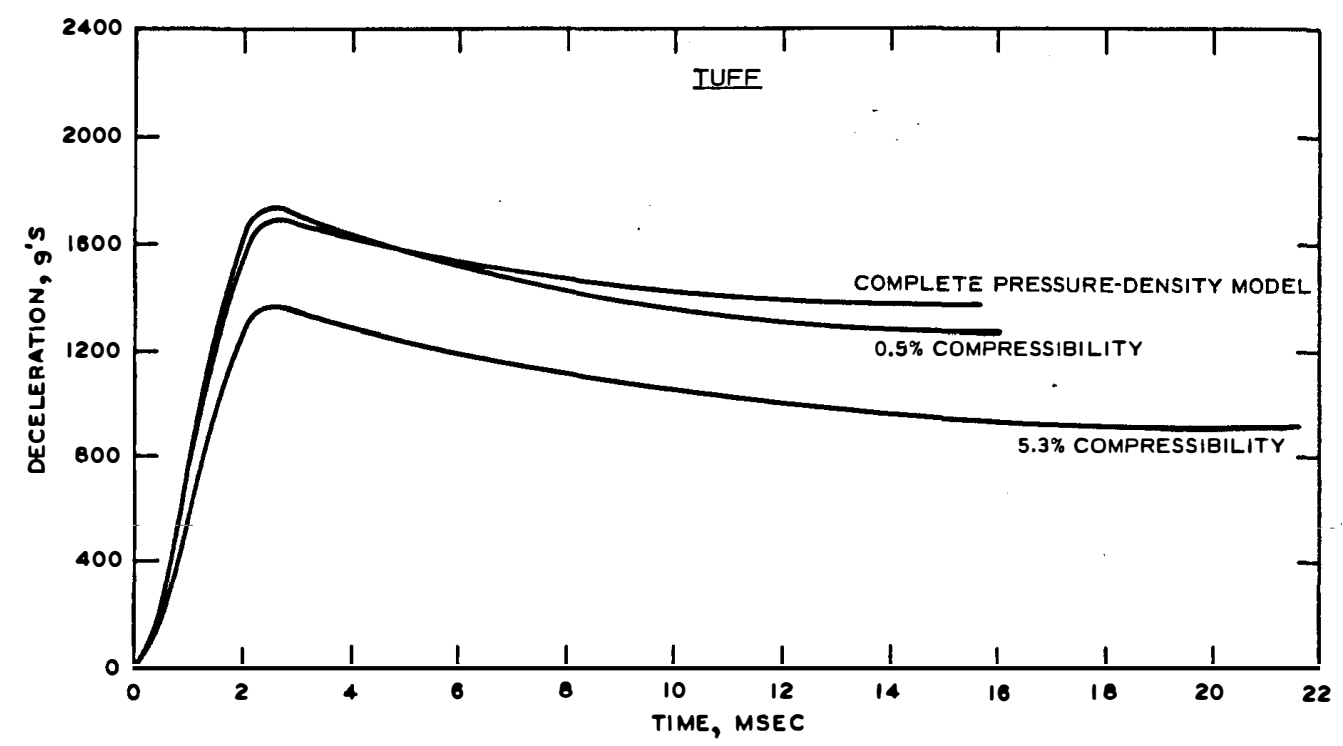

Figure 4.16 Comparison of complete target pressure-density model with two constant locked plastic density model predictions of deceleration versus time. 


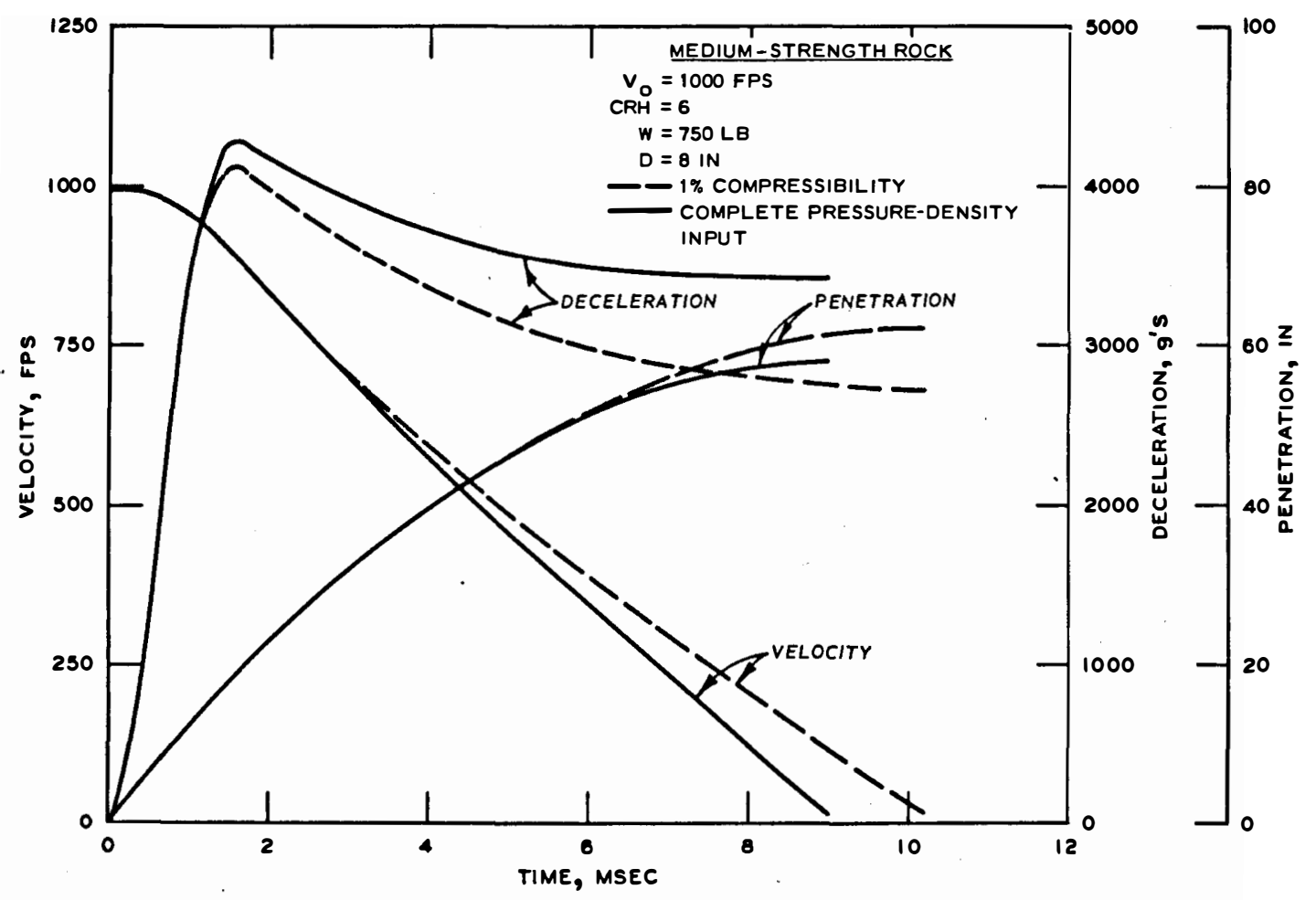

Figure 4.17 Comparison of penetration model time histories for 1 percent compressibility and the complete target Hugoniot. 


\subsection{SYSTEMATICS OF PARAMETER STUD.Y}

The rock properties used in the rock penetration parameter study to be discussed in this chapter were summarized in Table 3.3. In the remainder of this report, the three rock parameter groups will be indicated by L (low strength), M (medium strength), and $\mathrm{H}$ (high strength). Table 5.1 summarizes the ranges of projectile parameters to be considered. Obviously, it was unnecessary and impractical to consider all possible combinations of rock and projectile parameters; only those combinations of projectile weight and diameter which give values of $\mathrm{W} / \mathrm{A}$ in the range of 10-15 psi are considered, as this is probably the reasonable range to be expected for EPW's. Table 5.2 summarizes some of the combinations considered.

The systematics followed during the general parameter study are outlined in Table 5.3. In each case, the final depth of penetration was calculated using the penetration model presented in Chapter 2 for initial velocities ranging from 1000 to $3000 \mathrm{fps}$ in increments of 250 fps. It must be emphasized that the projectiles are considered as rigid bodies, and hence the range of velocities may not seem realistic, since it is known that structural failure of the projectile may occur at velocities considerably below $3000 \mathrm{fps}$ and that the critical velocity for failure depends, of course, on target strength. However, as the state of the art in projectile design advances and as more exotic materials become available for use, the upper bound of survivable velocities for impact and penetration into rock may reasonably be expected to increase. The next three sections present the results of the parameter study, with a discussion of the results given in Section 5.5 .

\subsection{TIME HISTORIES}

Since the penetration equation presented in Chapter 2 (Equation 2.1) is a differential equation, the model can be used to produce time 
histories of penetration, velocity, and deceleration ${ }^{1}$ for the projectiles as well as final depth of penetration. In order to illustrate the kinematics predicted by the model, typical complete time histories are presented for Cases IBI and IIIB3 at an impact velocity of $2000 \mathrm{fps}$ in Figures 5.1a and 5.2, respectively. Figure 5.1b compares the deceleration versus time plots for the three rock strengths of Cases IBI through IB3.

\subsection{PENETRATION VERSUS IMPACT VELOCITY PLOTS}

Figures 5.3 through 5.14 are final depth of penetration versus impact velocity plots for Cases I through IV of Table 5.3; each figure contains plots for the three rock strength groups with other parameters held constant.

\subsection{ADDITIONAL PARAMETER STUDY PLOTS}

Using the data from Figures 5.3 through 5.14 and the results of other cases as required, further plots were made illustrating the effects of various parameters on predicted penetration. Figure 5.15 illustrates the effect of projectile diameter and hence sectional pressure W/A on the penetration versus impact velocity plot for medium-strength rock and a given $\mathrm{CRH}$ and $\mathrm{W}$, i.e., W/A varies due only to a varying projectile diameter. The effect of $\mathrm{CRH}$ on penetration is shown in Figures $5.16 \mathrm{a}$ and $5.16 \mathrm{~b}$ for low- and medium-strength rock, respectively, and for a given projectile W/A at three impact velocities. Figure $5.16 \mathrm{c}$ shows the effect of $\mathrm{CRH}$ on predicted penetration for the three rock types at a given impact velocity. Figures 5.17 a through $5.17 \mathrm{f}$ all show the effect of W/A on predicted penetration for various combinations of impact velocity and rock type.

\subsection{DISCUSSION OF RESULTS}

5.5.1 Time Histories. The time histories in Figures 5.1 and 5.2

1 The term deceleration is used to refer to a negative acceleration. Since the projectiles are treated as rigid bodies (i.e., no wave motions considered in the projectile) with the positive z-axis downward, all accelerations will be negative. 
illustrate the kinematics of the penetration model using a constant value for the locked plastic density. Figure 5.1b illustrates the concept of increasing peak deceleration and decreasing duration of the penetration event with increasing rock strength such that the area under the deceleration versus time plots remains constant for a given impact velocity. It is important to realize that although the penetration predictions given by using the constant value for locked plastic density have been shown to agree closely with experimental results (see References 4, 6, 7, and 9 and also Chapter 4 of this report), the deceleration versus time predictions (rigid body) do not in many cases reproduce experimentally measured records. Deceleration versus time records from actual penetration tests generally do not exhibit the sharp acceleration peak followed by a rapid drop to a much lower value which is typical of the deceleration-time curves calculated by the penetration model using a constant $\rho_{p}$. Rather the experimental records show a rise to a peak (as the nose imbeds) followed by a much smaller decrease during the remainder of the penetration event. Indeed, the experimental records in many cases resemble a step pulse of magnitude equal to the average deceleration $\bar{A}$ during the event (determined from energy-work equality) of duration $\bar{t}$; this is shown as a dashed line in Figure 5.2, where

$$
\begin{aligned}
& \bar{A}=\frac{V_{o}^{2}}{2 g P}\left(g^{\prime} s\right) \\
& \bar{t}=\frac{2 P}{V_{0}}(s e c)
\end{aligned}
$$

and $V_{0}, g$, and $P$ are the impact velocity, acceleration of gravity, and maximum depth of penetration, respectively. In cases where the actual deceleration versus time history can be approximated by a step pulse, the peak and average decelerations may not differ by more than a factor of two (Reference 7). Deceleration versus time predictions were discussed in Chapter 4, where it was shown that using a realistic nonlinear hydrostat instead of a constant locked plastic density provides more realistic deceleration-time histories. However, since this 
parameter study was conceived primarily to study the effects of independent variables on the maximum depth of penetration, and since $P$ is not seriously changed by using a constant $\rho_{p}$ instead of the actual hydrostat, the simple approach used in this study is adequate.

5.5.2 Penetration Versus Impact Velocity Plots. The first and perhaps most obvious comment regarding Figures 5.3-5.14 is that for a given velocity, penetration decreases with increasing target strength and modulus (maintaining $\mathrm{E} / \mathrm{Y}=350$ constant). For all three target strengths, penetration increases with increasing velocity as expected, although the curves tend to flatten with increasing velocity. The curves for the three rock targets are seen not to be parallel for any of the cases considered, i.e., the numerical difference between the penetration into low-strength rock $P_{L}$ and into medium-strength rock $P_{M}$ does not remain constant with increasing velocity, and the same is true for the difference between the medium-strength $P_{M}$ and high-strength $\mathrm{P}_{\mathrm{H}}$ penetration versus velocity curves. Nor does the percentage decrease in penetration remain constant, but is seen to be a slowly decreasing function of velocity.

Figure 5.18 is a summary plot showing the percent decrease in penetration versus impact velocity for all the cases considered in this report ( $\mathrm{CRH}$ range $2-10$ and $\mathrm{W} / \mathrm{A}$ range $10-15 \mathrm{psi}$ ). This figure is significant in that it illustrates qualitatively the effect of target strength on final depth of penetration predictions. Thus the relative, qualitative effect shown in Figure 5.18 is reasonable and may be more believable than the quantitative depth predictions. Three well-defined bands are identified, with the upper band representing the percent decrease in penetration between the low- and high-strength rocks $\left[\left(\mathrm{P}_{\mathrm{L}}-\mathrm{P}_{\mathrm{H}}\right) / \mathrm{P}_{\mathrm{L}}\right] \times 100$, the middle band representing the percent decrease in penetration between the low- and medium-strength rocks $\left[\left(P_{L}-P_{M}\right) / P_{L}\right] \times 100$, and the lower band representing the percent decrease in penetration between the medium- and high-strength rocks $\left[\left(\mathrm{P}_{\mathrm{M}}-\mathrm{P}_{\mathrm{H}}\right) / \mathrm{P}_{\mathrm{M}}\right] \times 100$. Figure 5.18 illustrates in summary fashion that the relative effect of increasing rock strength on decreasing the depth of penetration at a given velocity is not strongly sensitive to 
variations in $\mathrm{CRH}$ or W/A . However, this is only a relative effect and does not imply that for a given rock strength, penetration depth is unaffected by CRH or W/A . As an example of the practical value of this information, it is only necessary to have an experimental penetration depth for one rock target for a given projectile in order to estimate penetration depths for that projectile into other rock targets. 5.5.3 Effects of $\mathrm{W} / \mathrm{A}$ and $\mathrm{CRH}$. Figures 5.15-5.17 examine in detail the effects of $\mathrm{CRH}$ and $\mathrm{W} / \mathrm{A}$ on final depth of penetration for varying impact velocities and rock strengths. The effect of varying the projectile diameter for penetration into a medium-strength rock while maintaining $\mathrm{W}$ and $\mathrm{CRH}$ constant is illustrated in Figure 5.15; W/A varies from 10 to $17.7 \mathrm{psi}$. The increase in penetration over the velocity range considered is about 70 percent for a decrease in diameter from 8 to 6 inches. Thus, it is seen that for a W/A of $10 \mathrm{psi}$ at an impact velocity of $1000 \mathrm{fps}$, increasing the W/A from 10 to $17.7 \mathrm{psi}$ produces approximately the same increase in penetration as does increasing the impact velocity from 1000 to $1500 \mathrm{fps}$ and maintaining $\mathrm{W} / \mathrm{A}$ at $10 \mathrm{psi}$. Considerations such as this should be of great value in providing guidance for penetrator designers.

The effect of varying $\mathrm{CRH}$ is illustrated in Figure 5.16 for the three rock targets and at three impact velocities. $\mathrm{CRH}$ is seen to have little effect on depth of penetration for a given impact velocity and rock strength; the effect is greatest for high impact velocity and low rock strength. The curve for $\mathrm{V}_{0}=1000 \mathrm{fps}$ in Figures $5.16 \mathrm{a}$ and $5.16 \mathrm{~b}$ is seen to be virtually flat over the range of CRH values (2-10). Likewise, the curve in Figure 5.16c for high-strength rock at $\mathrm{V}_{\mathrm{o}}=2000 \mathrm{fps}$ shows virtually no change in penetration with variation in $\mathrm{CRH}$ - Thus, within the limits of parameters considered in this study, the penetration model indicates that the choice of projectile nose shape can be based solely on structural integrity and terradynamic stability considerations and not desired depth of penetration considerations. The slight coupling between $\mathrm{CRH}$ and impact velocity and rock strength does not appear to be significant. 
Figure 5.17 demonstrates the effect of W/A on depth of penetration of a projectile with a given nose shape $(\mathrm{CRH}=6)$ into the three rock targets at three impact velocities. For a given rock strength, sensitivity of depth of penetration to W/A is seen to increase as impact velocity increases, and for a given impact velocity, the sensitivity to W/A decreases as rock strength increases. It is interesting to note that the penetration versus W/A relations shown in Figures 5.17 a through $5.17 \mathrm{c}$ for all three rock strengths appear to be linear and pass between the two predicted penetration depths for $\mathrm{W} / \mathrm{A}=12.7 \mathrm{psi}$ (the two points for each rock strength are for projectiles with the same W/A but different weights and diameters). However, these points are separated from each other by less than 10 inches (3-20 percent) for all rock strengths and impact velocities; thus the effect is small enough to ignore in most cases.

The effect of projectile W/A on penetration varies somewhat with impact velocity and rock target being considered; however, for the range of impact velocities and rock strengths considered, the penetration model is relatively insensitive to variations in projectile CRH . For a medium-strength rock at impact velocities of 1000, 2000, and 3000 fps and $\mathrm{CRH}=6$, the percent increase in penetration produced by a change in W/A from 10 to $15 \mathrm{psi}$ is 43, 46, and 50 percent, respectively. Changing $\mathrm{CRH}$ from 2 to 10 for penetration into a medium-strength rock produces an average increase of only about 16 percent for the three impact velocities. 
TABLE 5.1 PROJECTILE PARAMETER

\section{RANGES}

\begin{tabular}{lr}
\hline Projectile Parameter & $\frac{\text { Range }}{\text { Impact velocity }}$ \\
W & 250 to $1000 \mathrm{lb}$ \\
D & 10 to $10 \mathrm{in}$ \\
W/A & 2 to $15 \mathrm{psi}$
\end{tabular}

TABLE 5.2 W/A COMBINATIONS

\begin{tabular}{ccccccc}
\hline $\begin{array}{llllll}\text { W/A } \\
\text { No. }\end{array}$ & W, Ib & & D, in & $\begin{array}{c}\text { Area } \\
\text { in }^{2}\end{array}$ & $\begin{array}{c}\text { W/A } \\
\text { psi }\end{array}$ \\
\cline { 5 - 6 } 1 & 250 & 5 & 14.64 & 12.73 \\
2 & 500 & 7.5 & 44.18 & 11.32 \\
3 & 500 & 7 & 38.48 & 12.99 \\
4 & 500 & 8 & 50.27 & 9.95 \\
5 & 750 & 9 & 64.51 & 11.63 \\
6 & 750 & 8 & 50.27 & 14.92 \\
7 & 1000 & 10 & 78.54 & 12.73
\end{tabular}


TABLE 5.3 PARAMETER STUDY SYSTEMATICS

\begin{tabular}{|c|c|c|c|c|c|c|c|}
\hline $\begin{array}{c}\text { Case } \\
\text { Identification } \\
\text { No. } \\
\end{array}$ & W/A No. & $\mathrm{CRH}$ & $\begin{array}{l}\text { Rock } \\
\text { Type }\end{array}$ & $\begin{array}{c}\text { Case } \\
\text { Identification } \\
\text { No. } \\
\end{array}$ & W/A No. & CRH & $\begin{array}{l}\text { Rock } \\
\text { Type }\end{array}$ \\
\hline $\begin{array}{r}\text { IAI } \\
2 \\
3\end{array}$ & 6 & 2 & $\begin{array}{l}\mathrm{L} \\
\mathrm{M} \\
\mathrm{H}\end{array}$ & $\begin{array}{r}\text { IIIBI } \\
2 \\
3\end{array}$ & 1 & 6 & $\begin{array}{l}\mathrm{L} \\
\mathrm{M} \\
\mathrm{H}\end{array}$ \\
\hline $\begin{array}{r}\text { IBI } \\
2 \\
3\end{array}$ & 6 & 6 & $\begin{array}{l}\mathrm{L} \\
\mathrm{M} \\
\mathrm{H}\end{array}$ & $\begin{array}{r}\text { IIICl } \\
2 \\
3\end{array}$ & 1 & 10 & $\begin{array}{l}\mathrm{L} \\
\mathrm{M} \\
\mathrm{H}\end{array}$ \\
\hline $\begin{array}{r}\text { ICl } \\
2 \\
3\end{array}$ & 6 & 10 & $\begin{array}{l}\mathrm{L} \\
\mathrm{M} \\
\mathrm{H}\end{array}$ & $\begin{array}{r}\text { IVAI } \\
2 \\
3\end{array}$ & 2 & 2 & $\begin{array}{l}\mathrm{L} \\
\mathrm{M} \\
\mathrm{H}\end{array}$ \\
\hline $\begin{array}{r}\text { IIAI } \\
2 \\
3\end{array}$ & 7 & 2 & $\begin{array}{l}\mathrm{L} \\
\mathrm{M} \\
\mathrm{H}\end{array}$ & $\begin{array}{r}\text { IVBI } \\
2 \\
3\end{array}$ & . & 6 & $\begin{array}{l}\mathrm{L} \\
\mathrm{M} \\
\mathrm{H}\end{array}$ \\
\hline $\begin{array}{r}\text { IIBI } \\
2 \\
3\end{array}$ & 7 & 6 & $\begin{array}{l}\mathrm{L} \\
\mathrm{M} \\
\mathrm{H}\end{array}$ & $\begin{array}{r}\text { IVCI } \\
2 \\
3\end{array}$ & 2 & 10 & $\begin{array}{l}\mathrm{L} \\
\mathrm{M} \\
\mathrm{H}\end{array}$ \\
\hline $\begin{array}{r}\text { IICl } \\
2 \\
3 \\
\text { IIIAI } \\
2 \\
3\end{array}$ & 1 & 10 & $\begin{array}{l}\mathrm{L} \\
\mathrm{M} \\
\mathrm{H} \\
\mathrm{L} \\
\mathrm{M} \\
\mathrm{H}\end{array}$ & $\begin{array}{r}\text { VAl } \\
2 \\
3 \\
4 \\
5\end{array}$ & $\begin{aligned} 3 \\
4 \\
5 \\
D=6.5 \\
W=500 \\
D=6 \text { in } \\
W=500\end{aligned}$ & $\begin{array}{l}\text { in, } \\
\text { ib } \\
\text { ib }\end{array}$ & $\begin{array}{l}\text { M } \\
M \\
\text { M } \\
\text { L } \\
\text { L }\end{array}$ \\
\hline , & $\cdot$ & & & $\begin{array}{r}\text { VIAI } \\
2 \\
3 \\
4 \\
\\
\\
4\end{array}$ & c & $\begin{array}{r}4 \\
8 \\
4 \\
8\end{array}$ & $\begin{array}{l}\mathrm{M} \\
\mathrm{M} \\
\mathrm{L} \\
\mathrm{L}\end{array}$ \\
\hline
\end{tabular}




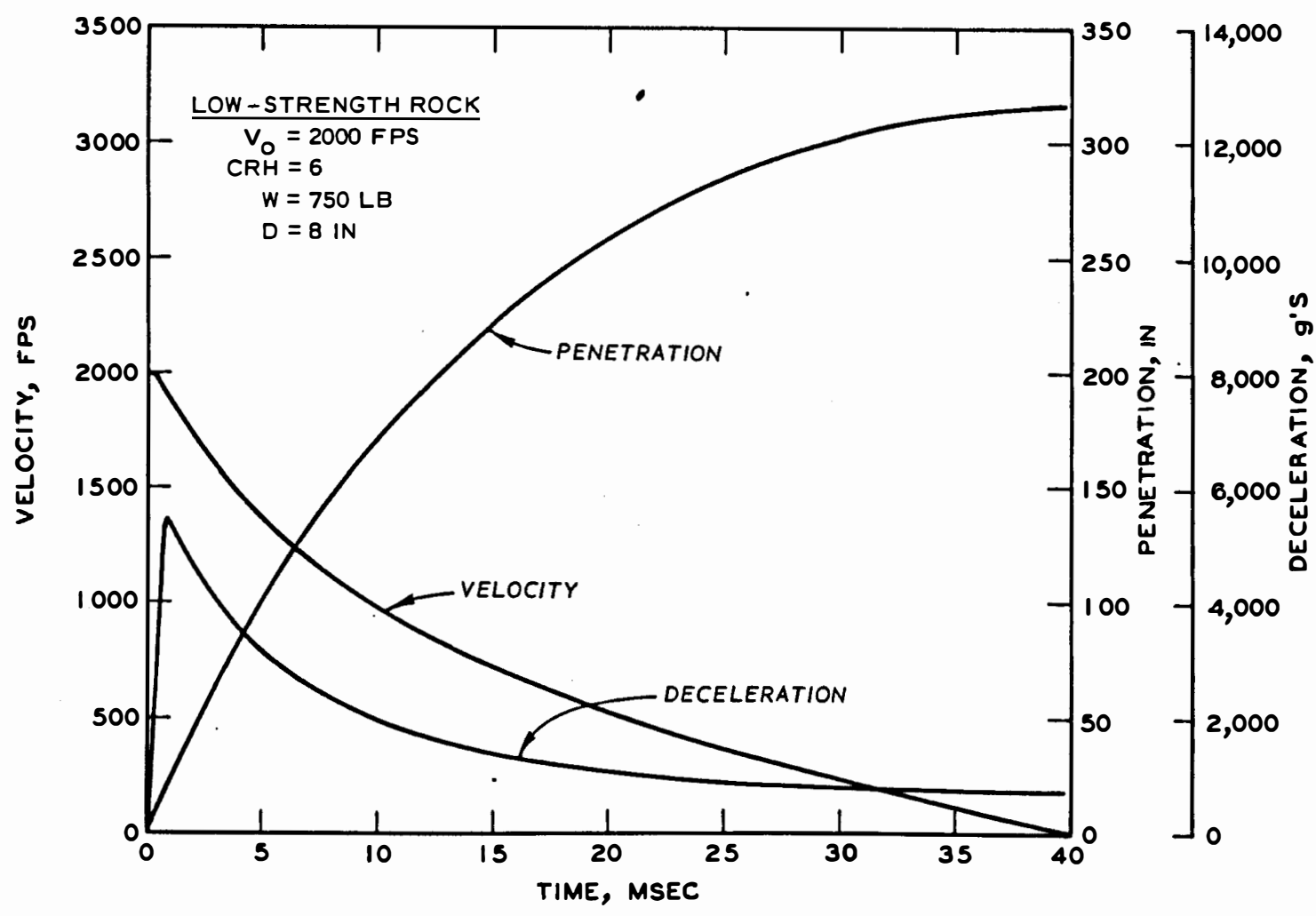

a. Case IBI.

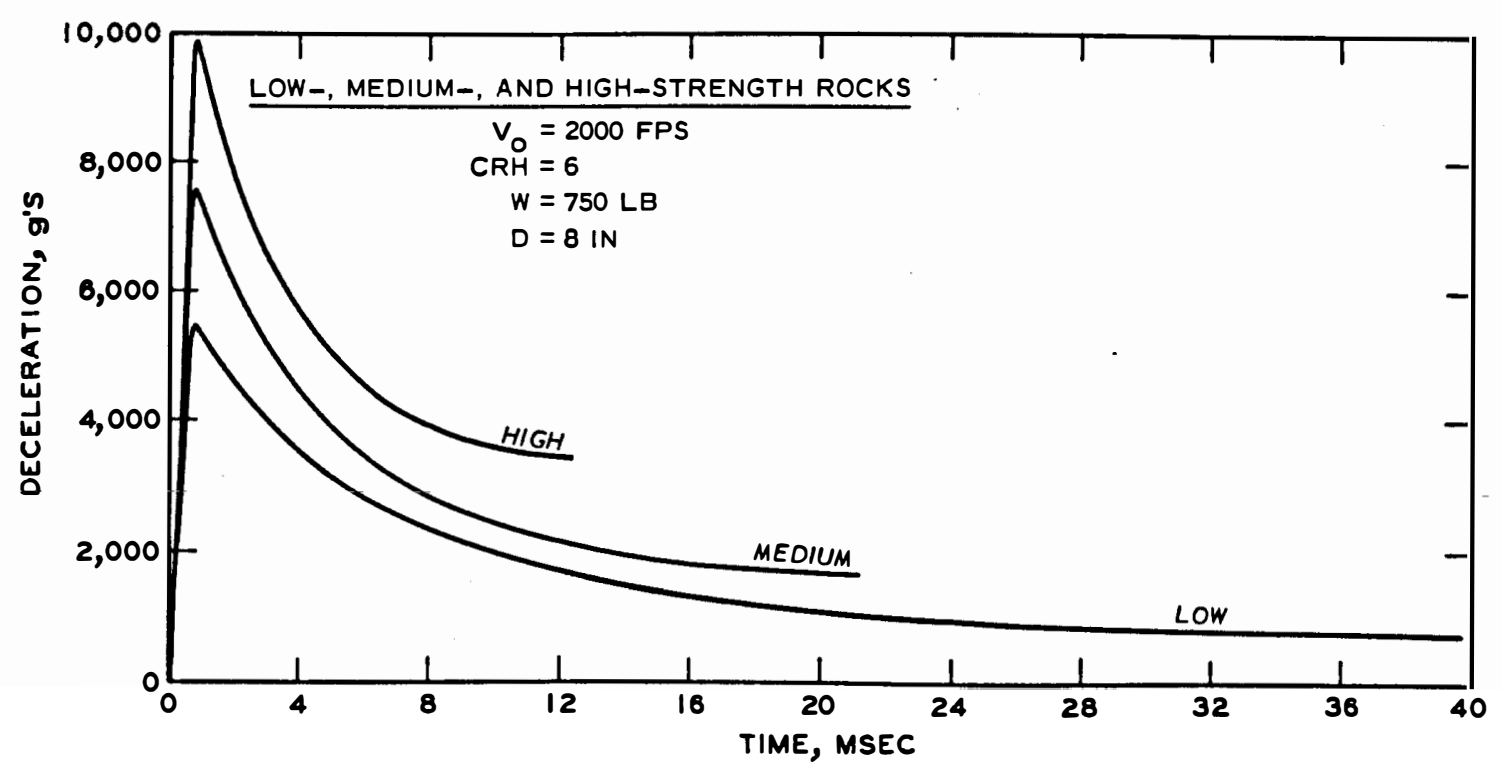

b. Case IB.

Figure 5.1 Time histories for Cases IBI and IB. 


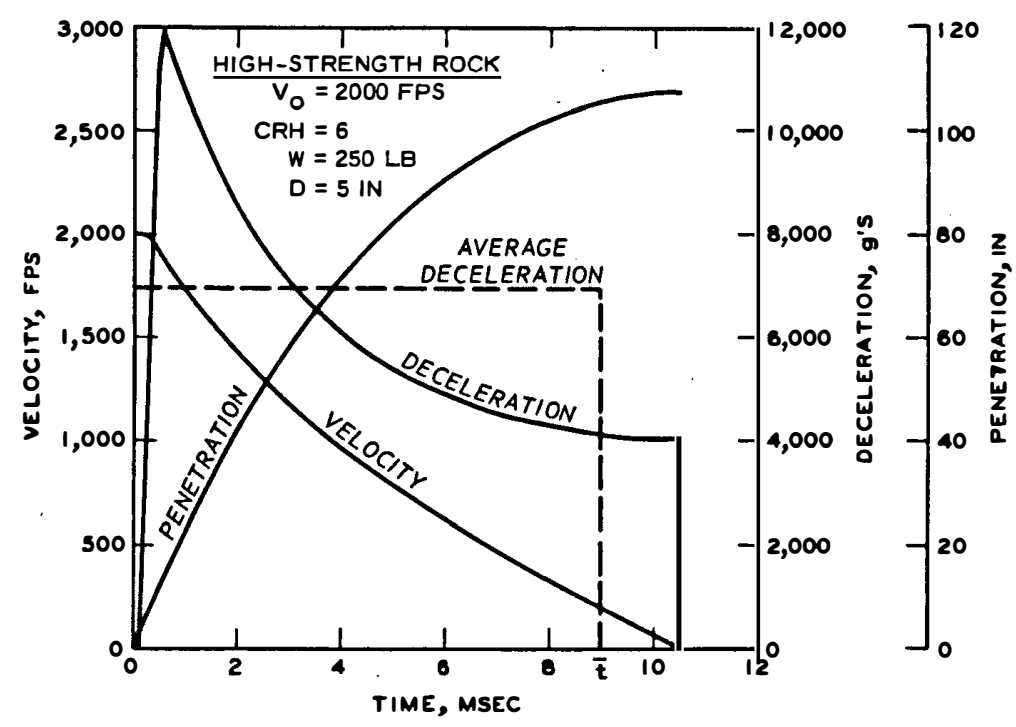

Figure 5.2 Time histories for Case IIIB3.

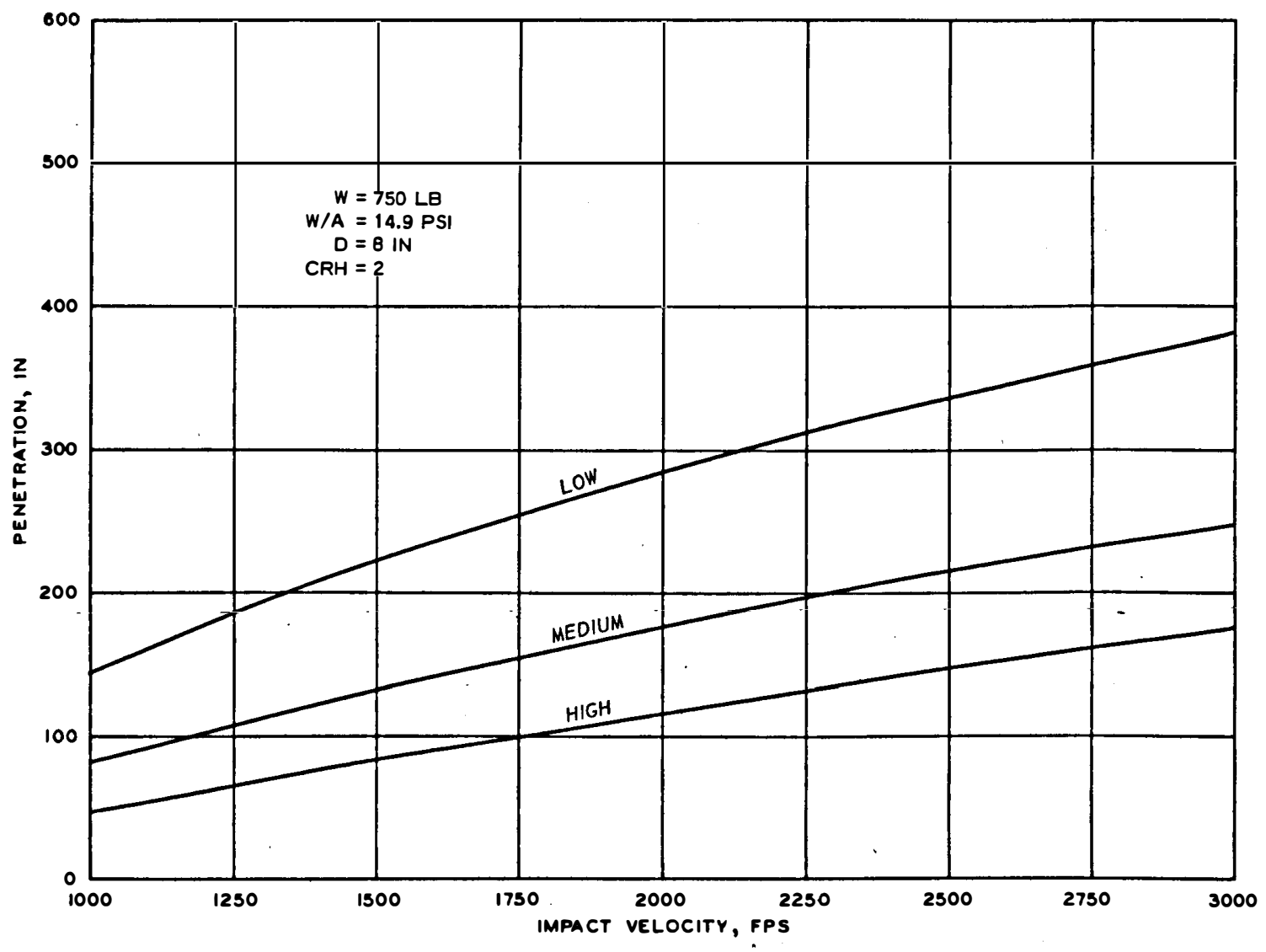

Figure 5.3 Case IA. 


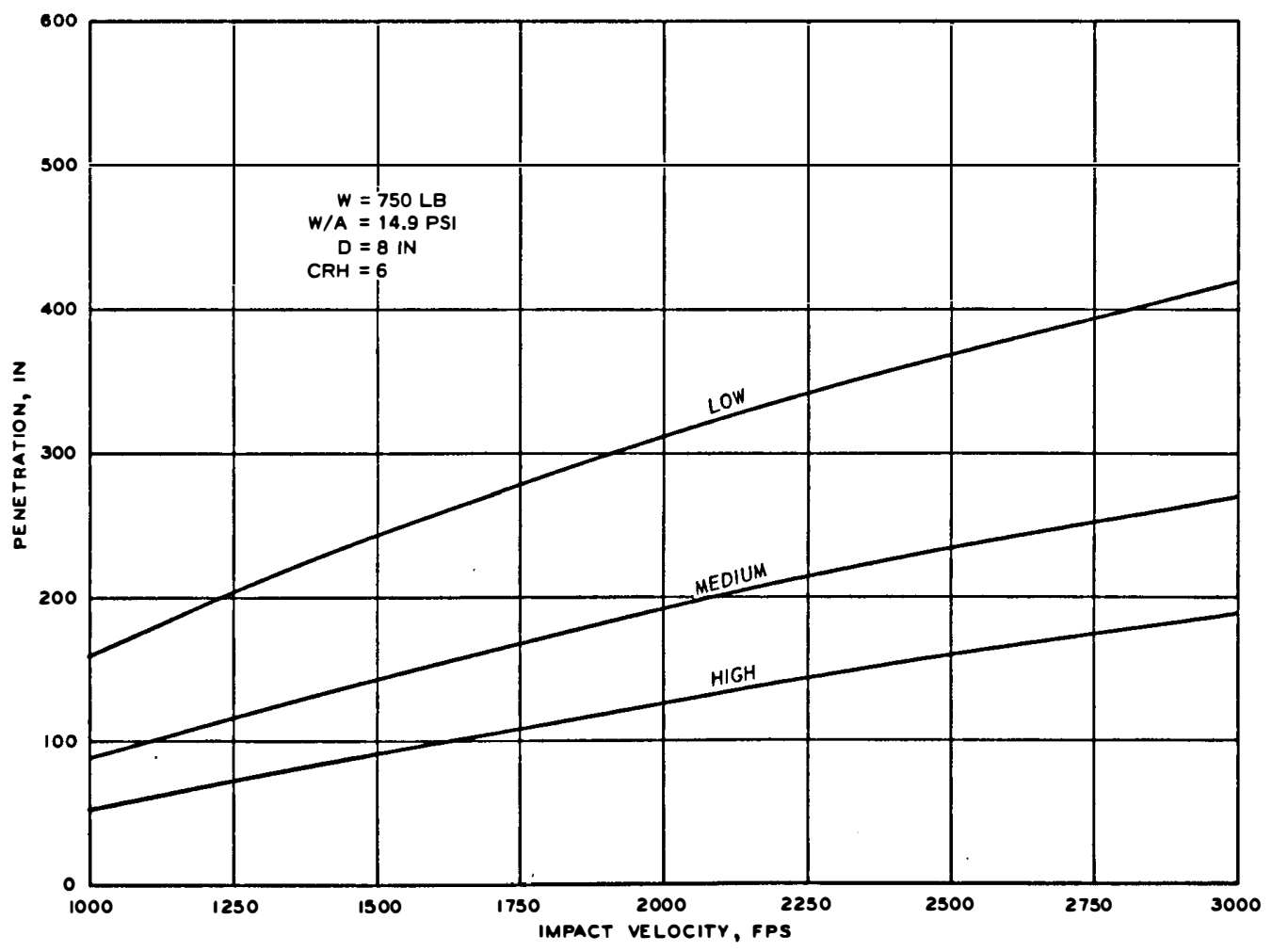

Figure 5.4 Case IB.

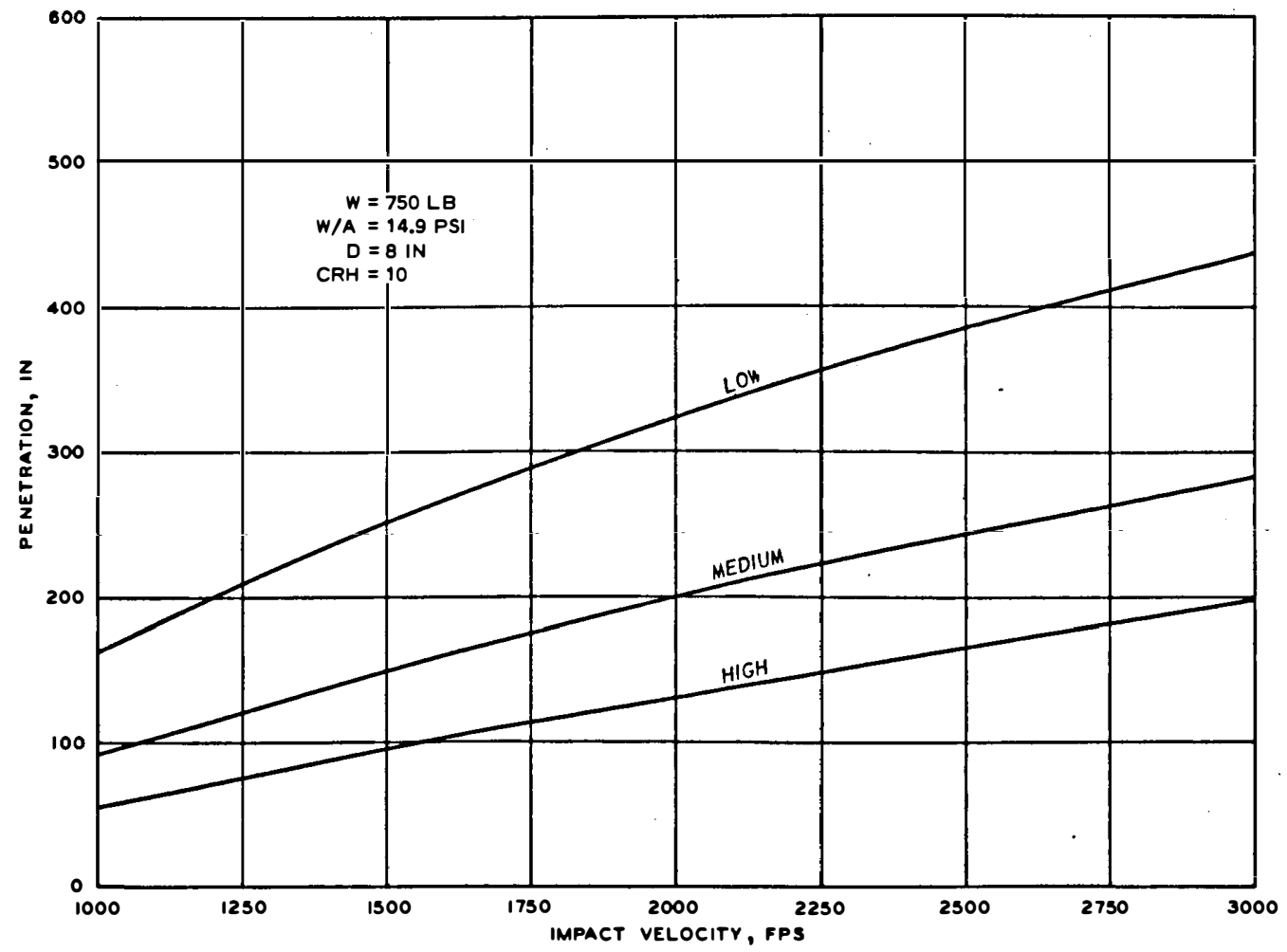

Figure 5.5 Case IC. 


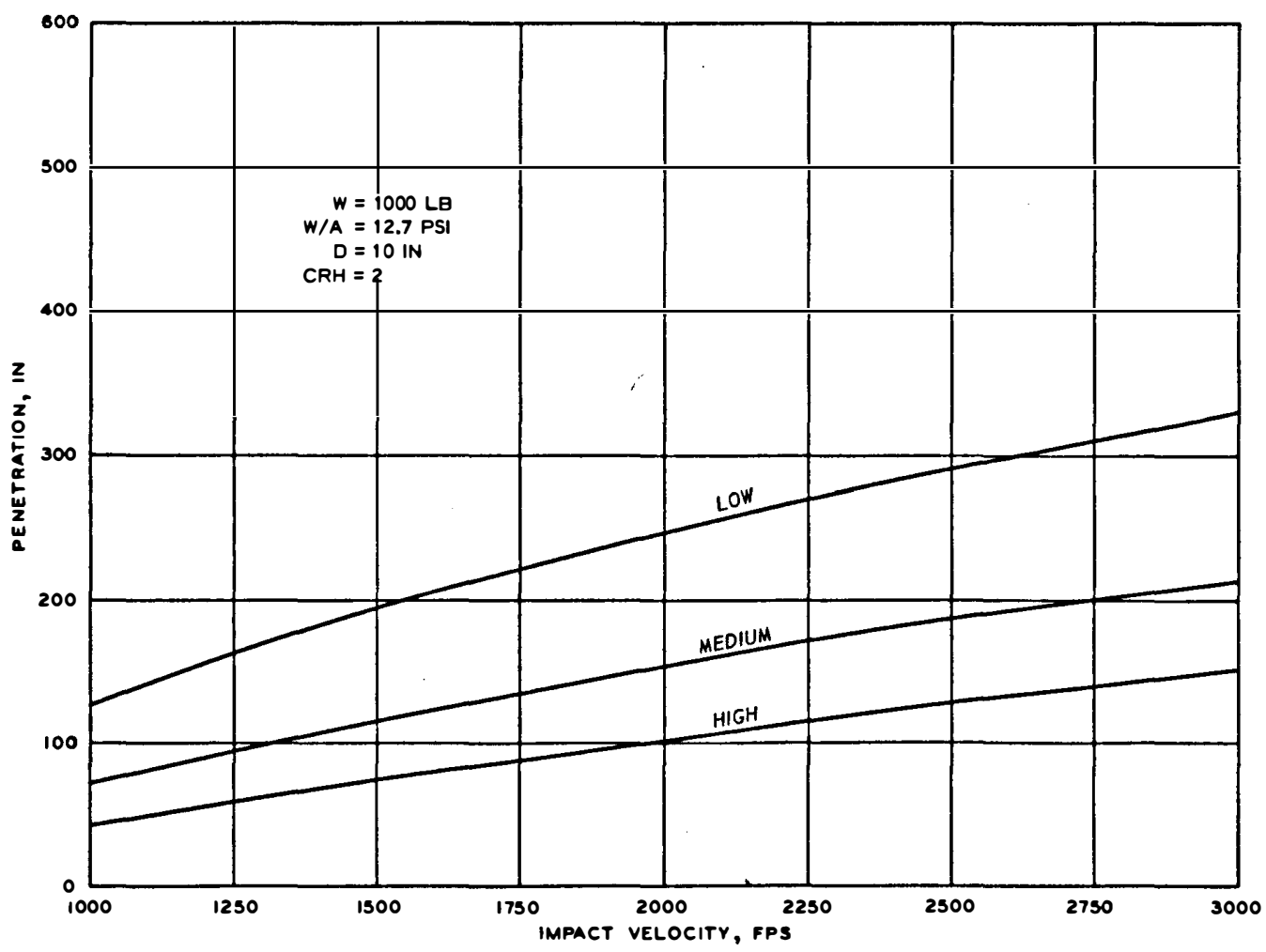

Figure 5.6 Case IIA.

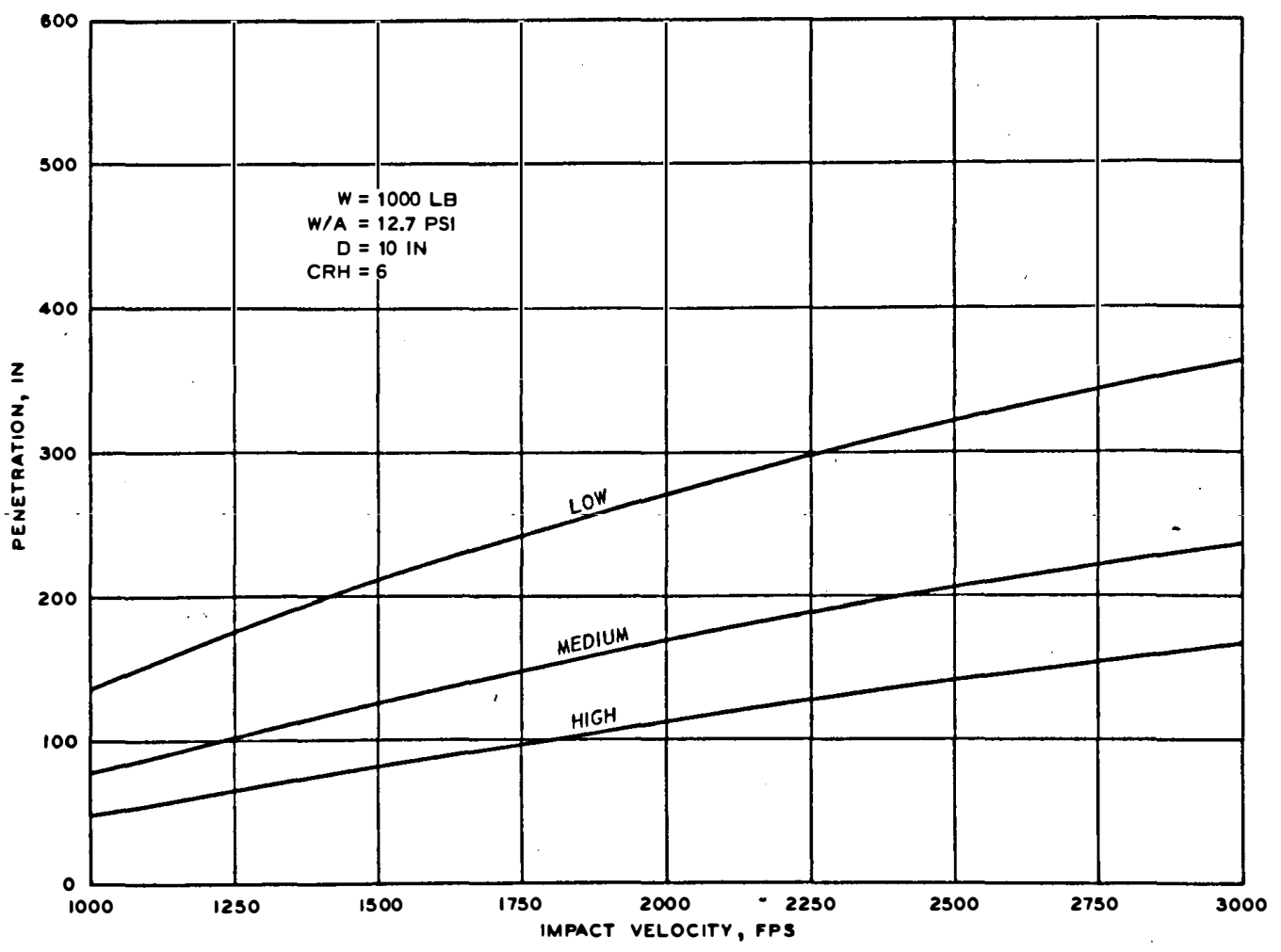

.Figure 5.7 Case IIB. 


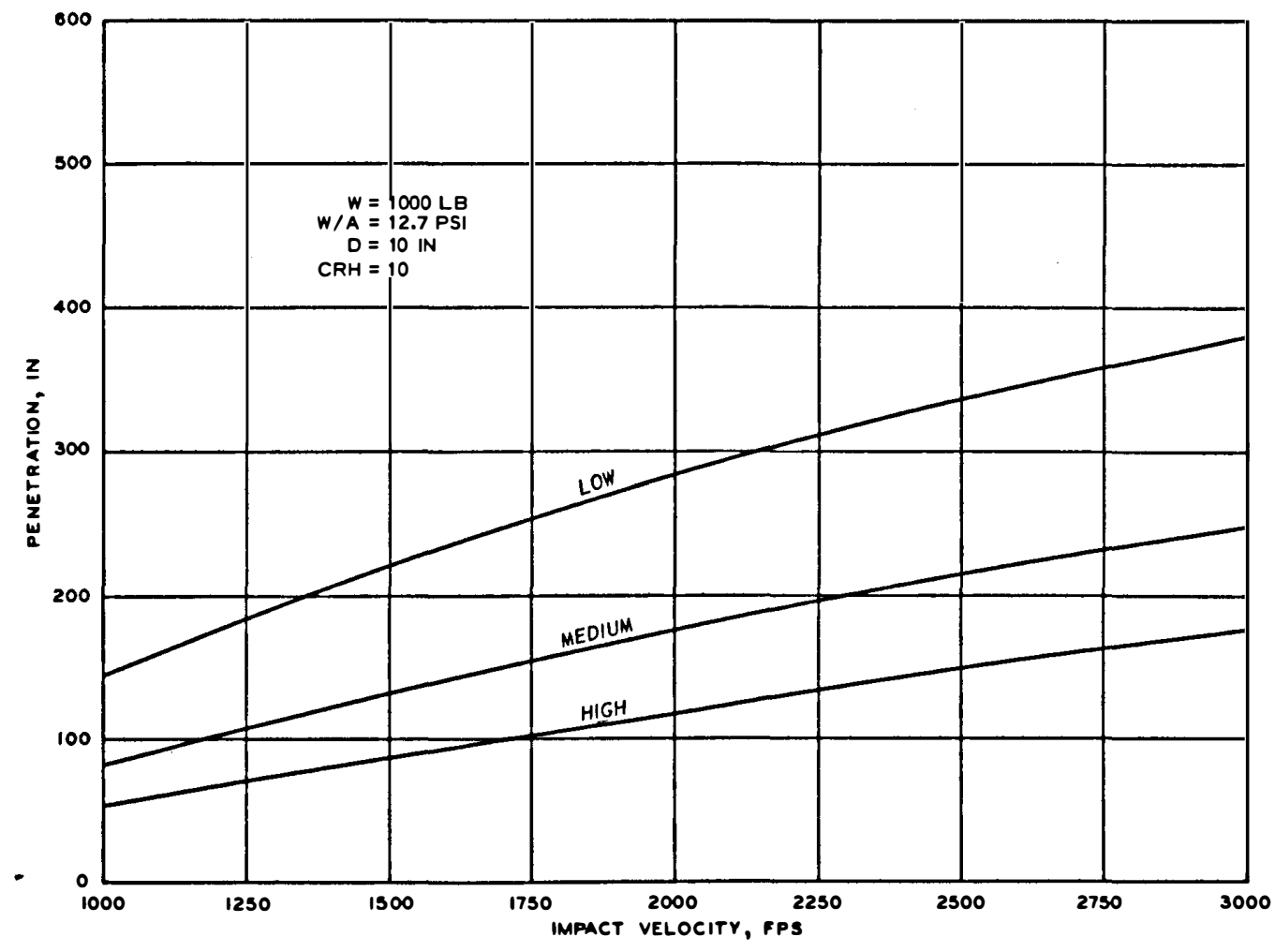

Figure 5.8 Case IIC.

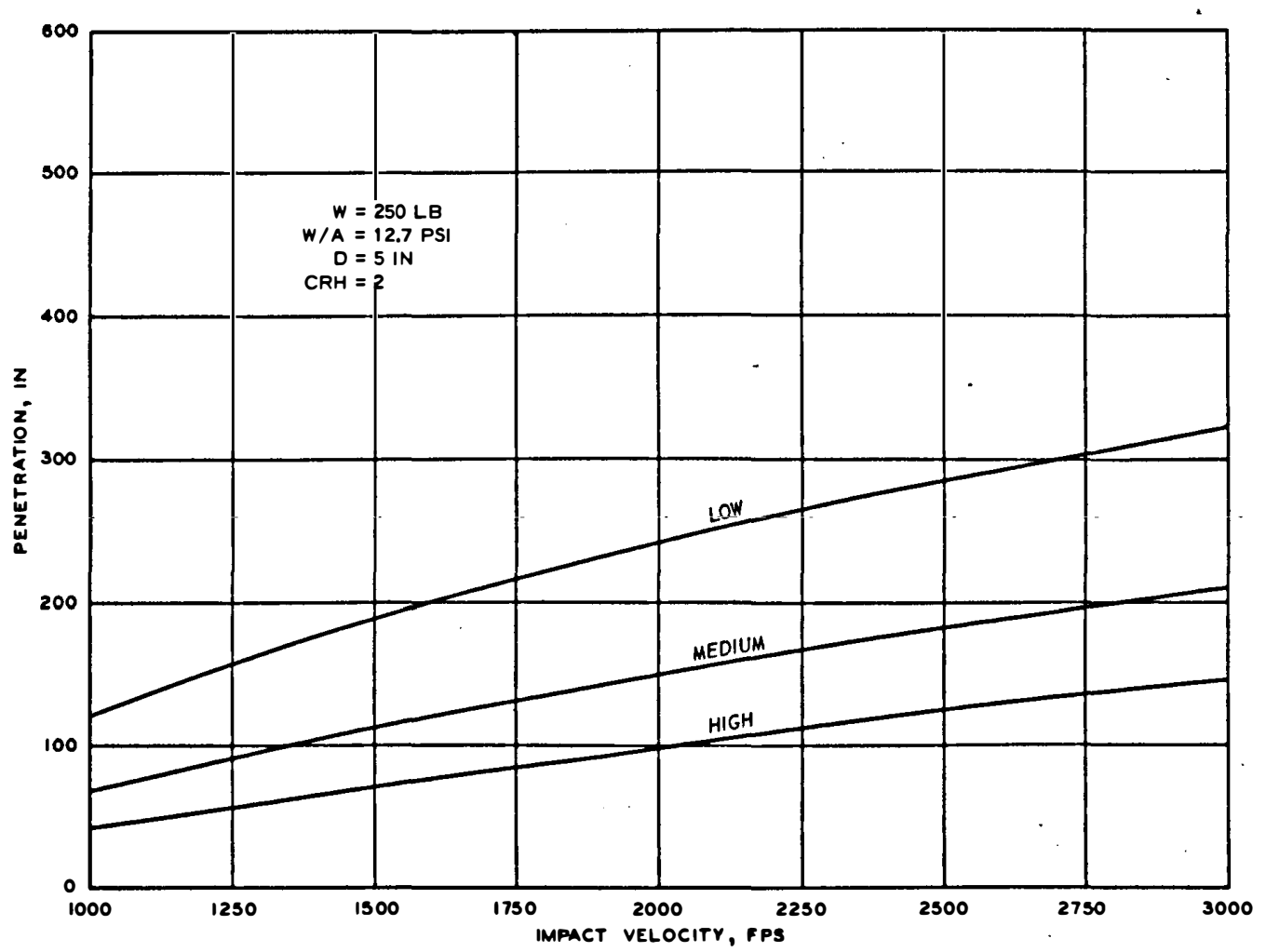

Figure 5.9 Case IIIA. 


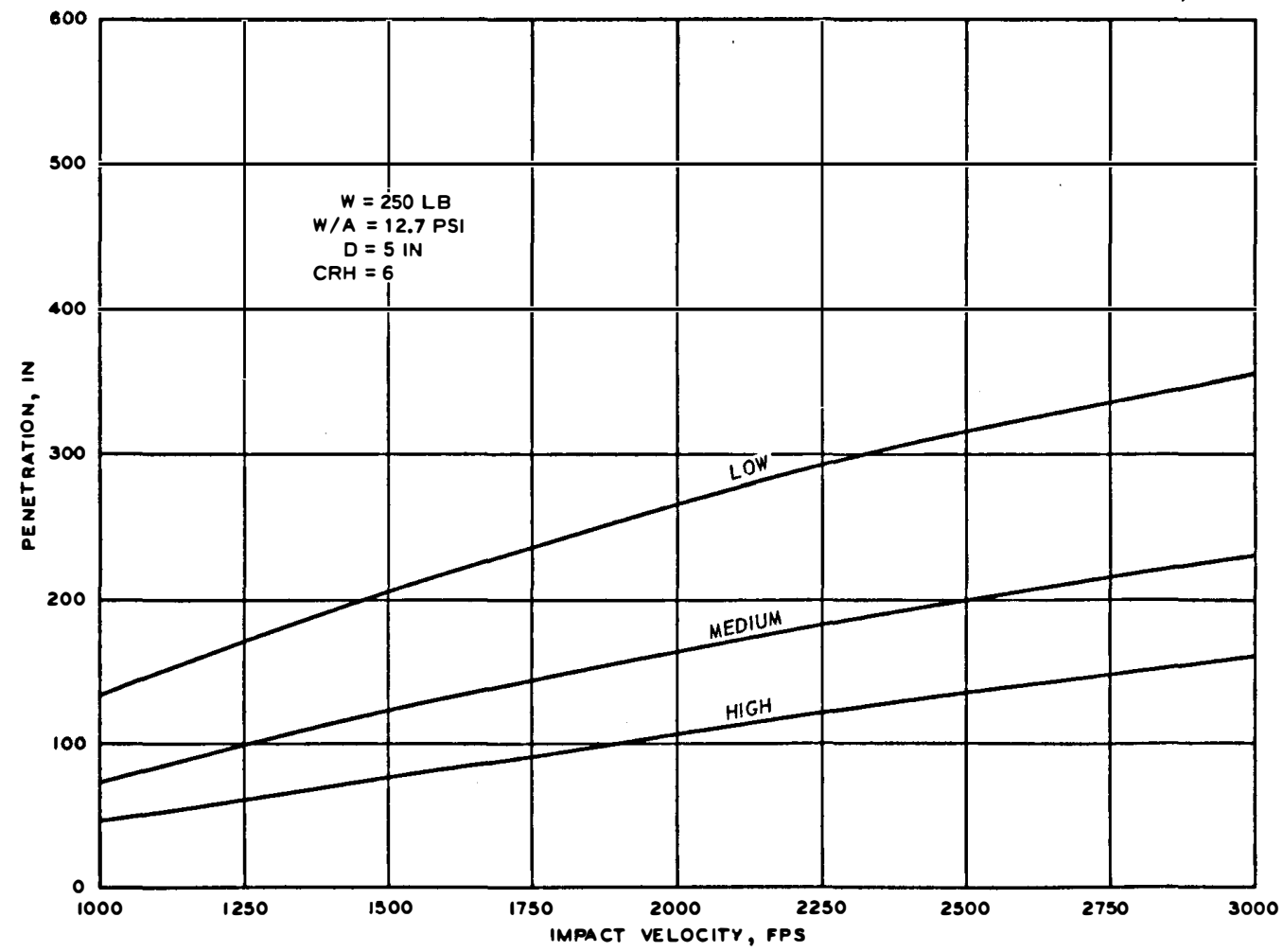

Figure 5.10 Case IIIB.

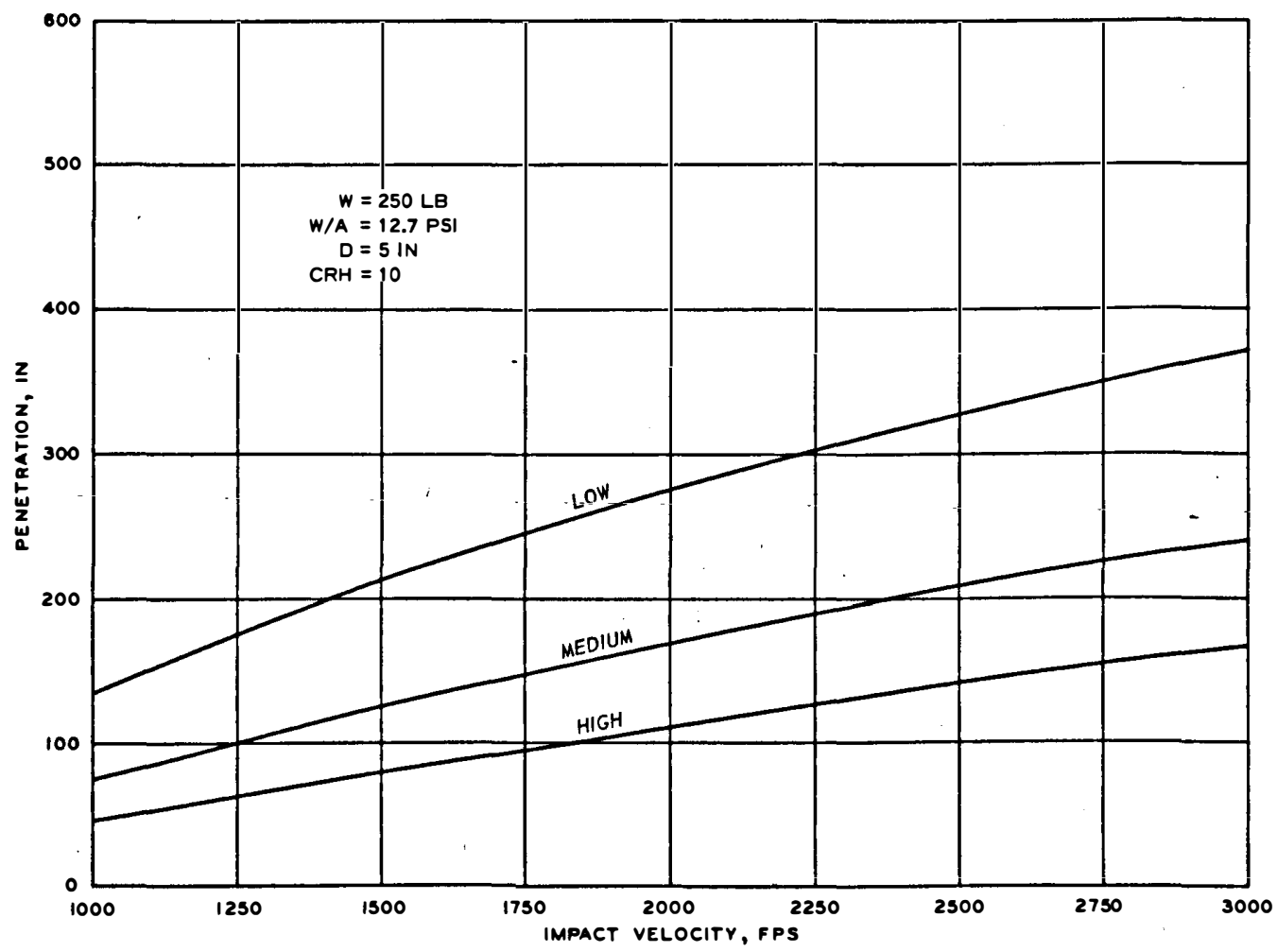

Figure 5.11 Case IIIC. 


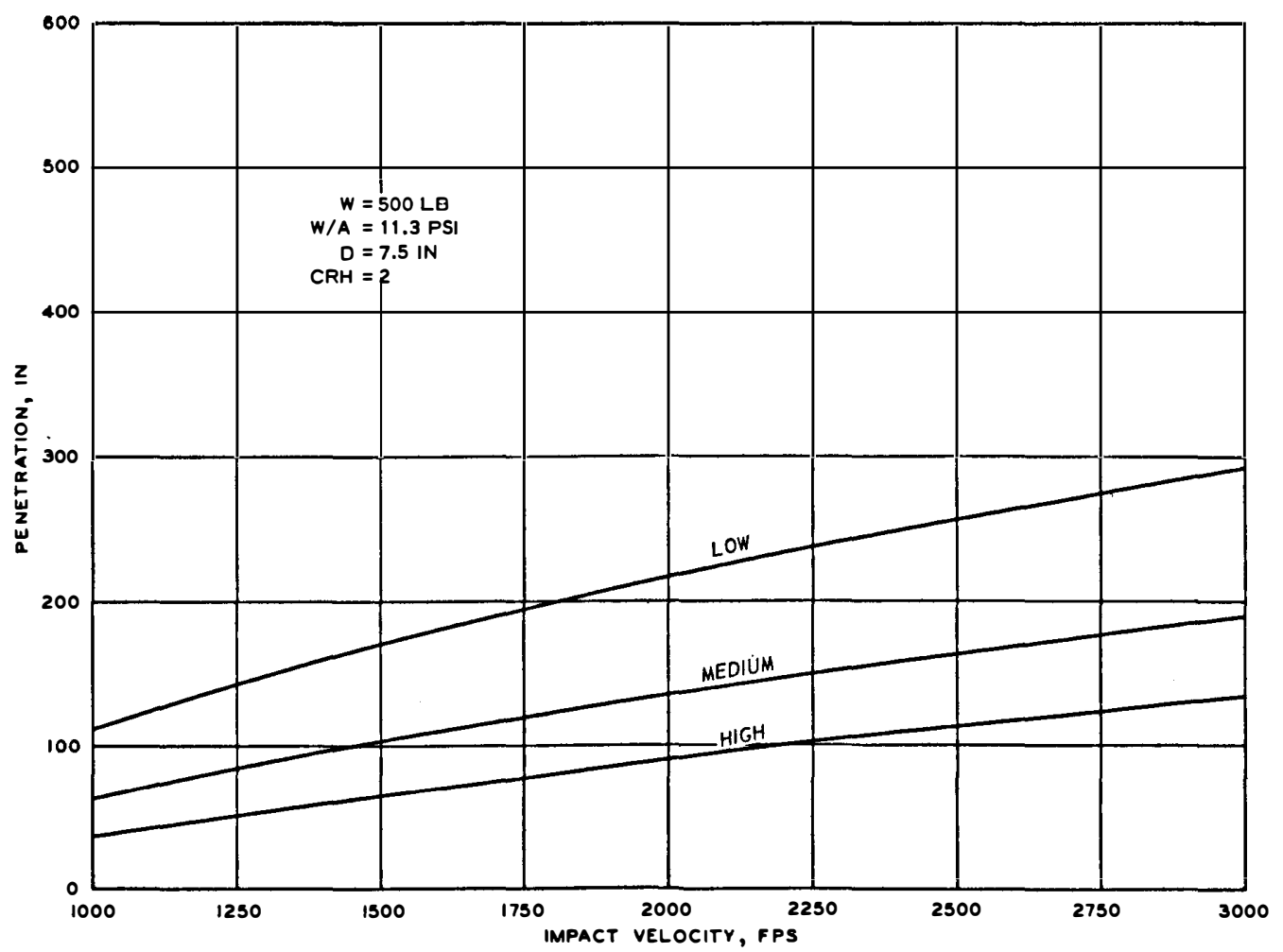

Figure 5.12 Case IVA.

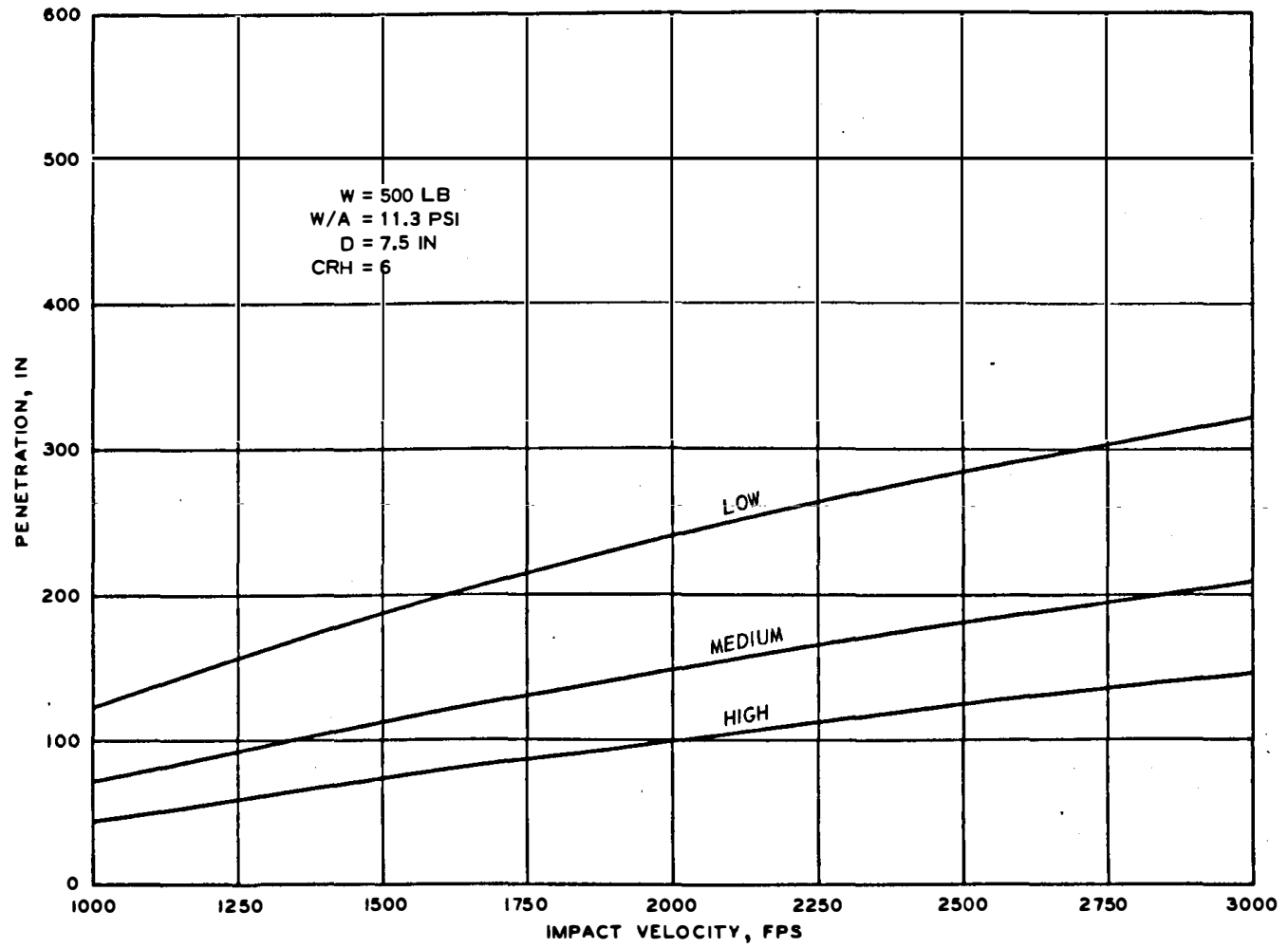

Figure 5.13 Case IVB. 


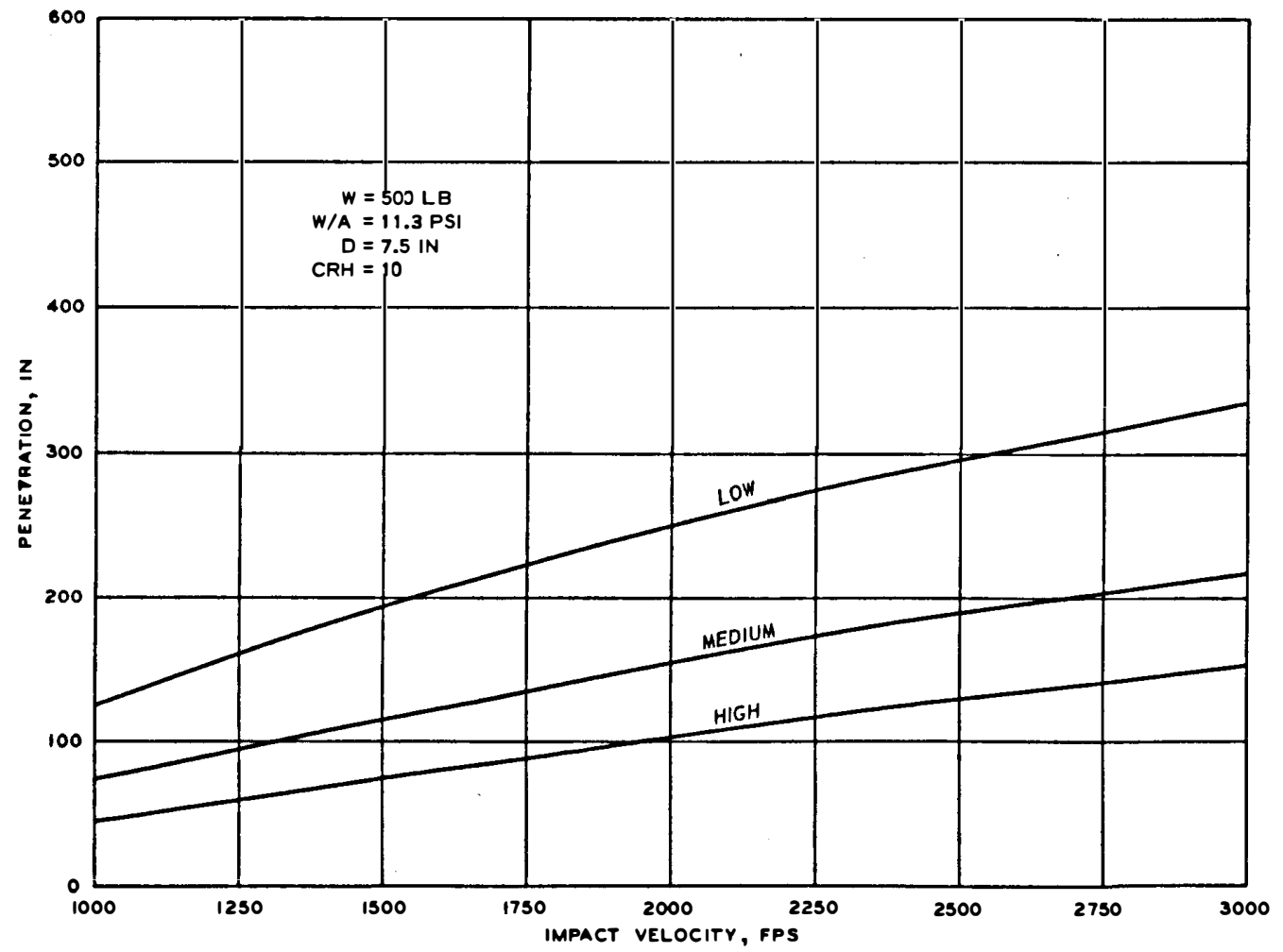

Figure 5.14 Case IVC.

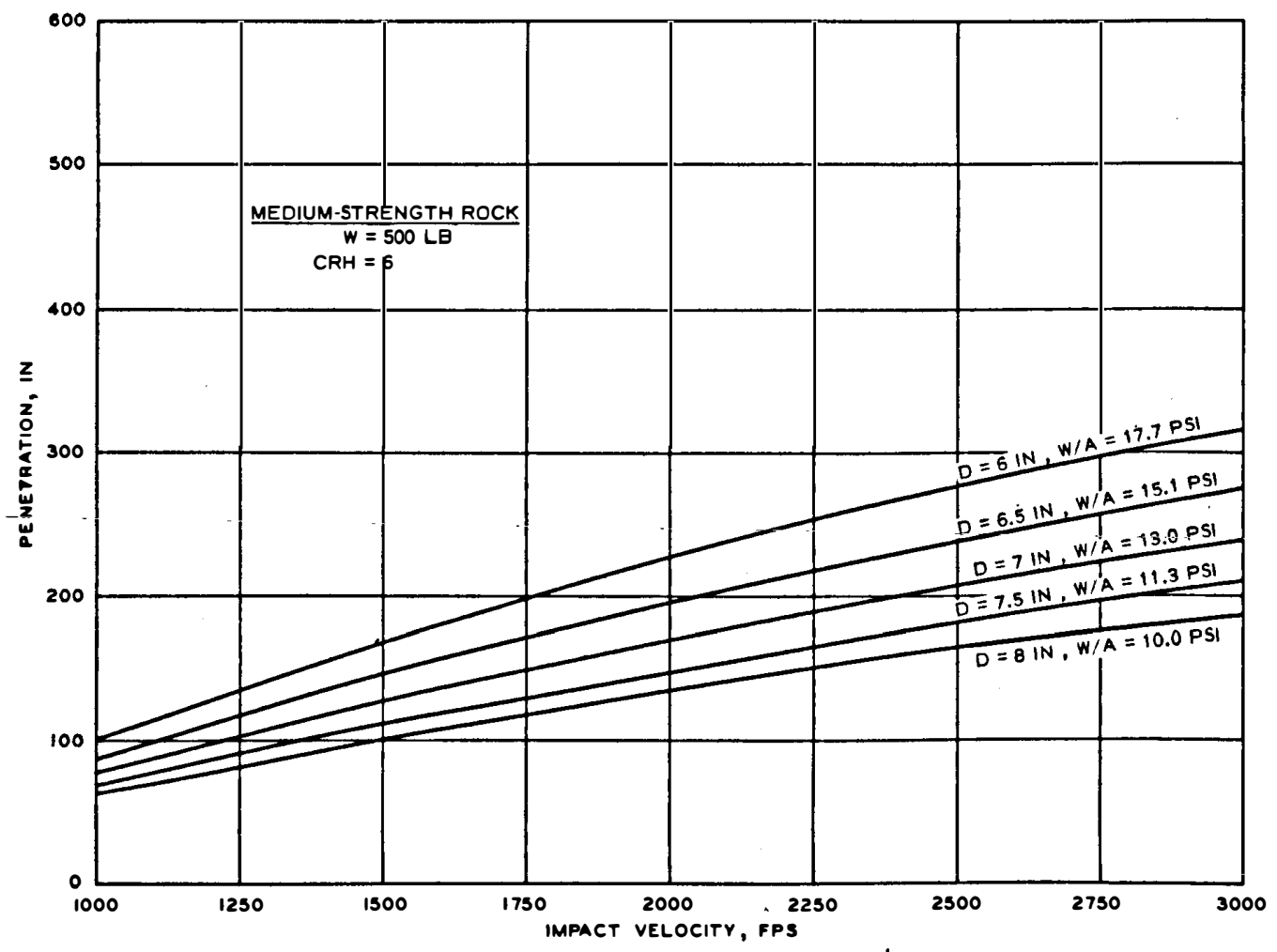

Figure 5.15 Effect of W/A on penetration versus impact velocity plots for given rock type, $\mathrm{CRH}$, and weight. 


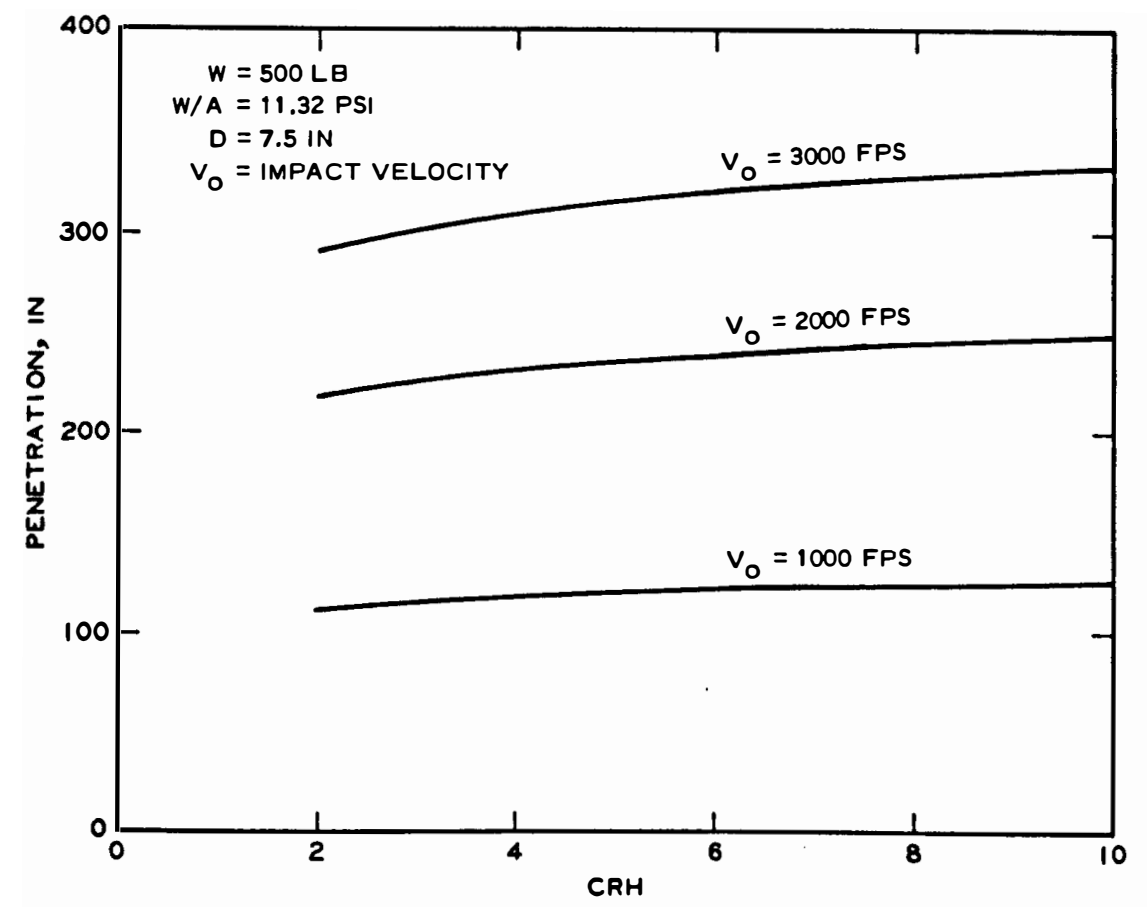

a. Low-strength rock: $V_{0}=1000,2000$, and 3000 fps.

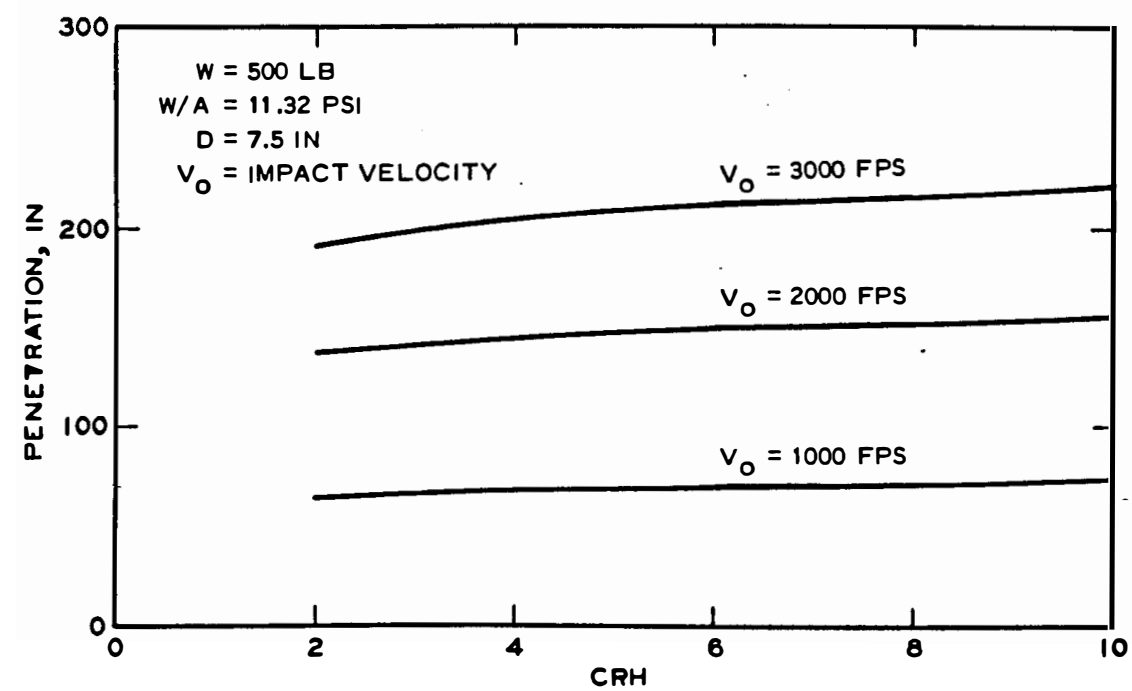

b. Medium-strength rock; $\mathrm{V}_{\mathrm{o}}=1000,2000$,
and 3000 fps.

Figure 5.16 Effect of $\mathrm{CRH}$ on predicted penetration (sheet 1 of 2 ). 


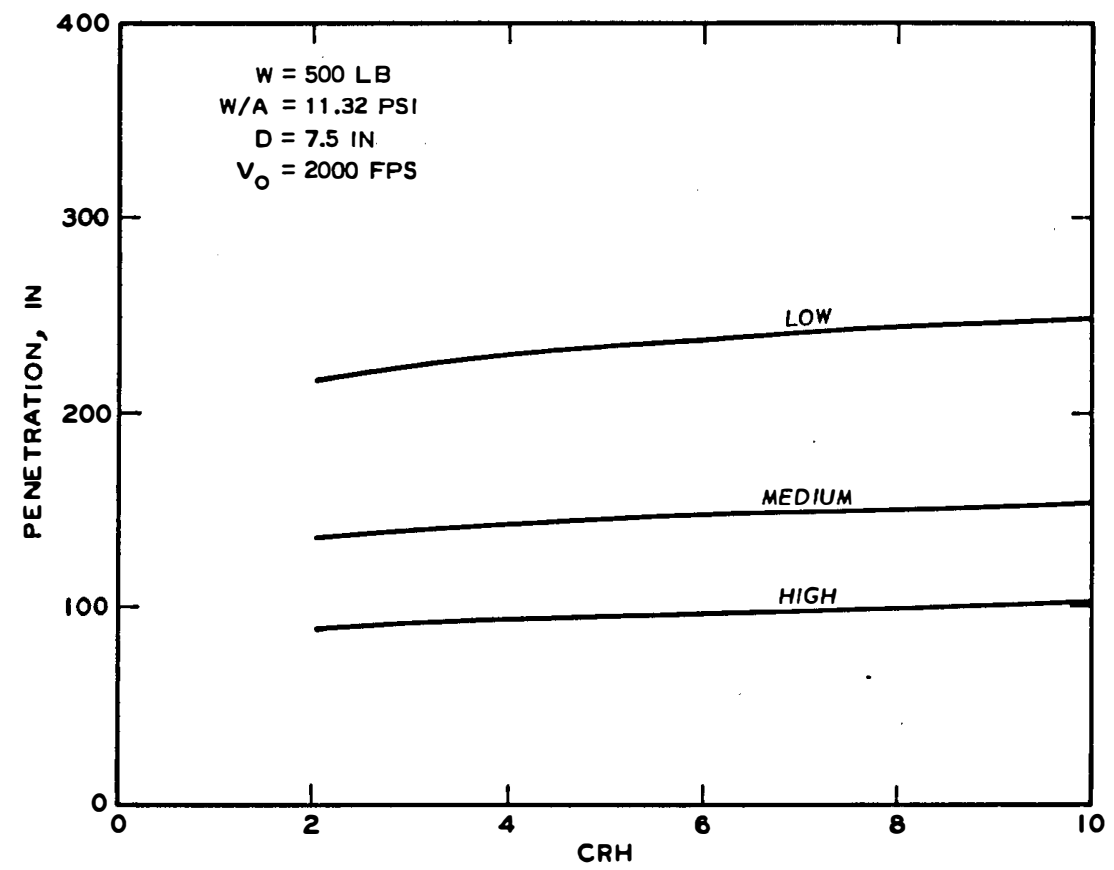

c. Low-, medium-, and high-strength rocks; $V_{0}=2000 \mathrm{fps}$. Figure 5.16 (sheet 2 of 2 ). 


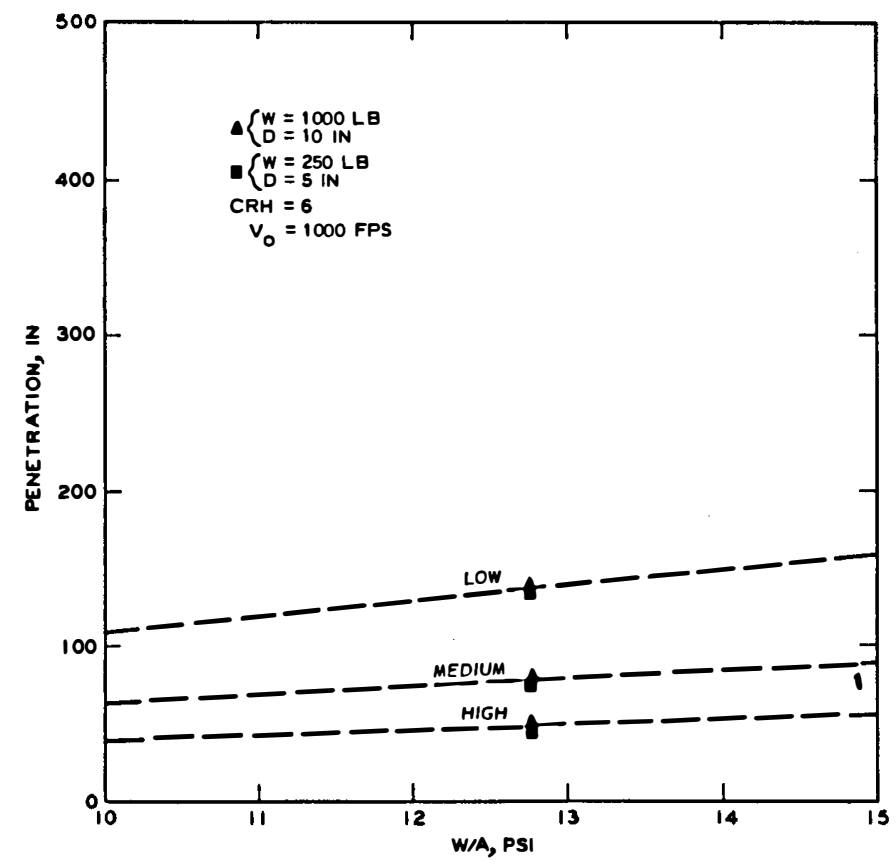

a. Low-, medium-, and high-strength rocks; $\mathrm{v}_{\mathrm{o}}=1000 \mathrm{fps}$.

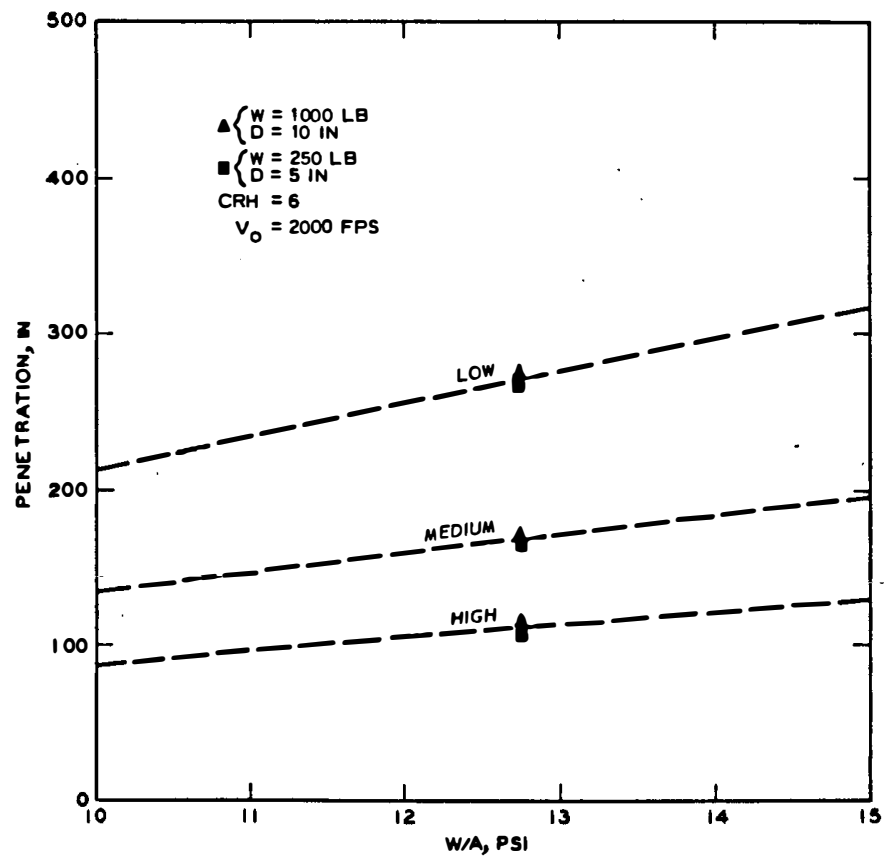

b. Low-, medium-, and high-strength rocks; $\mathrm{V}_{\mathrm{O}}=1000 \mathrm{fps}$.

Figure 5.17 Effect of W/A on predicted penetration (sheet 1 of 3 ). 


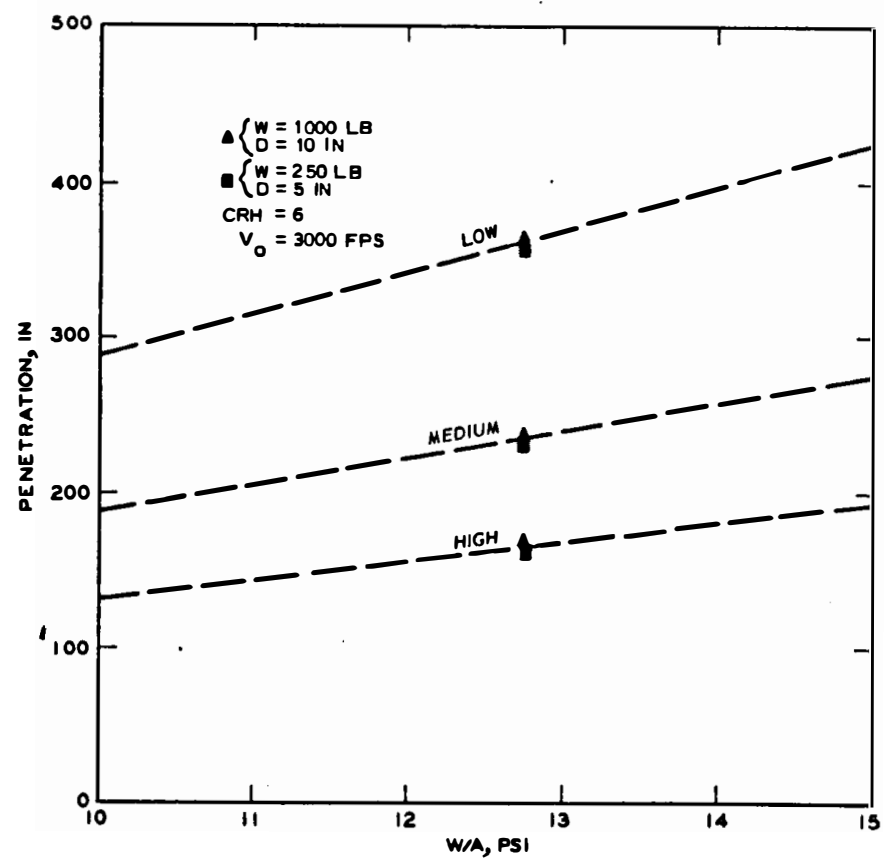

c. Low-, medium-, and high-strength rocks; $\mathrm{V}_{\mathrm{o}}=3000$ fps.

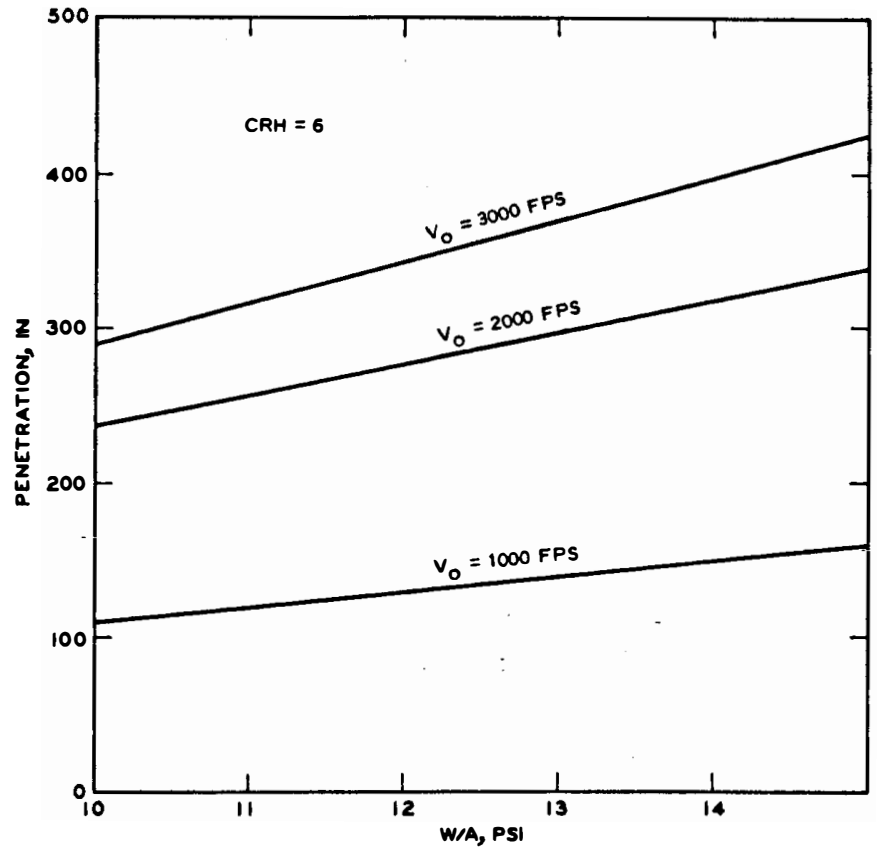

d. Low-strength rock; $V_{0}=1000,2000$, and 3000 fps.

Figure 5.17 (sheet 2 of 3 ). 


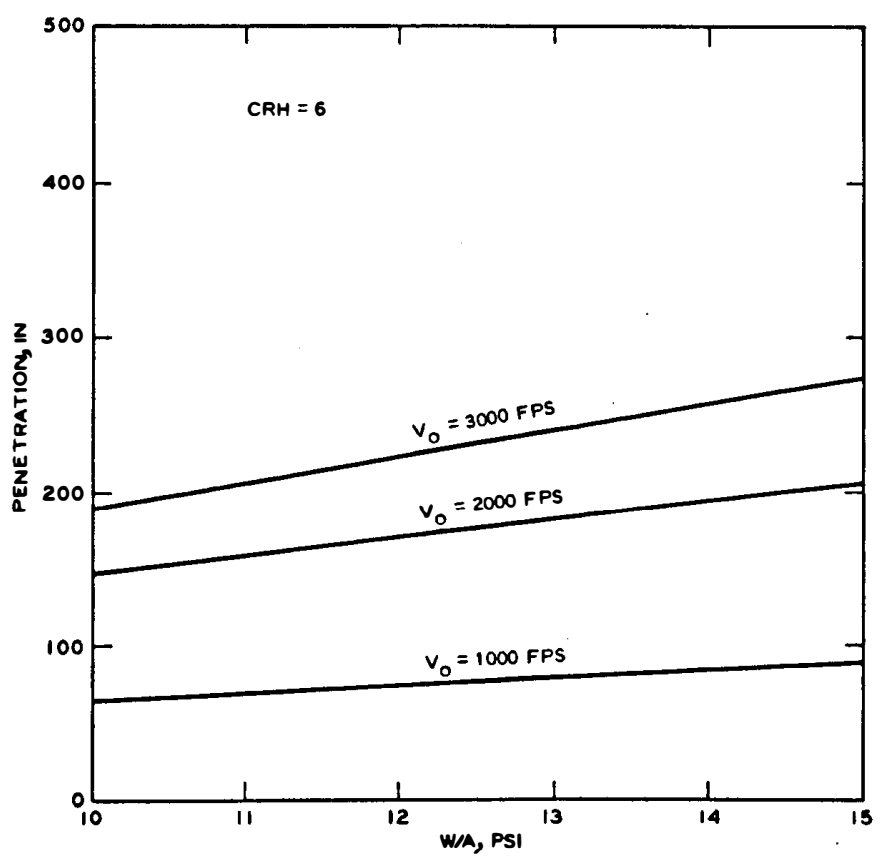
e. Medium-strength rock; $\mathrm{V}_{\mathrm{o}}=1000$,
2000 , and 3000 fps.

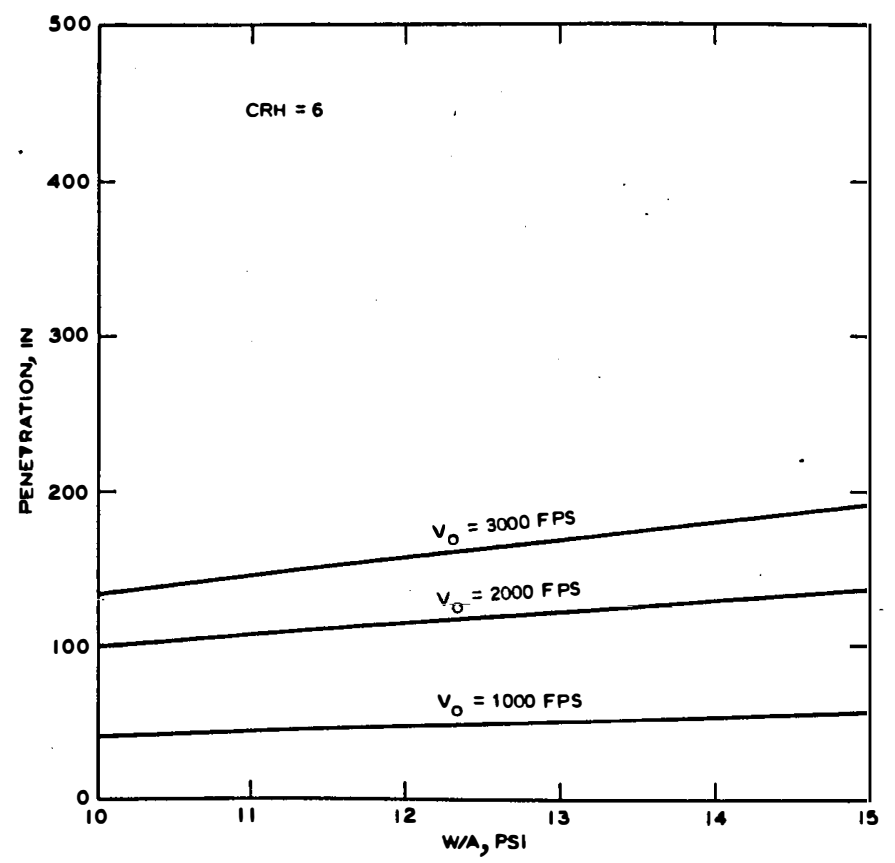
f. High-strength rock; $V_{0}=1000$,
2000 , and 3000 fps.

Figure 5.17 (sheet 3 of 3 ). 


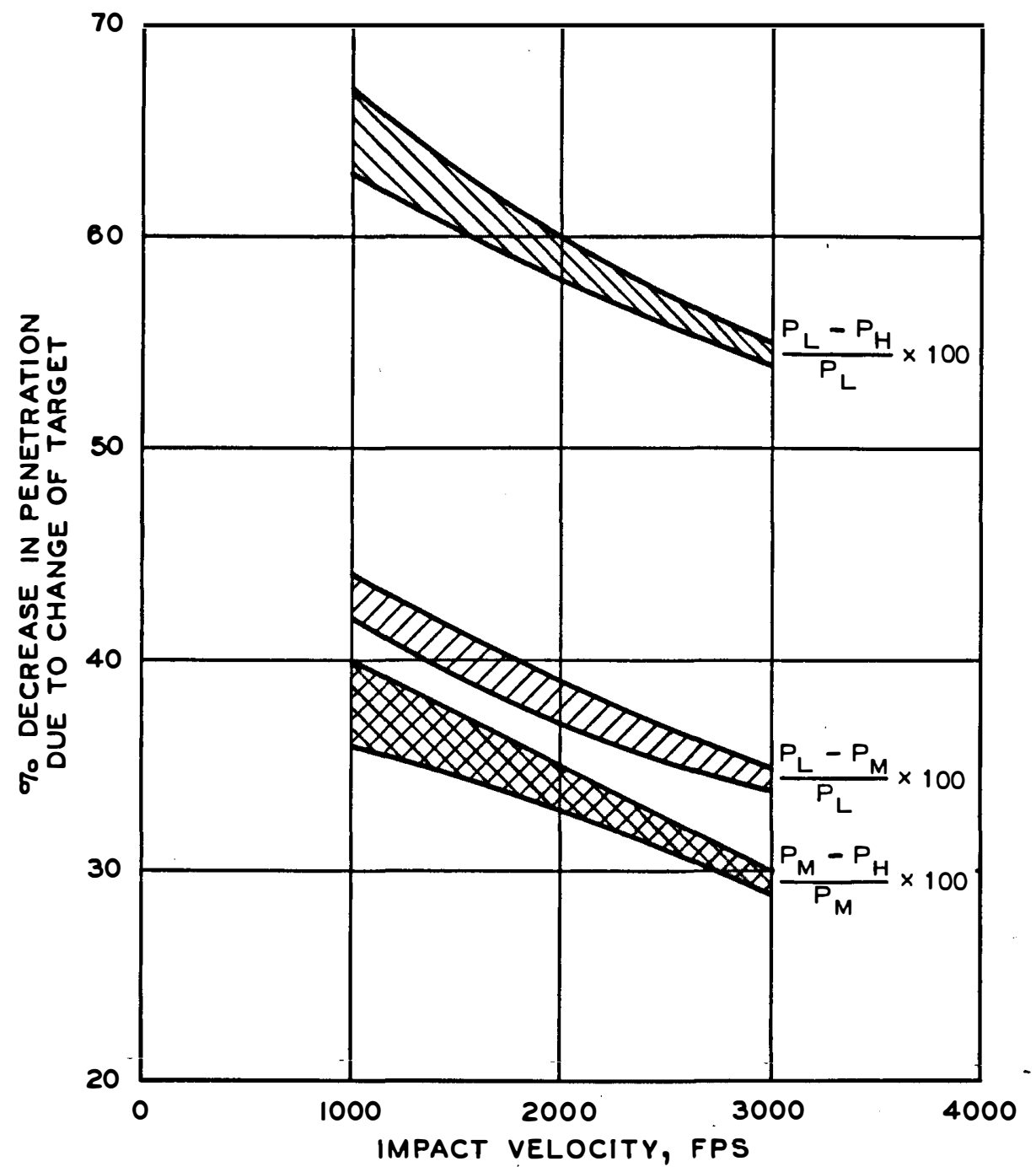

Figure 5.18 Percent decrease in penetration versus impact velocity for all cases considered in this report between the low- and high-strength rock, between the low- and medium-strength rock, and between the medium- and highstrength rock. 
Projectile penetration into earth media is an extremely complicated phenomenon, and the state of the art in penetration theory is such that the problem cannot be solved in all its complexity. Thompson and Bryant (Reference 39) discuss the philosophical and physical formulation of the general penetration problem, and Chapter 3 of this report presents an overview of the problems involved in characterizing rock as the target medium for penetration. Based on a theoretical penetration model discussed in Chapter 2, which requires only target material properties that can be determined from standard laboratory tests, a study of projectile penetration into rock is presented in Chapters 4 and 5.

Three rock targets are considered, with material properties chosen to be representative of general classes of rocks characterized as being low-, medium-, and high-strength. The three rock targets are characterized by only four parameters: (1) initial density, (2) locked plastic density, which is based on estimate of compressibility, (3) modulus, and (4) strength. For target sites about which only a minimum amount of information is available, it is proposed that reliable penetration depth estimates can be obtained if it is possible (on the basis of laboratory examination of cores, drillers' logs, air-photo interpretation, or geologic maps and literature) to classify the intact and in situ material according to established engineering rock classifications (Tables 3.1 and 3.2 and Figures 3.1 through 3.3, for example).

The modified Ross-Hanagud penetration theory (Chapter 2) with the WES "recipe" for selecting material properties for rock (Chapter 3) adequately predicts depth of projectile penetration into rock (Chapter 4). When the model is extended to include realistic pressuredensity relations for the targets, it also appears to adequately simulate rigid body deceleration-time histories for relatively low impact velocities and low- to medium-strength rocks (Chapter 4). Therefore, the conclusions derived from parametric studies using this model (Chapters 4 and 5) have relevance for the real world problem of rock penetration. 
Using the general rock properties proposed in Chapter 3, the results of five actual field penetration tests into rock (targets classified according to Tables 3.1 and 3.2) were compared with the penetration model predictions in Table 4.1, and agreement is shown to be good. A parameter study of one of the field tests resulted in the following conclusions:

1. For a given value of modulus, variation of strength within the bounds of the classification categories (low-strength " $D$ " in this case) can produce variations in penetration for a given velocity of the order of 30-40 percent decrease in penetration for a factor of two increase in strength.

2. For a given strength, variation in modulus by a factor of 20 produces a negligible change in penetration over the velocity range 5001900 fps.

3. For realistic values of $\rho_{o}$ and $\rho_{p}$, variation of 10 percent in the estimate of $\rho_{\mathrm{p}} / \rho_{0}$ for the target will produce a change in the penetration depth prediction of the order of 10 percent.

Also, in Chapter 4 the penetration model is extended to treat the complete target pressure-density relation, and good agreement is obtained with motion-time histories from two finite difference code calculations of rock penetration. For these two cases, involving low- and medium-strength rock and rather low impact velocities (570 and 695 fps), inclusion of the detailed target pressure-density relation in the theoretical penatration model produces not only good penetration depth predictions but also deceleration versus time histories in general qualitative and quantitative agreement with experimental results. If this trend continues when compared with future test data from higher impact velocity field events, this will prove to be a significant advancement in the state of the art of rock penetration predictions. Also, if time histories from the penetration model are improved by use of the complete pressure-density curves, better results can be anticipated for predicting penetration into layered targets.

On the basis of the parameter study of Chapter 5, the following comments and conclusions can be made:

1. Peak deceleration increases with increasing rock strength. 
2. Event duration decreases with increasing rock strength.

3. Final penetration depth decreases with increasing rock strength at a given velocity.

4. For a given rock target strength, penetration increases with increasing impact velocity, although the curves tend to flatten with increasing velocity.

5. For a given velocity and rock strength, penetration increases only slightly with projectile $\mathrm{CRH}$, and the effect is greatest for higher velocities and low rock strengths. Thus, the theory suggests that for rock penetration, projectile nose shape (for ogives) can be based solely on consideration of structural integrity and stability, and not desired depth of penetration considerations.

6. The effect of sectional pressure $\mathrm{W} / \mathrm{A}$ on penetration, over the range considered, is more significant than $\mathrm{CRH}$.

a. Penetration increases with increasing W/A .

b. As with $\mathrm{CRH}$, the effect is more significant for higher velocities and low rock strengths.

c. The information contained in Figures 5.15 and 5.17 should be of value to designers in determining practicality of achieving increased penetration depths by increased impact velocity and/or W/A .

Further work is needed in the following areas and is planned for future study under this project.

1. Effect of in situ rock condition ( $R Q D$, for example) on material properties for input to the penetration model. .

2. Comparison of penetration model time histories with finite difference calculations and new experimental results of penetration into rock as they become available.

3. Comparison of constant plastic density calculations with complete hydrostat calculations of penetration into rock in order to develop better methods of estimating compressibilities in cases where the hydrostat is not known.

4. Oblique impact and consideration of angle of attack.

5. Inclusion of projectile material properties in the penetration model, if possible without greatly complicating the model. 
1. R. H. McNeill; "Rapid Penetration of Terrestrial Materials"; Proceedings, Conference on Rapid Penetration of Terrestrial Materials, J. L. Colp, Editor, February 1972; Texas A\&M University, College Station, Texas.

2. W. J. Patterson; "Projectile Penetration of In Situ Rock"; SLA-73-0831, November 1973; Sandia Laboratories, Albuquerque, New Mexico.

3. Classified Reference. 1

4. B. Rohani; "Fragment and Projectile Penetration Resistance of Soils; High-Velocity Fragment Penetration into Laboratory-Prepared Soil Targets"; Miscellaneous Paper S-71-12, Report 2, June 1973; U. S. Army Engineer Waterways Experiment Station, CE, Vicksburg, Mississippi.

5. J. N. Goodier; "On the Mechanics of Indentations and Cratering in Solid Targets of Strain-Hardening Metal by Impact of Hard and Soft Spheres"; Technical Report, 002-64, July 1964; Stanford Research Institute, Poulter Laboratories, Menlo Park, California.

6. B. Ross and S. Hanagud; "Penetration Studies of Ice with Application to Arctic and Subarctic Warfare"; Project 7000-452, Final Report, September 1969; Stanford Research Institute, Menlo Park, California; Prepared under Contract No. 0014-64-A-0243, NR 274-008 for Submarine Arctic Warfare and Scientific Program, Naval Ordnance Laboratory, Silver Spring, Maryland, and Office of Naval Research, Washington, D. C.

7. B. Rohani; "Penetration Performance of Terminal Delivery Vehicle T-98WA into Soft and Frozen Ground; Analyses Based on Both Field Test Results and Theoretical Calculations"; Letter Report to Project Manager, Remotely Monitored Battlefield Sensor System, Army Materiel Command, Fort Monmouth, New Jersey, November 1973; U. S. Army Engineer Waterways Experiment Station, CE, Vicksburg, Mississippi.

8. B. Rohani; "Theoretical Study of Impact and Penetration of a Remotely Emplaced Antitank Mine Projectile into Earth Materials"; Miscellaneous Paper S-73-58, June 1973; U. S. Army Engineer Waterways Experiment Station, CE, Vicksburg, Mississippi.

9. B. Rohani, -P. F. Hadala, and J. G. Jackson, Jr.; "Penetration of SAP and AP Bombs into a Concrete Target"; Letter Report to Defense Nuclear Agency, Subtask SB211, Work Unit 04, January 1974; U. S. Army Engineer Waterways Experiment Station, CE, Vicksburg, Mississippi.

10. B. Ross, S. Hanagud, and G. Sidhu; "Penetration Studies of Ice with Application to Arctic and Subarctic Warfare"; NWRC 7000-452-5, Final Report--Phase IV, April 1971; Stanford Research Institute, Menlo Park, California; Prepared for Submarine Arctic Warfare and Scientific

1 Bibliographical material for the classified references(s) will be furnished to qualified agencies upon request. 
Program, Naval Ordnance Laboratory, and Office of Naval Research.

11. G. B. Baecher; "The Size Effect in Brittle Fracture"; MS Thesis, June 1970; Massachusetts Institute of Technology, Department of Civil Engineering, Cambridge, Massachusetts.

12. M. M. Singh and P. J. Huck; "Large Scale Triaxial Tests on Rock"; Proceedings, Fourteenth Sympósium on Rock Mechanics, H. R. Hardy, Jr., and R. Stefanko, Editors, June 1972, Pages 35-60; American Society of Civil Engineers, Ann Arbor, Michigan.

13. F. E. Heuze; "Sources of Errors in Rock Mechanics Field Measurements, and Related Solutions"; International Journal of Rock Mechanics and Mineral Science, 1971, Vol. 8, Pages 297-310.

14. H. H. Einstein, R. W. Bruhn, and R. C. Hirschfeld; "Mechanics of Jointed Rock"; Publication No. 268, August 1970; Department of Civil Engineering Soil Mechanics, Massachusetts Institute of Technology, Cambridge, Massachusetts.

15. J. S. Rosenblad; "Geomechanical Model Study of the Failure Modes of Jointed Rock Masses"; Technical Report MRD 1-71, January 1971; U. S. Army Engineer Division, Missouri River, St. Louis, Missouri.

16. D. R. Coates; "Classification of Rocks for Rock Mechanics"; International Journal of Rock Mechanics and Mineral Science, 1964, Vol. 1, No. 3, Page 421.

17. D. U. Deere and R. P. Miller; "Engineering Classification and Index Properties for Intact Rock"; Technical Report No. AFWL-IR65-116, December 1966; Air Force Weapons Laboratory, Albuquerque, New Mexico.

18. D. U. Deere, A. H. Merritt, and R. F. Coon; "Engineering Classification of In-Situ Rock"; Technical Report No. AFWL-TR-67-144, January 1969; Air Force Weapons Laboratory, Albuquerque, New Mexico.

19. R. L. Geyer and J. I. Myung; "The 3-D Velocity Log; A Tool for In-Situ Determination of the Elastic Moduli of Rocks"; Proceedings, Twelfth Annual Symposium on Rock Mechanics, G. B. Clark, Editor, November 1970, Pages 71-107; University of Missouri, Rolla, Missouri.

20. D. U. Deere and others; "Design of Surface and Near-Surface Construction in Rock"; Proceedings, Eighth Symposium on Rock Mechanics, 1967, Pages 237-302; University of Minnesota, Minneapolis, Minnesota.

21. J. M. Duncan and R. E. Goodman; "Finite Element Analysis of Slopes in Jointed Rock"; Contract Report S-68-3, February 1968; U. S. Army Engineer Waterways Experiment Station, CE, Vicksburg, Mississippi; Prepared under Contract No. DACW39-67-C-009l by College of Engineering, Office of Research Services, University of California, Berkley, California.

22. J. A. Hudson; "Estimation of the Mechanical Properties of Rock Masses"; Final Report, 11 June 1971; U. S. Bureau of Mines, Denver, Colorado. 
23. J. L. Colp; "Terradynamics; A study of Projectile Penetration of Natural Earth Materials"; Report SC-DR-68-215, June 1968; Sandia Laboratories, Albuquerque, New Mexico.

24. L. Obert and W. I. Duvall; "Rock Mechanics and the Design of Structures in Rock"; 1967; John Wiley and Sons, Inc., New York, N. Y.

25. B. V. Baidyuk; "Mechanical Properties of Rocks at High Temperatures and Pressures"; Institute of Geology and Development of Mineral Resources, 1963, Moscow, USSR; Translated by J. P. Fitzsimmons, University of New Mexico.

26. S. R. Swanson and W. S. Brown; "The Mechanical Response of Pre-Fractured Rock in Compression"; Report UTEC-ME-70-037, 1970; Mechanical Engineering Department, University of Utah, Salt Lake City, Utah.

27. E. T. Brown; "The Strength of Jointed Rock Masses"; 1970; School of Mineral and Metallurgical Engineering, University of Minnesota, Minneapolis, Minnesota.

28. M. Van Thiel, Editor; "Compendium of Shock Wave Data"; UCRL50108, June 1966; Lawrence Radiation Laboratory, Livermore, California.

29. J. Isenberg; "Nuclear Geoplosics; Part Two: Mechanical Properties of Earth Materials"; DNA 1285H2 (Formerly DASA 1285-2), November 1972; Defense Nuclear Agency, Washington, D. C.

30. R. C. Bass; "Additional Hugoniot Data for Geologic Materials"; Report No. SC-RR-66-548, October 1966; Sandia Laboratories, Albuquerque, New Mexico.

31. T. J. Ahrens, J. T. Rosenberg, and M. H. Ruderman; "Dynamic Properties of Rock; Final Report"; DASA 1868, September 1966; Stanford Research Institute, Menlo Park, California.

32. S. H. Shuster and J. Isenberg; "Equations of State for Geologic Materials"; DNA 2925Z, September 1972; Defense Nuclear Agency, Washington, D. C.

33. D. Braslau; "Partitioning of Energy in Hypervelocity Impact Against Loose Sand Targets"; Journal of Geophysical Research, 10 July 1970, Vnl. 75, No. 20, Pages 3987-3999; Richmond, Virginia.

34. C. H. Johansson and P. A. Persson; "Detonics of High Explosives"; 1970; Academic Press, New York, N. Y.

35. G. E. Duvall; "Shock Waves in Solids"; Proceedings, First Conference, Shock Metamorphism of Natural Materials, B. M. French and N. M. Short, Editors, 1968, Pages 19-29; Mono Book Company, Baltimore, Maryland.

36. L. V. Al'tshuler; "Use of Shock Waves in High-Pressure Physics"; Soviet Physics Uspekhi, 1965, Vol. 8, No. 1.

37. M. H. Rice, R. G. McQueen, and J:M. Walsh; "Compression of Solids by Strong Shock Waves"; Solid State Physics: Advances in Research and Applications, F. Seitz and D. Turnbull, Editors, 1958, 
Vol. 6, Page 1; Academic Press, New York, N. Y.

38. L. Thigpen; "Penetration of Projectiles into Continuous"Earth Media"; Research Report SC-44-72-0204, May 1972; Sandia Corporation, Albuquerque, New Mexico.

39. L. J. Thompson and W. R. Bryant; "Projectile Penetration Theory"; Proceedings, Conference on Rapid Penetration of Terrestrial Materials, February 1972; Texas A\&M University, College Station, Texas. 


\section{APPENDIX A}

NOTATION

A Deceleration

$\bar{A} \quad$ Average deceleration

BM Classification of low-strength rock targets

$\mathrm{B}_{1} \quad 1-\delta^{1 / 3}$

$\mathrm{B}_{2} \quad 3 / 2-\left(1+\alpha_{p}\right) \delta^{1 / 3}+1 / 2\left(\delta^{4 / 3}\right)$

co Initial velocity of sound

CM Classification of medium-strength rock targets

CRH Caliber Radius Head

D Diameter of projectile

DM Classification of high-strength rock targets

$e_{i}$ Volumetric strain related to the jump from zero to finite stress (elastic region) in the stress-strain curves in Figure 2.1

e Volumetric strain related to the jump from the elastic to the plastic region of the uniaxial stress (i.e., unconfined compression) stress-strain curve in Figure 2.1b

E Young's modulus of elasticity, corresponding to locked elastic region in Figure 2.1, psf $=3 G$

$E_{i} \quad$ Internal energy

Einsitu In situ modulus of deformation

Eintact Intact modulus of deformation

$E_{t} \quad$ Strain-hardening modulus, corresponding to locked plastic region in Figure 2.1 , psf $=3 G_{t}$

$E_{t 50}$ Tangent modulus at 50 percent ultimate strength

EPW Earth penetrating weapon

$f \quad$ Fracture frequency

$f(\varepsilon) \quad$ Ogive nose factor

$g$ Acceleration of gravity

G Elastic shear modulus

$G_{t} \quad$ Strain-hardening shear modulus

H High strength

$\mathrm{K}_{\mathrm{n}} \quad$ Normal joint stiffness 


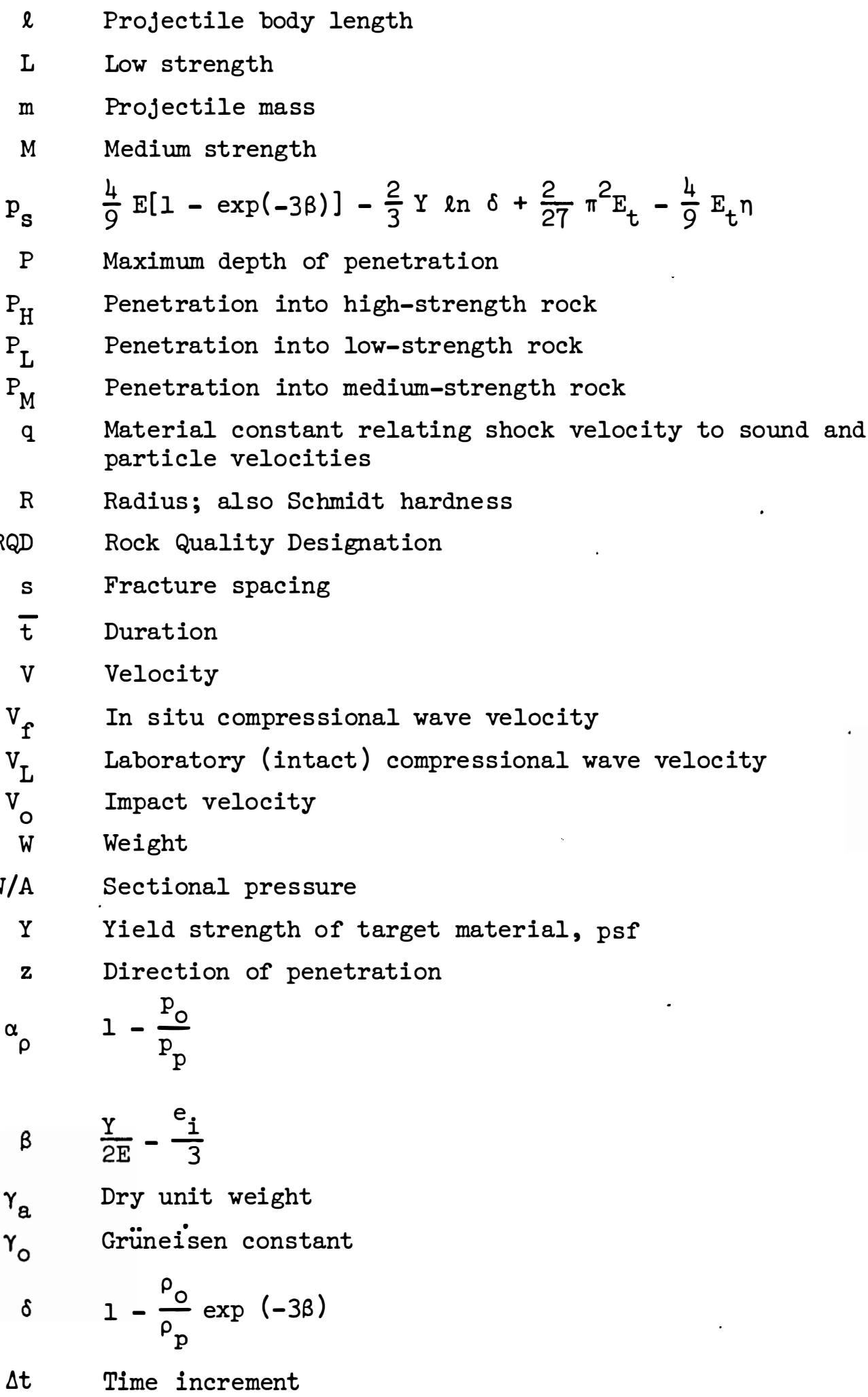



$\Delta \mathrm{V}_{\mathrm{k}} \quad \begin{aligned} & \text { Incremental velocity change in the } \mathrm{k}^{\text {th }} \text { time step as com- } \\ & \text { puted from Equation } 2.1\end{aligned}$

$\Delta \mathrm{z}_{\mathrm{k}} \quad$ Distance penetrated during the $\mathrm{kth}$ time step

$\varepsilon \quad \frac{1}{2 \mathrm{CRH}}$

$n \quad \sum_{n=1}^{\infty} \frac{\delta^{n}}{n^{2}} ;$ also $1-\frac{\rho_{0}}{\rho}$

$\rho \quad$ Density

$\rho_{0} \quad$ Initial density of target material, slugs/cu ft

$\rho_{\mathrm{p}} \rho_{\mathrm{o}} \exp \left(\mathrm{e}_{\mathrm{p}}\right)$

$\sigma_{a} \quad$ Uniaxial compressive strength

$\phi \quad$ Limiting cone half-angle.

$\phi(\varepsilon) \quad \operatorname{Tan}^{-1}\left(\frac{2 \varepsilon-\varepsilon^{2}}{1-\varepsilon}\right)$ 
$\underline{\mathrm{DOD}}$

Assistant to the Secretary of Defense, Atomic Energy,

Washingt on, D. C. 20301

ATTN : Donald R. Cotter

Director, Defense Advanced Research Projects Agency,

Architect Building, 1400 Wilson Blvd., Arlington,

Virginia 22209

ATTN: Technical Library

Eric H. Willis

COL B. Pafe

Paul C. McMonigal

CDR J. Beatty

LTC M. Franklin

S. Lukasik

NMRO

PMO

STO

Director, Defense Civil Preparedness Agency, Washington,

D. C. 20301

ATTN: Technical Library

Defense Documentation Center, Cameron Station, Alexandria,

Virginia 22314

ATTN : Myer Kahn

Director, Defense Intelligence Agency, Washington,

D. C. 20301

ATTN: DT-2, Weapons \& Systems Division

DI-7D, Phys. Vul. Div., Edward O'Farrell

DI-7E

Technical Library

Defense Mapping Agency, Washington, D. C. 20305

ATTN : H. Lindsey

Director, Defense Nuclear Agency, Washington, D. C. 20305

ATTN: STTL (Technical Library)

STSI (Archives)

DDST

2

SPSS 


\section{DOD (Continued)}

Director of Defense Research and Engineering, Washington,

D. C. 20301

ATTN: Deputy Director, Tactical Warfare

Deputy Director, Strategic Systems

Assistant Director, Strategic Weapons

M. J. Minneman

George Barse

Craig W. Hartsell

R. Thorkildsen

Commander, Field Command, Defense Nuclear Agency, Kirtland

Air Force Base, New Mexico 87115

ATTN : FCTA

FCTA-D

Interservice Nuclear Weapons School, Kirtland AFB,

New Mexico 87115

ATTN: Technical Library

Director, Joint Strategic Target Planning Staff, JCS, Offutt AFB, Nebraska 68113

ATTN: Science and Technology Info Library

Director, Weapons Systems Evaluation Group, 400 Army-Navy

Drive, Arlington, Virginia 22202

ATTN: Technical Library

\section{Army}

Assistant Chief of Staff for Force Development, Department of

the Army, Washington, D. C. 20310

ATTN: Director of Chem \& Nuc Ops

Technical Ifibrary

Director, U. S. Army Ballistic Missile Defense, Advanced Tech

Ctr, Huntsville Office, P. 0. Box 1500, Huntsville,

Alabama 35807

ATTN : ICRDABH-X

CRDABH-S

Headquarters, Central Army Group, APO New York 09099

ATTN: CENEN LTC J. L. Spruill 


\section{Army (Continued)}

Office, Chief of Engineers, Department of the Army, Washington, D. C. 20314

ATTN: DAEN-RDM

Office, Chief of Research, Development, and Acquisition,

Department of the Army, Washington, D. C. 20310

ATTN: DAMA-CSM/LTC Edward V. DeBoeser, Jr.

Technical Library

Commander, Harry Diamond Laboratories, Connecticut Avenue and

Van Ness St., N.W., Washington, D. C. 20438

ATTN: F. Vrateric

A. Holmes .

AMXDO-NP

AMXDO-RBH/J. Gwaltney

Commanding Officer, Picatinny Arsenal, Dover,

New Jersey 07801

ATTN : Technical Library

$P$. Angelloti

SMUPA-ND-S/E. Zimpo

William Meyer

Ray Moessner

Jerry Pental

SUMPA-AD-D-A-7

SUMPA-AD-D-A

SUMPA-AD-D-M

Director, U. S. Army Ballistic Research Laboratories;

Aberdeen Proving Ground, Maryland 21005

ATTN : AMXBR-X/J. J. Meszaros

AMOXBR-TB/J. T. Frasier

Norris J. Huffington, Jr.

G. Grabarek

G. Roecker

Technical Library/Edward Baicy

J. W. Apgar

Commander/Director, U. S. Army Cold Regions Research and Engineering Laboratory, P. 0. Box 282, Hanover,

New Hampshire 03755

ATTN: G. Swinzow 


\section{Army (Continued)}

Commander, U. S. Army Strategic Communications Command,

Fort Huachuca, Arizona 85613

Division Engineer, U. S. Army Engineer Division, Huntsville,

P. 0. Box 1600, West Station, Huntsville, Alabama 35807 ATTN: HNDED-CS/Michael M. Dembo

Division Engineer, U. S. Army Engineer Division, Ohio,

P. 0. Box 1159, Cincinnati, Ohio 45201

ATTN: ORDAS-L/Technical Library

Director, U. S. Army Engineer Waterways Experiment Station,

P. 0. Box 631, Vicksburg, Mississippi 39180

ATTN : John Strange

L. F. Ingram

Library

William J. Flathau

Guy Jackson

L. K. Davis

Behzad Rohani

Allen D. Rooke

D. K. Butler

Paul Hadala

Commander, U. S. Army Materials and Mechanics Research Center,

Watertown, Massachusetts 02172

ATTN : John Mescall

Technical Library

Director, U. S. Army Material Systems Analysis Agency,

U. S. Army Aberdeen R\&D Center, Aberdeen Proving Ground,

Maryland 21005

ATTN: M. Reches

J. Sperazza

Commander, U. S. Army Mobility Equipment R\&D Center,

Building 314, Fort Belvoir, Virginia : 22060

ATTN : Technical Library

Commander, U. S. Army Engineer Center, Fort Belvoir, Virginia 22060

ATTN : ATSEN-SY-L 


\section{Army (Continued)}

Commandant, U. S. Army Engineer School, Fort Belvoir,

Virginia 22060

ATTN : S. Grazier

Commander, U. S. Army Materiel Command, 5001 Eisenhower Avenue, Alexandria, Virginia 22333

ATTN: Technical Library

AMCRD-WN

AMCRD-BN

Commander, U. S. Arrmy Materiel Command, Foreign and Scientific

Technical Center, 220 7th St., N.E., Charlottesville,

Virginia 22901

ATTN: Research and Concepts Branch

Commander, U. S. Army Missile Command, Redstone Arsenal,

Huntsville, Alabama 35809

ATTN: Technical Library

F. Fleming

W. Jann

Commander, U. S. Army Nuclear Agency, Fort Bliss, Texas 79916

ATTN : MAJ F. P. Weichel

COL Quinn

Technical Library

Commandant, U. S. Army War College, Carlisle Barracks,

Pennsylvania 17013

ATTN : Library

Commander,' U. S. Army Armament Command, Rock Island Arsenal,

Rock Island, Illinois 61201

ATTN: Frank Black

COL C. Treat

Technical Library

Commander, U. S. Army Training and Doctrine Command,

Institute of Nuclear Studies, Fort Bliss, Texas 79916

ATTN : Document Control

Division Engineer, U. S. Army Engineer Division, Missouri

River, P. 0. Box 103, Downtown Station, Omaha,

Nebraska 68101

ATTN : Library 
Navy

Chief of Naval Research, Department of the Navy, Arlington, Virginia 22217

ATTN: Technical Library

Officer In Charge, Civil Engineering Laboratory, Naval

Construction Battalion Center, Port Hueneme,

California 93041

ATTN: Technical Library

Commander, Naval Electronic Systems Command, Headquarters, Washington, D. C. 20360

ATTN: PME-117-21A

Commander, Naval Facilities Engineering Command, Headquarters, Washington, D. C. 20390

ATTN: Technical Library, Code 09llC

Superintendent, U. S. Naval Postgraduate School, Monterey,

California 93940

ATTN: Library, Code 2124

Director, Naval Research Laboratory, Washington,

D. C. 20375

ATTN : Code 2027/Tech Library

Commander, Naval Surface Weapons Center, White Oak, Silver

Spring, Maryland 20910

ATTN: Mr. Kasdorf

- Jules Enig

Technical Library Code 730

Code 1224 Navy Nuc Prgms Off

Mary P. King

Robert D. Heidenreich

G. Briggs

L. Roslund

Commander, Naval Surface Weapons Center, Dahlgren Laboratory Dahlgren, Virginia 22448

ATTN: William Wisherd

Ted Williams

Technical Library

M. Weiland 


\section{Navy (Continued)}

Commander, U. S. Naval Weapons Center, China Lake,

California 93555

ATTN: Code 603, Dr. Carl Austin

P. Cordle

Code 533, Technical Library

Commander, Naval Weapons Evaluation Facility,

Kirtland AFB, Albuquerque, New Mexico 87117

ATTN: Technical Library

Director, Strategic Systems Project Office, Navy Department,

Washington, D. C. 20376

ATTN: NSP-43, Technical Library

\section{Air Force}

Air Force Armament Laboratory, AFSC, Eglin AFB, Florida 32542 ATTN: Technical Library

CPT Larry Looney

William Cramer

MAJ Thomas Tomasetti

John Collins

Air Force Institute of Technology, AU, Wright-Patterson AFB, Ohio 45433

ATTN: Library, AFIT Bldg 640 Area B

Commander, Air Force Weapons Laboratory, AFSC, Kirtland Air

Force Base, New Mexico 87117

ATTN: Technical Library

DEV, R. J. Port

Headquarters, Air Force Systems Command, Andrews AFB,

Washington, D. C. 20331

ATTN: Technical Library

Air Force Office of Scientific Research, 1400 Wils on Boulevard, Arlington, Virginia 22209

ATTN: LTC L. P. Mosteller, Jr.

Commander, Rome Air Development Center, AFSC, Griffiss Air

Force Base, New York 13440

ATTN: EMTLD, Documents Library 


\section{Air Force (Continued)}

Commander, Armament Development and Test Center, Eglin AFB, Florida 32542

ATTN: Technical Library

Commander, Foreign Technology Division, AFSC, Wright-Patters on AFB, Ohio 45433

ATTN: Technical Library

HQ USAF/IN, Washington, D. C. 20330

ATTN : INATA

HQ USAF/RD, Washington, D. C. 20330

ATTN: RDMP, COL J. E. McCormick

Commander, Rome Air Development Center, AFSC, Griffiss AFB, New York 13440

ATTN: EMTLD DOc Library

Commander, Space and Missile Systems Organization, AFSC

Norton Air Force Base, California 92409

ATTN: DEB

Commander, Space and Missile Systems Organization, AFSC,

P. 0. Box 92960, Worldway Postal Center, Los Angeles, California 90009

ATTN: Technical Library

U. S. Energy Research and Development Administration

U. S. Energy Research and Development Administration, Division of Military Application, Washington, D. C. 20545 ATTN: Doc Control for Test Office

U. S. Energy Research \& Development Administration, Albuquerque Operations Office, P. O. Box 5400, Albuquerque, New Mexico 87115

ATTN: Technical Library

U. S. Energy Research and Development Administration, Division of Headquarters Services, Washington, D. C. 20545 ATTN: Doc Control for Class Tech Lib, Library Branch G-043 
ER\&DA (Continued)

U. S. Energy Research and Development Administration, Nevada Operations Office, P. O. Box 14100 , Las Vegas, Nevada 89114 ATTN: Technical Library

Los Alamos Scientific Laboratory, P. O. Box 1663, Los Alamos, New Mexico 87544

ATTN: Doc Control for Tom Dowler

Report Librarian

Doc Control for C. Cremer

Doc Control for G. Dials

Sandia Laboratories, Livermore Laboratory, P. O. Box 969 ,

Livermore, California 94550

ATTN : Doc Control for T. Gold

Technical Library

Sandia Laboratories, P. 0. Box 5800 , Albuquerque, New Mexico 87115

ATTN: Doc Control for John Colp

Dr. Walter Herrmann

Doc Control for John Keizur

Doc Control for William Patterson

Doc Control for William Caudle

Doc Control for 3141 Sandia Rpt Coll

Doc Control for W. Altsheimer

University of California, Lawrence Livermore Laboratory,

P. 0. Box 808 , Livermore, California 94550

ATTN: Doc Control for W. Scanlin

Doc Control for R. L. Walker

Larry Woodruff, I-125

Frank Walker

Technical Information Division

Other Government Agencies

Bureau of Mines, Twin Cities Research Center, P. O. Box 1660, Minneapolis, Minnesota 55111

ATTN: R. E. Thill 
DOD Contractors

Aerospace Corporation, P. O. Box 92957, Los Angeles,

California 90009

ATTN: R. Strickler

1

Technical Information Services

Agbabian Associates, 250 North Nash Street, El Segundo,

California 90245

ATTN: Dr. M. S. Agbabian

Applied Theory Incorporated, 1010 Westwood Boulevard,

Los Angeles, California 90024

ATTN : Dr. John G. Trulio

AVCO, Government Products Group, 201 Lowell Street,

Wilmington, Massachusetts 01887

ATTN: David Henderson 1

Research Library A830, Room 7201

Battelle Columbus Laboratories, 505 King Avenue, Columbus, Ohio 43201

ATTN: Technical Library

Bell Telephone Laboratories, Inc., Mountain Avenue, Murray

Hill, New Jersey 07974

ATTN : Technical Library 1

Boeing Company, P. O. Box 3707, Seattle, Washington 98124

ATTN: Aerospace Library

Reynold Atlas

California Research and Technology, Inc., 6269 Variel Avenue, Woodland Hills, California 91364

ATTN: Dr. K. N. Kreyenhagen

Civil/Nuclear Systems Corporation, 1200 University N.E.,

Albuquerque, New Mexico. 87102

ATTN : Robert Crawford

EG\&G, Inc., Albuquerque Division, P. 0. Box 10218,

Albuquerque, New Mexico 87114

ATTN: Technical Library

General Dynamics Corporation, Pomona Operation, P. O. Box 2507 , Pomona, California 91766

ATTN : Keith Anders on 


\section{DOD Contractors (Continued)}

General Electric Company, TEMPO-Center for Advanced Studies,

816 State Street, Santa Barbara, California 93101

ATTN: DASIAC

Institute for Defense Analyses, 400 Army-Navy Drive, Arlington, Virginia 22202

ATTN: Ruth S. Smith, Librarian

Commander, U. S. Army Mobility Equipment Research and

Development Center, Fort Belvoir, Virginia 22060

ATTN : STSFB-MW

STSFB-XS

Project Manager, Remotely Monitored Battlefield Sensor

System, AMC, Fort Monmouth, New Jersey 07703

ATTN: Chuck Higgins

Project Manager, Gator Mine Program, Eglin Air Force Base, Florida 32542

ATTN : E. J. Lindsey

Oklahoma State University, Field Office for Weapons Effectiveness, P. 0. Box 1925, Eglin Air Force Base, Florida 32542

ATTN: Ed Jackett

Consulting and Special Engineering Services, Inc.,

P. 0. Box 1206, Redlands, California 92373

ATTN: Dr. J. L. Merritt

Kaman Avidyne, Division of Kaman Sciences Corp.,

83 Second Avenue, Northwest Industrial Park, Burlington, Maryland 01803

ATTN : E. S. Crisicone

Technical Library

N. P. Hobbs

Kaman Sciences Corporation, P. O. Box 7463, Colorado Springs, Colorado 80933

Lockheed Missiles and Space Company, 3251 Hanover Street,

Palo Alto, California 94304

ATTN: Tech Info Center D/Coll 


\section{DOD Contractors (Continued)}

Lockheed Missiles and Space Company, Inc., P. O. Box 504, Sunnyvale, California 94088

ATTN: Technical Library

Martin Marietta Aerospace, Orlando Division, P. O. Box 5837, Orlando, Florida 32805

ATTN: M. Anthony

Al Cowan

University of New Mexico, Dept of Campus Security and Police, 1821 Roma N.E., Albuquerque, New Mexico 87106

ATTN : G. E. Triandafalidis

H. D. Southward

Physics International Company, 2700 Merced Street, San Leandro, California 94577

ATTN: Dennis Orphal

Technical Library

R\&D Associates, P. O. Box 3580, Santa Monica, California 90403

ATTN: Technical Library

J. G. Lewis

Dr. H. F. Cooper, Jr.

Dr. Harold L. Brode

C. P. Knowles

C. Knowles

Science Applications, Inc., 7850 Edgewater Drive, Oakland,

Califormia 94621

ATTN: David Bernstein

D. E. Maxwell

Science Applications, Inc., P. O. Box 2351, La Jolla, California 92038

ATTN: C. Huds on

Technical Library

Science Applications, Inc., 1911 North Ft. Myer Drive,

Suite 808, Arlington, Virginia 22209

ATTN: Dr. W. M. Layson

Stanford Research Institute, 333 Ravenswood Avenue,

Menlo Park, California 94025

ATTN: Lynn Seamans

Dr. G. Abrahams on

1

SRI Library Room G02I 


\section{DOD Contractors (Continued)}

Systems, Science and Software, P. 0. Box 1620, La Jolla, California 92037

ATTN: Technical Library

$$
\begin{aligned}
& \text { Dr. D. R. Grine } \\
& \text { Dr. E. W. Gaffney }
\end{aligned}
$$

Terra Tek, Inc., University Research Park, 420 Wakara Way,

Salt Lake City, Utah 84108

ATTN: S. J. Green

Texas A\&M University, c/० Texas A\&M Research Foundation,

P. 0. Box 3222, Bryan, Texas 77801

ATTN: Harry Coyle Prof L. J. Thompson

Braddock, Dunn, \& McDonald, Inc., 1920 Aline Ave., Vienna, Virginia 22180

ATTN: Technical Library

Braddock, Dunn, \& McDonald, Inc., P. O. Box 8885, Station C, Albuquerque, New Mexico 87108

ATTN: Hank Ponsford

TRW Systems Group, One Space Park, Redondo Beach, California 90278

ATTN: Tech Info Center/S-1930

University of Oklahoma, Department of Information and Computing Science, 905 Asp, Norman, Oklahoma 73069

ATTN: Dr. J. C. Thompson

Weidlinger Associates, Consulting Engineers,

110 East 59th Street, New York, New York 10022

ATTN: Dr. M. L. Baron

Weidlinger Associates, Consulting Engineers, 2710 Sand Hill Road, Suite 230, Menlo Park, California 99025

ATTN: J. Is enberg

Lowell Technical Institute, Department of Civil Engineering, Lowell, Massachusetts 01854

ATTN: L. W. Thigpen 
DOD Contractors (Continued)

Georgia Institute of Technology, Department of Aerospace

Engineering, Atlanta, Georgia 30332

ATTN : S. V. Hanagud

L. N. Rehfield

Pacifica Technology, Inc., P. O. Box 148, Del Mar,

California 92014

ATTN : R. L. Bjork

Shock Hydrodynamics, Incorporated, 15010 Ventura Boulevard,

Sherman Oaks, California 91403

ATTN : Dr. L. Zernow

\section{Foreign Exchanges}

Federal Bureau for Highway Engineering, Cologne,

West Germany (ENG-366)

Department of Physical Geography, Uppsala University, Box 554, S-75122, Uppsala, Sweden (ENG-374)

Prof. Leopold Muller, Abteilung Felsmechanik, Institut

fur Bodenmechanik und Felsmechanik, Universitat Karlsruhe, 75 Karlsruhe, Germany (ENG-383)

\section{Domestic Exchange}

Manager, Engineering Design and Construction, Tennessee Valley Authority, 600 Union Building, Knoxville, Tennessee 37902 